Field Testing of an Unvented Roof with Fibrous Insulation, Tiles, and Vapor Diffusion Venting

K. Ueno and J. W. Lstiburek Building Science Corporation

February 2016 


\section{NOTICE}

This report was prepared as an account of work sponsored by an agency of the United States government. Neither the United States government nor any agency thereof, nor any of their employees, subcontractors, or affiliated partners makes any warranty, express or implied, or assumes any legal liability or responsibility for the accuracy, completeness, or usefulness of any information, apparatus, product, or process disclosed, or represents that its use would not infringe privately owned rights. Reference herein to any specific commercial product, process, or service by trade name, trademark, manufacturer, or otherwise does not necessarily constitute or imply its endorsement, recommendation, or favoring by the United States government or any agency thereof. The views and opinions of authors expressed herein do not necessarily state or reflect those of the United States government or any agency thereof.

Available electronically at SciTech Connect http:/www.osti.gov/scitech

Available for a processing fee to U.S. Department of Energy and its contractors, in paper, from:

U.S. Department of Energy

Office of Scientific and Technical Information

P.O. Box 62

Oak Ridge, TN 37831-0062

OSTI http://www.osti.gov

Phone: 865.576 .8401

Fax: 865.576.5728

Email: reports@osti.gov

Available for sale to the public, in paper, from:

U.S. Department of Commerce

National Technical Information Service

5301 Shawnee Road

Alexandria, VA 22312

NTIS http://www.ntis.gov

Phone: 800.553 .6847 or 703.605 .6000

Fax: 703.605.6900

Email: orders@ntis.gov 


\title{
Field Testing of an Unvented Roof with Fibrous Insulation, Tiles, and Vapor Diffusion Venting
}

\author{
Prepared for: \\ The National Renewable Energy Laboratory \\ On behalf of the U.S. Department of Energy's Building America Program \\ Office of Energy Efficiency and Renewable Energy \\ 15013 Denver West Parkway \\ Golden, CO 80401 \\ NREL Contract No. DE-AC36-08GO28308 \\ Prepared by: \\ K. Ueno and J. W. Lstiburek \\ Building Science Corporation \\ 3 Lan Drive, Suite 102 \\ Westford, MA 01886 \\ NREL Technical Monitor: Stacey Rothgeb \\ Prepared under Subcontract No.KNDJ-0-40337-05
}

February 2016 
The work presented in this report does not represent performance of any product relative to regulated minimum efficiency requirements.

The laboratory and/or field sites used for this work are not certified rating test facilities. The conditions and methods under which products were characterized for this work differ from standard rating conditions, as described.

Because the methods and conditions differ, the reported results are not comparable to rated product performance and should only be used to estimate performance under the measured conditions. 


\section{Contents}

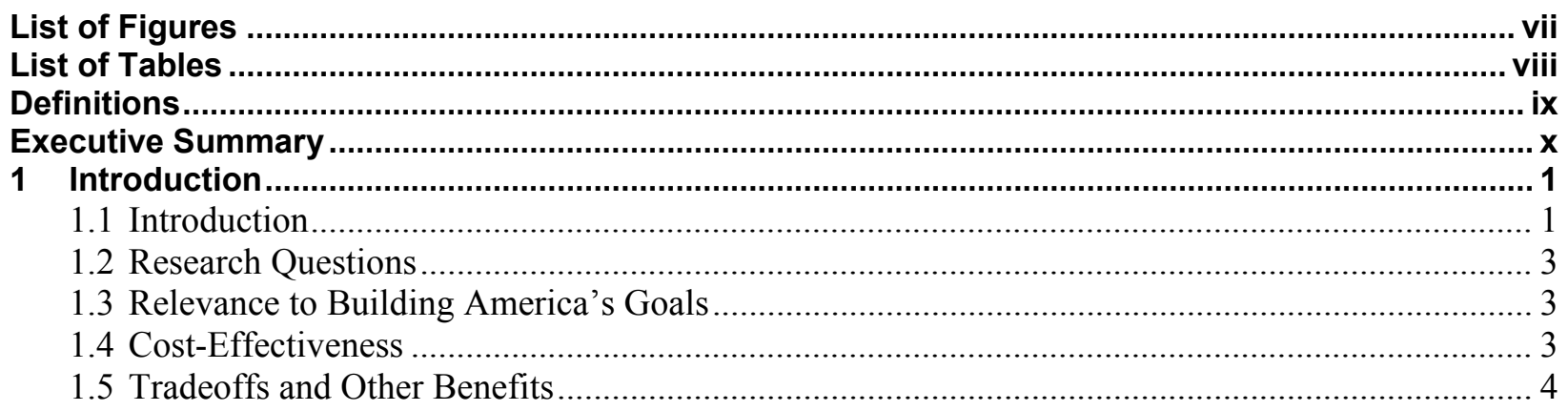

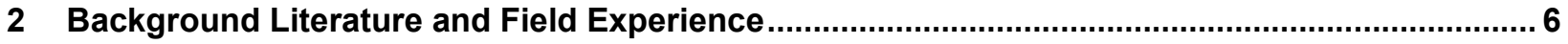

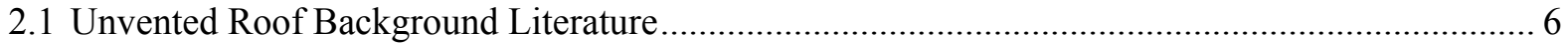

2.2 Field Experience in Houston, Texas, and Jacksonville, Florida (Climate Zone 2A) .................... 9

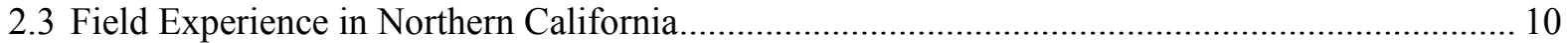

2.4 Salonvaara et al. (2013): Modeling Unvented Roofs in Climate Zones 1-4 .............................. 11

2.5 Boudreaux et al. (2013): Sealed Attic Monitored Performance (Climate Zones 3A and 4A) ....... 12

2.6 Lstiburek (2014): Humidity Behavior of Unvented and Sealed Attics....................................... 13

2.7 Smegal and Straube (2014): Monitoring and Simulation of Spray Polyurethane Foam-Insulated

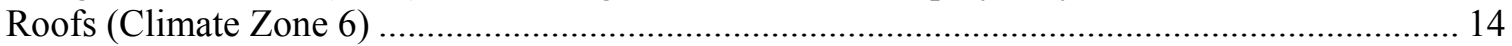

2.8 Pallin et al. (2014): Unvented Attic Indoor Climate and Moisture Durability Simulations

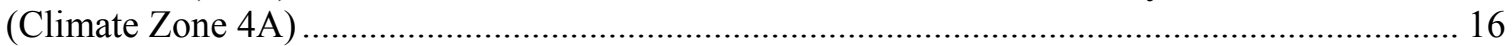

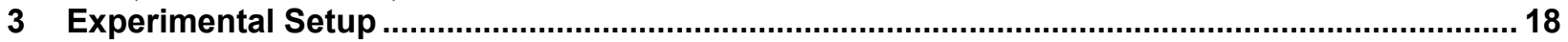

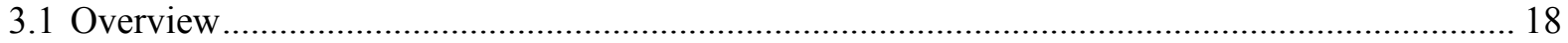

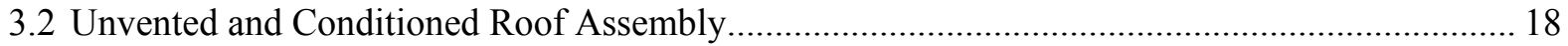

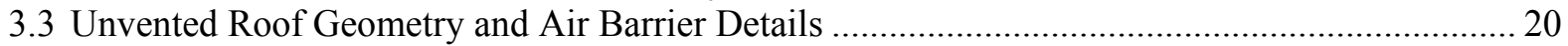

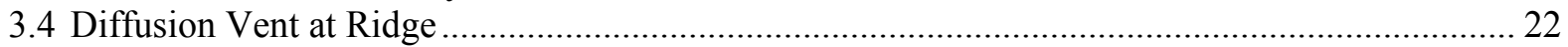

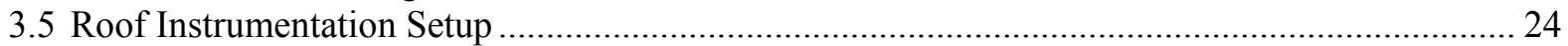

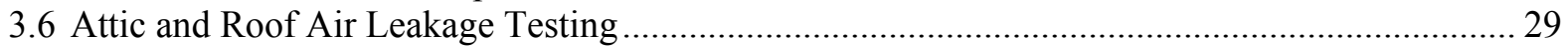

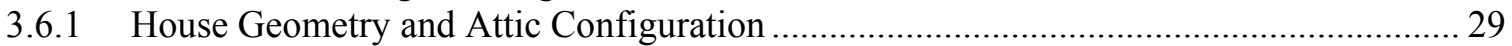

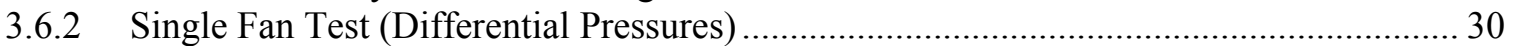

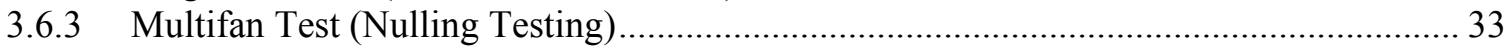

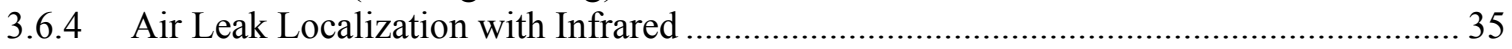

3.6.5 Air Handling Unit Pressure Differential Effects............................................................. 39

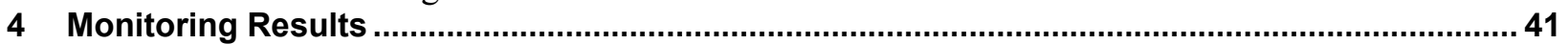

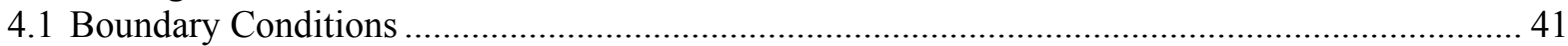

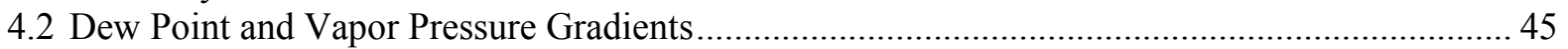

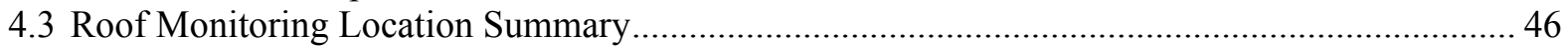

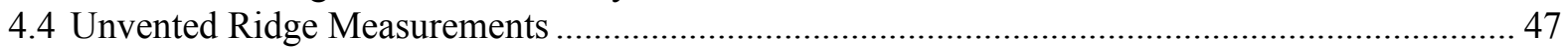

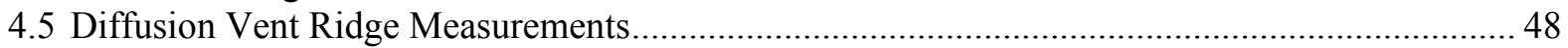

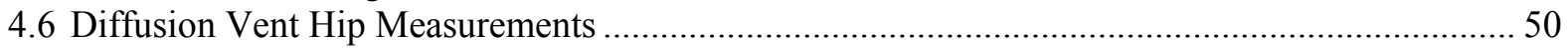

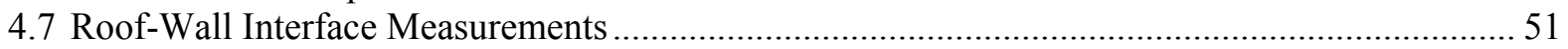

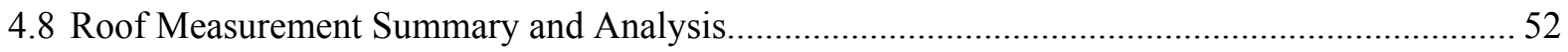

4.8.1 Diffusion Vent versus Unvented Roof Comparison ................................................ 52

4.8.2 Peak Relative Humidity, Wafer Moisture Content, and Wood Ridge Moisture Content

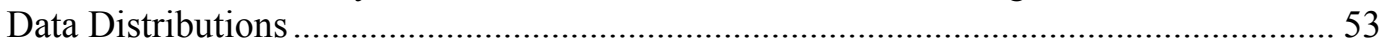

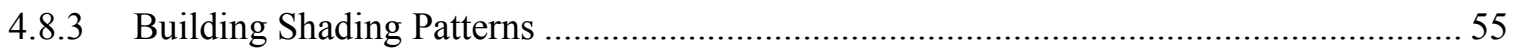

4.8.4 Roof Sheathing Hours Higher Than 20\% Moisture Content ....................................... 57

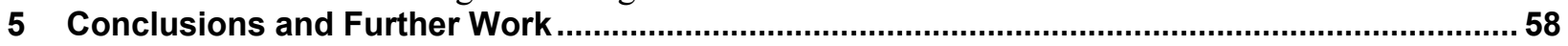

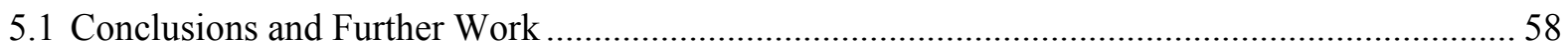




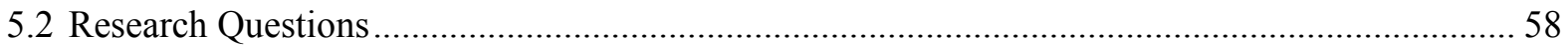

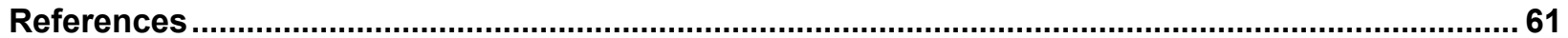

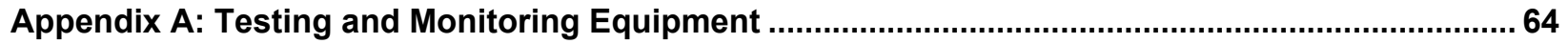

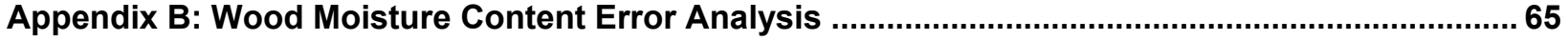

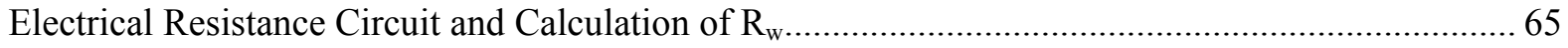

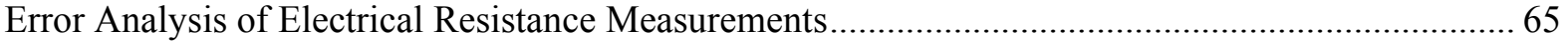

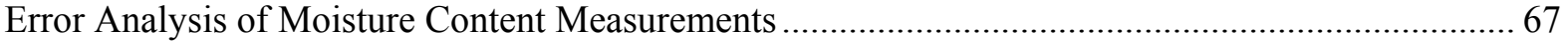

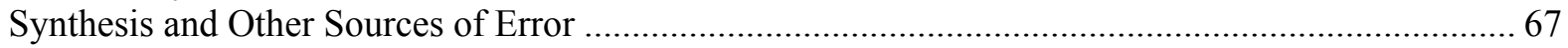




\section{List of Figures}

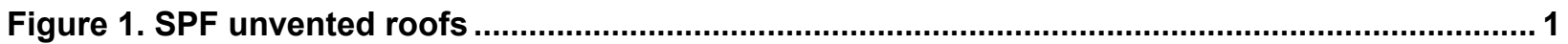

Figure 2. Typical concrete tile roofs used in Florida installations ................................................ 2

Figure 3. Use of fully adhered water control layer under concrete tile roofing................................. 2

Figure 4. Insulation material costs (no installation) in $\$ / \mathrm{ft}^{2} \cdot \mathrm{R}$ value ............................................... 4

Figure 5. Condensation on HVAC equipment located in vented attic (CZ 2A) ..............................5

Figure 6. Unvented roof hybrid insulation options: rigid foam overclad (left); SPF (right) ............... 7

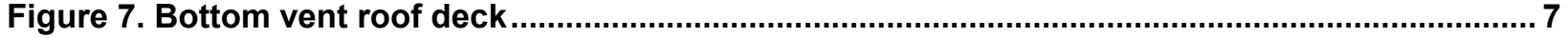

Figure 8. Top vent dense-packed roof assembly .............................................................................. 8

Figure 9. Netted and blown cellulose roof insulation in Houston (left); MC at the roof ridge

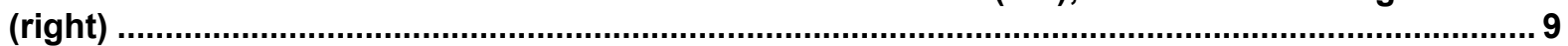

Figure 10. Cellulose roof insulation in Jacksonville (left); corrosion of ridge truss plate (right) .... 10

Figure 11. Ridge sheathing degradation with dense-pack cellulose in northern California............. 10

Figure 12. Dry sheathing lower at roof (left); interior ridge conditions (right) ................................. 11

Figure 13. Air leakage communication from unvented attic to main space (left); Houston-area

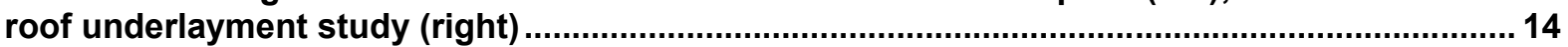

Figure 14. Front and side views of Orlando-area test house ......................................................... 18

Figure 15. Rear and overhead views of Orlando-area test house ..................................................... 18

Figure 16. Installation sequence for boxed netting system (left) and images of netting product

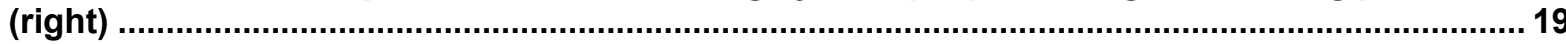

Figure 17. Boxed netting insulation system before (left) and after (right) insulation blowing ......... 20

Figure 18. Typical completed attic conditions at ridge (left) and roof-to-wall (right) ....................... 20

Figure 19. Air sealing roof-to-wall connection; note $2 x$ blocking and single-component foam....... 21

Figure 20. Insulated attic knee wall (left) and waterproofing/air barrier at roof penetration

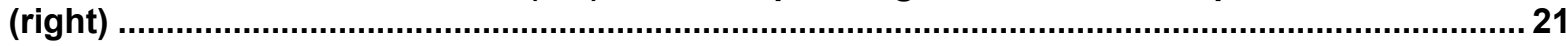

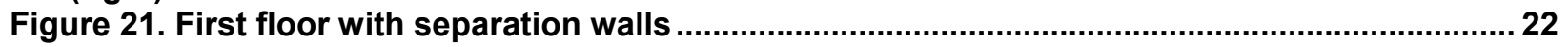

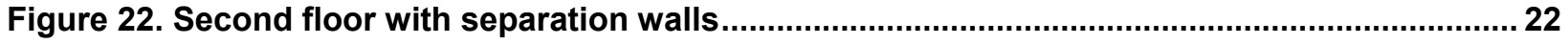

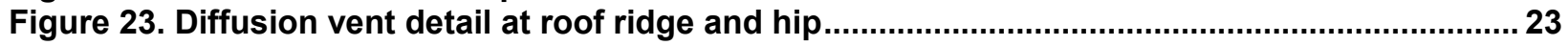

Figure 24. Open slots for vapor diffusion vent (left), diffusion vent membrane (right)................... 23

Figure 25. Completed diffusion vent (left); installation of ridge metal (right) ....................................24

Figure 26. Completed roof ridge tile geometry (left); gaps in ridge tile (right) ................................ 24

Figure 27. Orlando roof plan showing ridges, hips, valleys, and measurement locations............... 26

Figure 28. Ridge monitoring package (sensors at ridge and hip peaks) ..................................... 27

Figure 29. Typical ridge monitoring package with sensors highlighted ........................................... 27

Figure 30. Close-up of ridge package (left); ridge package at unvented roof (right)...................... 28

Figure 31. Typical temperature/RH sensor for attic interior (left) and exterior (right) conditions.... 28

Figure 32. Front-left isometric of unvented roof geometry .................................................................29

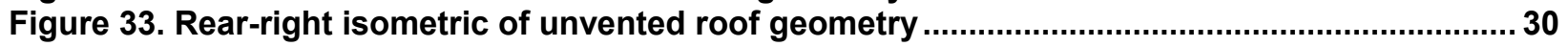

Figure 34. Air leakage (single blower door) testing of the tile roof test house ................................. 30

Figure 35. Hatch open/hatch closed multipoint testing with curve fits............................................. 31

Figure 36. Visual (left) and infrared (right) image during depressurization testing, showing

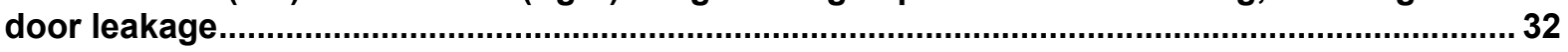

Figure 37. Depressurization fans placed in lower (left) and upper (right) attics ............................. 33

Figure 38. Multipoint testing of individual zones (main house and two attics), nonnulled .............. 34

Figure 39. Multipoint testing of zones (main house and two attics) with simultaneous fans

(nulled)

Figure 40. Front-left isometric of unvented roof geometry, keyed to Figure 41 through

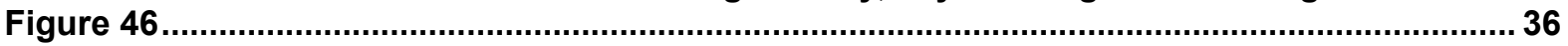

Figure 41. Bathroom ceiling air leakage at roof-wall interface; water leak in blue (Location A) ...... 36

Figure 42. Roof-wall connection above bathroom; water damage at ceiling visible (Location A) ... 37

Figure 43. Air leakage at wiring penetrations at garage wall-top plate (Location B) ......................... 37

Figure 44. Air leakage at stud below roof-wall interface (Location C) ......................................... 38

Figure 45. Air leakage at roof-wall interface, and at unconditioned porch attic (Location D) .......... 38

Figure 46. Construction image of roof-wall interface self-adhered membrane (Location E)............. 39 
Figure 47. Upper attic $\Delta \mathrm{P}$ measurement (left); ductwork located in upper attic (right).................... 39

Figure 48. Exterior, attic, and main conditioned space temperatures .............................................. 41

Figure 49. Exterior, attic, and main conditioned space temperatures, May 2015 .......................... 41

Figure 50. Heating degree days (left) and cooling degree days (right) for Orlando (MCO airport) .. 42

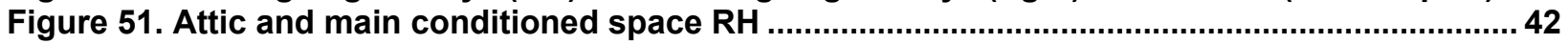

Figure 52. Attic and main conditioned space RH, July 2015 detail .............................................. 43

Figure 53. Exterior, attic, and main conditioned space dew point temperatures...............................43

Figure 54. Attic and main space dew point temperatures (March 2015) with sky conditions .......... 44

Figure 55. Attic and main space dew point temperatures (August 2015) with sky conditions......... 45

Figure 56. Interior and exterior dew point temperatures, March 2015 detail ....................................45

Figure 57. Interior and exterior dew point temperatures, August 2015 detail ...................................46

Figure 58. Roof instrumentation locations on isometric of house .................................................4 47

Figure 59. Unvented roof (UVR1) MC and RH measurements (second-floor attic) ..........................48

Figure 60. Diffusion vent ridge (DVR1) MC and RH measurements (upper/second-floor attic) ....... 49

Figure 61. Diffusion vent ridge (DVR2) MC and RH measurements (upper/second-floor attic) ....... 49

Figure 62. Diffusion vent ridge (DVR3) MC and RH measurements (lower/first-floor attic).............. 49

Figure 63. Diffusion vent roof hip (DVH1; lower) MC and RH measurements ..................................50

Figure 64. Diffusion vent roof hip (DVH2; upper) MC and RH measurements .................................51

Figure 65. Roof-wall (RW1) MC and RH measurements (downhill area) ........................................ 52

Figure 66. Roof-wall (RW2) MC and RH measurements (no downhill area) ..................................52

Figure 67. Comparison of unvented (UVR1) and diffusion vent (DVR1) ridge wafer MC and RH..... 53

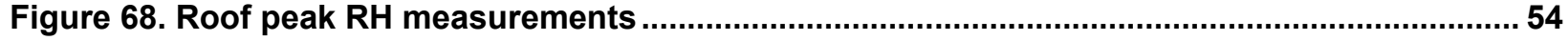

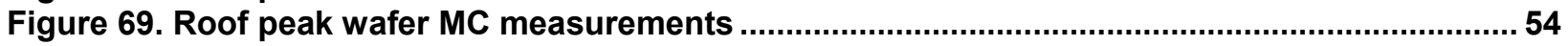

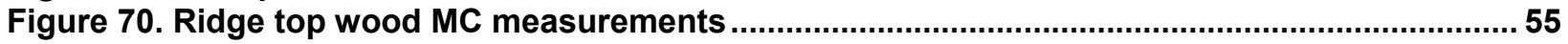

Figure 71. Overhead view of roof shading with key sensor locations ..........................................56

Figure 72. DVH1 versus DVH2 ridge and ridge board temperatures, March-April 2015 ..................56

Figure 73. DVH1 versus DVH2 ridge and ridge board temperatures, July-August 2015 ................. 57

Figure 74. Schematic of resistance measurement circuit ...........................................................65

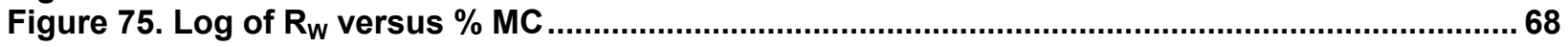

Unless otherwise noted, all figures were created by Building Science Corporation.

\section{List of Tables}

Table 1. Summary of Simulation Results (roof sheathing MCs) ................................................ 12

Table 2. Test Roof Assemblies Monitored in Smegal and Straube (2014) ......................................... 14

Table 3. Results of Hatch Open/Hatch Closed Air Leakage Testing .............................................. 31

Table 4. $\Delta \mathrm{Ps}$ at $-49.2 \mathrm{~Pa}$ across Closed Hatches to Attics with Hole Size Ratios .............................. 33

Table 5. Results of Individual Space Air Leakage Testing (nonnulled)............................................ 33

Table 6. Results of Simultaneous Fans/Nulled Air Leakage Testing................................................ 35

Table 7. Roof Instrumentation Location Summary, with Attic Location ............................................. 47

Table 8. Summary of Ridge/Peak RH Conditions Higher Than 80\% RH...........................................54

Table 9. Testing and Monitoring Equipment Specifications...............................................................64

Table 10. Calculation of Wood Resistance Error $\left(\Delta r_{w}\right)$ at Various Wood MC Levels .......................66

Table 11. Calculation of Wood MC Error $\left(\Delta \mathrm{mc}_{\mathrm{uncorrected}}\right)$ at Various Wood MC Levels ..................... 67

Unless otherwise noted, all tables were created by Building Science Corporation. 


\section{Definitions}

ACH50 Air changes per hour at $50 \mathrm{~Pa}$

ASHRAE American Society of Heating, Refrigerating and Air-Conditioning Engineers, Inc.

ccSPF Closed-cell spray polyurethane foam

CFM 50 Cubic feet per minute at $50 \mathrm{~Pa}$

$\mathrm{CZ} \quad$ Climate zone

DV Diffusion vent (roof)

EqLA Equivalent leakage area

GWB Gypsum wall board

HVAC Heating, ventilating, and air conditioning

MC Moisture content

ocSPF Open-cell spray polyurethane foam

OSB Oriented strand board

$\Delta \mathrm{P} \quad$ Differential pressure

$\mathrm{Pa} \quad$ Pascal

RH Relative humidity

SPF Spray polyurethane foam

ZPD Zone pressure diagnostic 


\section{Executive Summary}

Unvented roofs (aka cathedralized attics) are an established presence in Florida residential building markets. These roofs are built with a layer of spray polyurethane foam (SPF) on the underside of the roof deck. Such a roof configuration positions the heating, ventilating, and airconditioning equipment and ductwork within the conditioned space and improves airtightness in practice (by shifting the air barrier from the ceiling to the roofline). However, SPF is more expensive than fibrous insulation. Some builders have also become wary of using SPF because of liability concerns about indoor air quality and offgassing. Unfortunately, unvented roofs that use only air-permeable fibrous insulation (cellulose or fiberglass) have been demonstrated to be at risk of moisture issues in climate zone $2 \mathrm{~A}$ because condensation and moisture accumulation occur at the ridge.

This report describes research about a test implementation of an unvented tile roof assembly in a hot-humid climate (Orlando, Florida; climate zone 2A); the roof was insulated with airpermeable insulation (netted and blown fiberglass). Given the localized moisture accumulation and failures seen in previous work, the U.S. Department of Energy's Building America research team Building Science Corporation theorized that installation of diffusion vents might allow for the wintertime release of moisture to safe levels. Diffusion vents are open slots at the roof's highest points (the ridge and hips) that are covered with a water-resistant but vapor-open (500+ perm) air barrier membrane.

The test home is a two-story slab-on-grade structure $\left(3,600 \mathrm{ft}^{2}\right)$; the roof was insulated with a prototype insulation system (called boxed netting), which allows full depth insulation (i.e., it is not limited by the depth of the truss top chord). As a control comparison, one part of the roof was constructed as a typical unvented roof (with a self-adhered membrane at the ridge). Ideally, failure would occur in the control roof and the experimental (diffusion vent) roofs would show sufficient drying to avoid failure. No intentional space conditioning was provided in the unvented attic so worst-case humidity buildup conditions could be observed.

Instruments were installed to capture a variety of orientations and roof conditions including multiple roof ridges (both diffusion vent and unvented), hips, and roof-wall interfaces. Measurements included temperature and relative humidity (RH), wood moisture content (MC) (in sheathing), and a wood wafer sensor intended as an RH surrogate and condensation indicator. Instrumentation was completed in November 2014; the house was largely completed by February 2015 and occupied by homeowners in May 2015.

As part of the commissioning process, the house and attics were tested for air leakage. The roof geometry includes an upper attic (over the second floor) and a lower attic (at the first floor where it was not covered by the second floor). The testing indicated that the overall house airtightness (with attic hatches open) was 7.6 air changes per hour at $50 \mathrm{~Pa}$ or 0.58 cubic feet per minute at $50 \mathrm{~Pa} / \mathrm{ft}^{2}$ enclosure area. This result exceeds the 5 air changes per hour at $50 \mathrm{~Pa}$ target for climate zone 2. Measurements indicated significant leakage from the lower attic to the exterior (196 in. ${ }^{2}$ equivalent leakage area [EqLA]). In comparison, the upper attic had 35 in. $^{2}$ EqLA and the conditioned space (first and second floors) had 311 in. ${ }^{2}$ EqLA (without door gaskets or finish floors). These air leakage results indicate that complicated details and roof-wall intersections can 
result in air leakage. However, the field (main body) of the roof and the diffusion vent ridge detail were not significant sources of air leakage.

Data were collected from November 2014 through August 2015 (for 9 months); this captured a winter (during construction) through summer. However, data were not collected from January to mid-February 2015 due to site power problems, and this caused a data gap. The boundary condition measurements show that the upper/second-floor attic has the highest risk of coldweather condensation issues, because it has the highest dew point (air moisture content) from construction moisture. This situation is consistent with the upper/second-floor attic being (1) relatively airtight and (2) located at the top of the conditioned space (moisture stratification). Also, interior moisture loading is minimal before the data gap but is then significant (some 100\% RH conditions in attics) after the gap due to drywall finishing and painting activities.

The data collected to date indicate that the diffusion vent roof has greater moisture safety than the conventional unvented roof design. The unvented roof had extended periods (under cold winter conditions) of $95 \%-100 \% \mathrm{RH}$ and wafer (wood surrogate RH sensor) measurements that indicated possible condensation. The high moisture levels were concentrated at the roof ridge, which is consistent with previous field experience in Texas, Florida, and California. In contrast, the diffusion vent roofs had drier conditions; most peak MCs (in sheathing) were lower than $20 \%$. In the spring as outdoor temperatures warmed, all roofs dried well into the safe range (10\% MC or lower). Some roof-wall interfaces showed moderately high MCs; this might be caused by moisture accumulation at the highest point in the lower attic, shading of the roof by the adjacent second story, or both.

Monitoring will be continued at least through spring 2016 (another winter and spring). The interior moisture levels in winter 2015-2016 may clarify the risks of unvented roofs versus roofs with the diffusion vent detail. During winter 2014-2015, the interior monitored areas had high moisture levels due to drying of construction moisture. After the house was occupied, interior moisture was generated; however, the cooling system was operated through summer 2015, which resulted in dehumidification and less stored moisture in finishes and furnishings. The net effect of this change could be higher or lower interior moisture levels, which will depend on occupancy, behavior, and ventilation rates. 


\section{Introduction}

\subsection{Introduction}

Unvented roofs (aka cathedralized attics) are an established presence in Florida residential building markets. Such roofs are built with a layer of spray polyurethane foam (SPF) at the underside of the roof deck (Figure 1) as discussed by Rudd and Lstiburek (1998) and Lstiburek $(2006,2011)$. Primary advantages to this construction are that (a) the attic ductwork and heating, ventilating, and air-conditioning (HVAC) system are brought into the thermal and air barrier of the conditioned space and (b) air leakage at the ceiling plane (often complicated by interior detailing) is eliminated, which typically results in improved overall airtightness. Secondary advantages include reduced wind-driven rain entry (because attic vents are eliminated) and potentially reduced hurricane blow-off issues (due to differential pressurization). Disadvantages include higher first cost and slightly larger surface area (conductive losses); the latter factor is often negated because duct leakage to the exterior is eliminated.

The U.S. Department of Energy's Building America team Building Science Corporation studied unvented roof assemblies, which have a higher risk of wintertime interstitial (hidden) condensation issues than vented roof assemblies. These risks are addressed in current building code with the requirement for air-impermeable insulation (i.e., rigid plastic foams) on the exterior side of the roof assembly; air-permeable (fibrous) insulation makes up the balance of the insulating value. This measure raises the temperature of the condensing surface (underside of the air-impermeable insulation), which reduces the risks of condensation. The minimum thickness of air-impermeable insulation varies by climate zone and is spelled out in $\$ R 806.4$ "Unvented attic assemblies" of the International Residential Code (ICC 2009). For climate zones (CZs) 1A and $2 \mathrm{~A}$ (Florida), the requirement is a minimum of R-5. The typical implementation in this market is to use full-thickness SPF (open cell [ocSPF] or closed cell [ccSPF]) as shown in Figure 1.
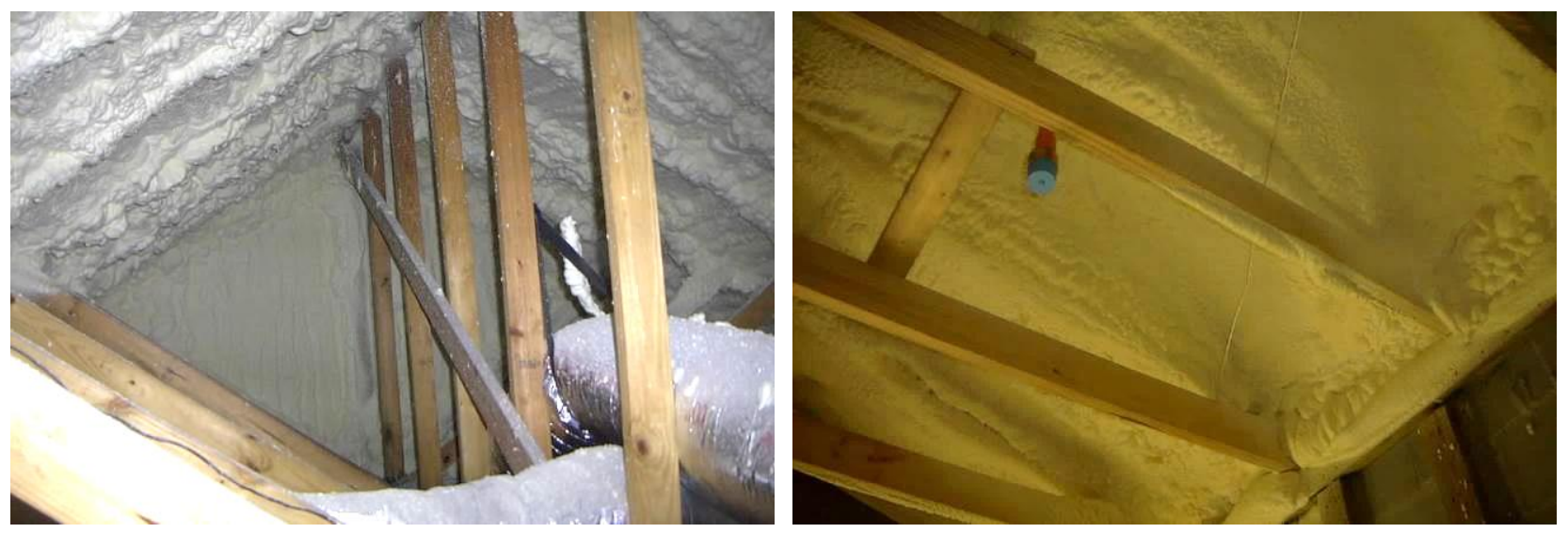

Figure 1. SPF unvented roofs

But recently some builders have become wary of using SPF because of liability concerns about indoor air quality and offgassing (Gibson 2013). Although these issues may be linked to installation defects and/or certain manufacturers or formulations, builders are pursuing options for alternatives to SPF for unvented roofs. 
Other specifics to the Florida market are relevant to the selected roof design. One is the use of concrete tile as a typical roof cladding (Figure 2); rounded barrel tile and flat tile profiles are common. This material has the advantage of greater durability relative to asphalt shingles; lifespans are commonly cited at about 50 years. This roof cladding is effectively self-ventilated, in that an air space or air gap is created between the drainage plane/water resistive barrier and the cladding. This air gap allows drainage of bulk water and drying from the underside of the concrete tile.
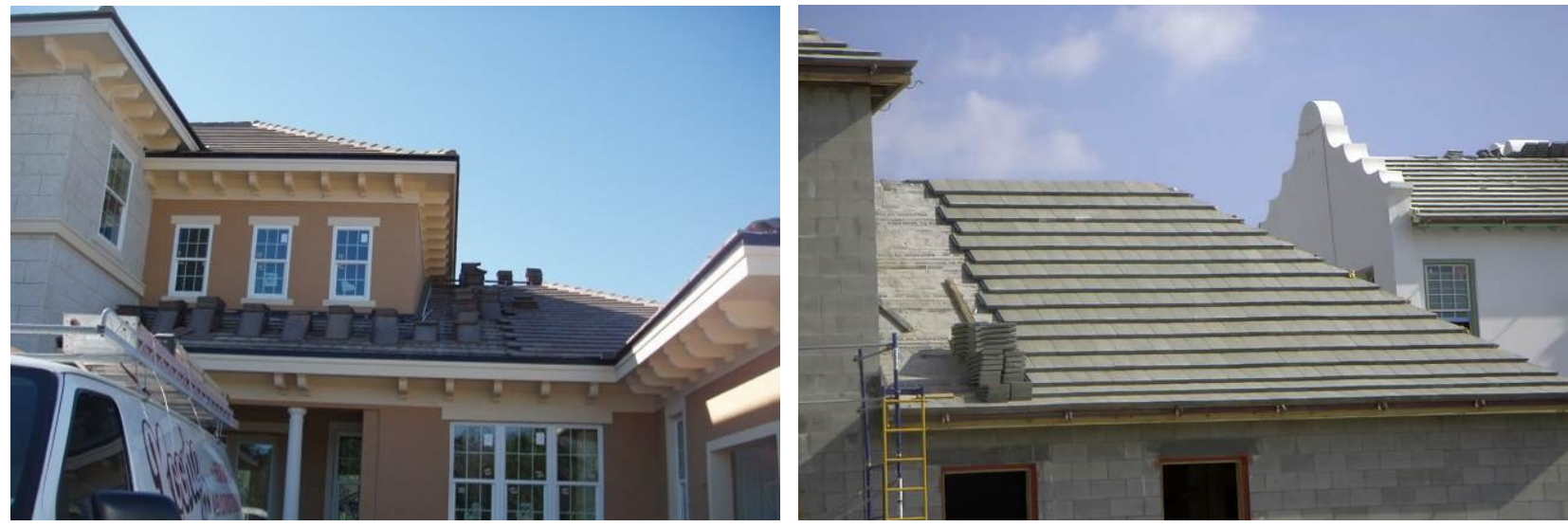

Figure 2. Typical concrete tile roofs used in Florida installations

Due to the severe wind-driven rain and shingle blow-off issues that occur during hurricanes in the Gulf Coast, implementing fully adhered water control layers (or drainage planes) under the roof cladding is common practice. Typical materials include granule-coated roll roofing felt that is adhered with bitumen and bituminous self-adhered membranes (Figure 3).
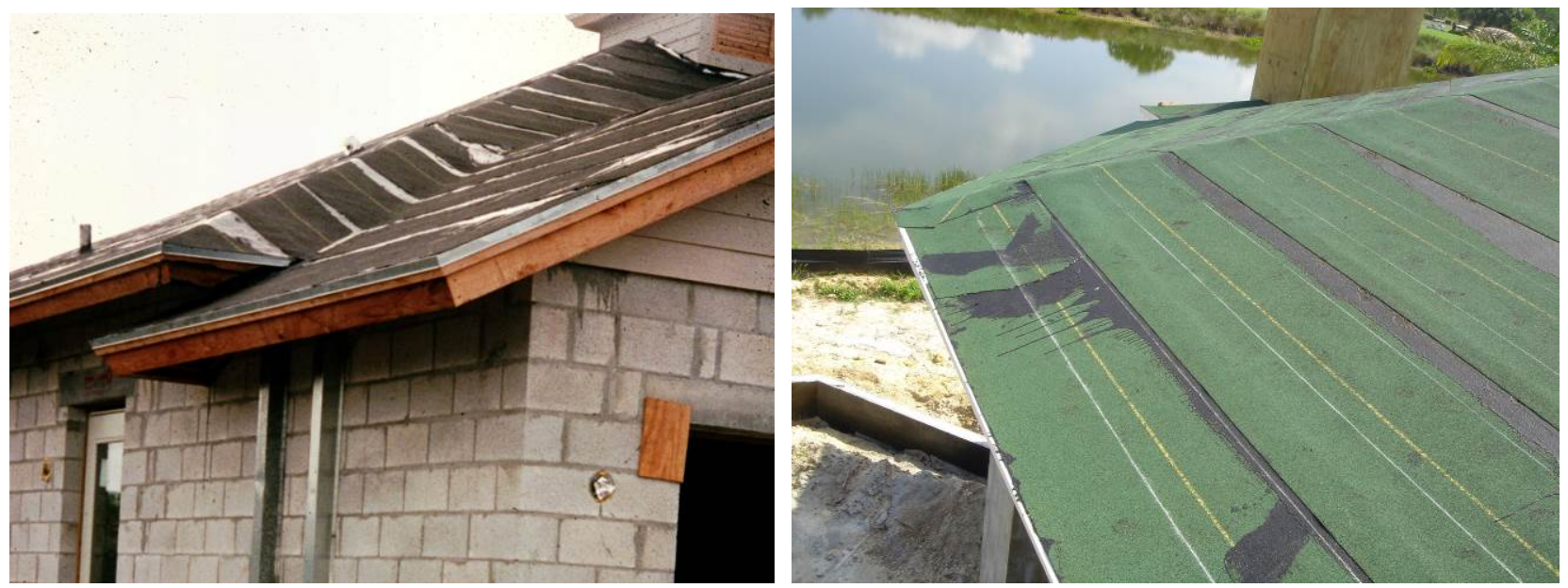

Figure 3. Use of fully adhered water control layer under concrete tile roofing

Given the requirements and constraints of the Florida market and available products, reexamining options for unvented roofs with air-permeable insulation appears to be an excellent opportunity for this measure. 
This research is a test implementation of an unvented roof design in a hot-humid climate (CZ 2A). The roof is insulated with air-permeable insulation (netted and blown fiberglass) and a diffusion vent detail at the ridge to allow for wintertime removal of accumulated moisture. One goal of the research is to determine the assembly's resistance to condensation or the design's moisture safety. This research has an additional advantage of potentially reducing the first cost of unvented roofs by eliminating SPF, which is a higher-cost material than fibrous insulations.

In addition, two research sites examining unvented roof assemblies with fibrous (cellulose and fiberglass) insulation have been instrumented by Building America. These sites are located in Chicago, Illinois (CZ 5A), and Houston, Texas (CZ 2A). Both sites have asphalt shingle roofs.

\subsection{Research Questions}

- Does implementing an unvented cathedralized attic with air-permeable insulation (such as blown fiberglass) present issues in a hot-humid climate? One potential issue is air barrier continuity at roof penetrations and at the perimeter roof-to-wall interface. What is the air barrier performance of the assembly as installed?

- Does installing the diffusion vent present any issues with rain control or durability? For instance, are fastener penetrations a greater issue with this material? Did the roofing crew report any installation issues?

- Do wood roof sheathing and framing moisture contents (MCs) remain within acceptable ranges throughout the winter in this roof design in a Florida climate? Are MCs at the ridge higher than at lower sections of the roof - as experienced in previous work?

- Does the conventional unvented roof assembly experience higher MCs than the diffusion vent roof, and do these moisture levels constitute failure?

- Do the reservoir cladding nature of concrete roof tile and the vapor-permeable water diffusion vent present any risks of inward vapor drive? Or is the inward vapor drive risk a nonissue because of the vapor-open nature of the interior insulation assembly?

\subsection{Relevance to Building America's Goals}

Given the Building America goals of reducing home energy use by 30\%-50\% (compared to 2009 energy codes for new homes and preretrofit energy use for existing homes), this research is an effort to reduce the first costs of unvented roof assemblies. In hot-humid climates, unvented roof assemblies can be used to bring ductwork and air handling units into the conditioned space and improve airtightness. Doing so with materials that cost less than SPF (the current solution) may increase the adoption of this measure.

This work also falls under the category of "2.0 Risk Reduction and Minimization" from the FY 2014 Residential Energy System Research Needs (NREL 2013).

\subsection{Cost-Effectiveness}

One of the goals of this research is to find moisture-safe methods to replace higher-cost SPF or rigid board foam with lower-cost fibrous fill insulation. The retrofit of an empty cavity (e.g., retrofit insulation of a cathedralized ceiling) is clearly cost-effective that is compounded by the moderate air sealing effects of dense-pack insulation. 
The installed cost of ccSPF varies strongly based on contractor availability, the size of the installation, regional pricing, feedstock (crude oil) prices, and access (e.g., requirement for lifts or scaffolding; confined space installation). However, a typical installed price used for estimation purposes is $\$ 1$ /board foot ( 1 in. $\times 12$ in. $\times 12$ in.), although pricing varies in practice from $\$ 0.45$ to $\$ 1.40 /$ board foot.

Figure 4 shows a comparison of insulation material costs based on "big box" home center pricing gathered from 2007 through 2011. It is shown using the normalization metric of $\$ / \mathrm{ft}^{2} \cdot \mathrm{R}$ value, which normalizes the area costs based on the R-values.

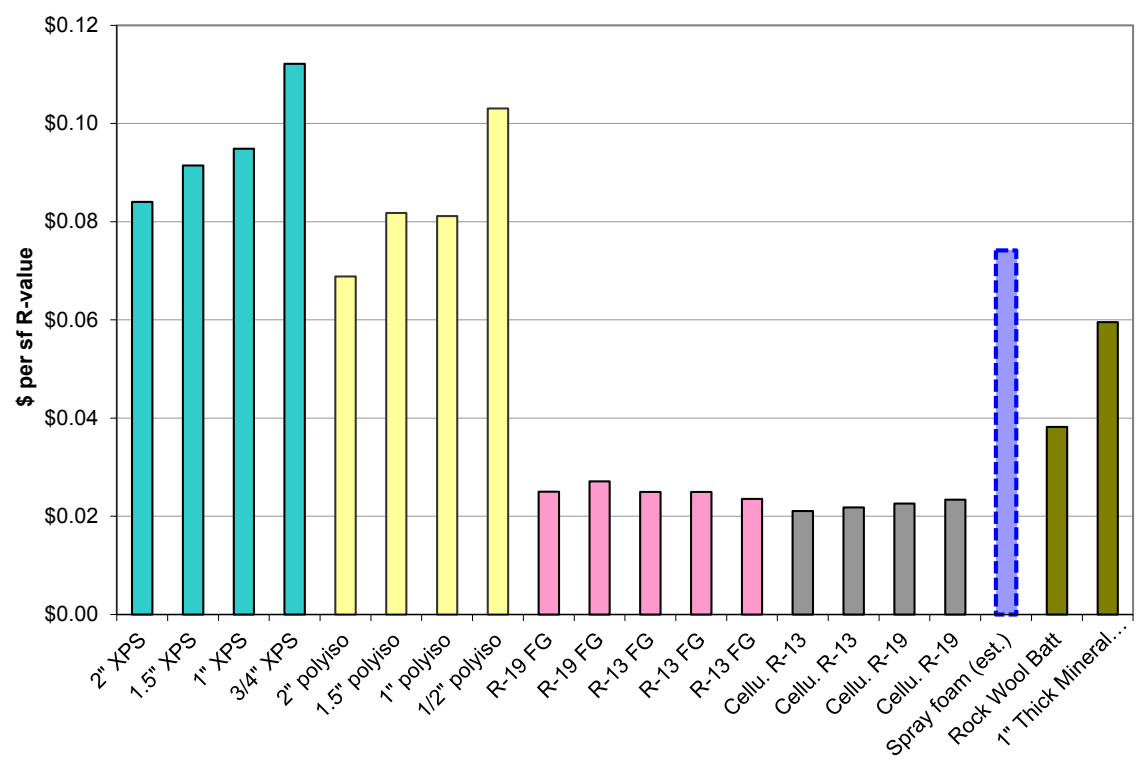

Figure 4. Insulation material costs (no installation) in $\$ / \mathrm{ft}^{2} \cdot \mathrm{R}$ value

The figure shows values for extruded polystyrene, polyisocyanurate, fiberglass, cellulose, ccSPF, and mineral fiber. Note that ccSPF is included in the graph with a caveat: no isolated material cost is shown for ccSPF, because it is effectively manufactured and installed in a single step. An estimate was made using the $\$ 1 /$ board foot price and dividing by 2 (50\% materials and $50 \%$ labor).

The graph shows that ccSPF is priced comparable to the rigid board foam plastic products (extruded polystyrene and polyisocyanurate), which are both substantially more expensive than cavity fill fibrous insulation such as fiberglass or cellulose.

\subsection{Trade-Offs and Other Benefits}

The basic benefits of retrofit insulation of compact roof assemblies (including cathedralized ceilings) include energy savings from reduced heat flow and reduced airflow and possible thermal comfort improvements (due to radiant surface temperature effects).

Benefits of unvented roof assemblies in hot-humid climates include energy savings from eliminating duct conductive and air leakage losses; shifting the enclosure geometry to the roof line commonly improves building airtightness. Also, bringing the ductwork and HVAC equipment within the conditioned space can reduce the risks of surface condensation on cold 
equipment surfaces compared with high-dew-point attic (essentially exterior) air (Figure 5). This condensation adversely affects durability of mechanical equipment over time.
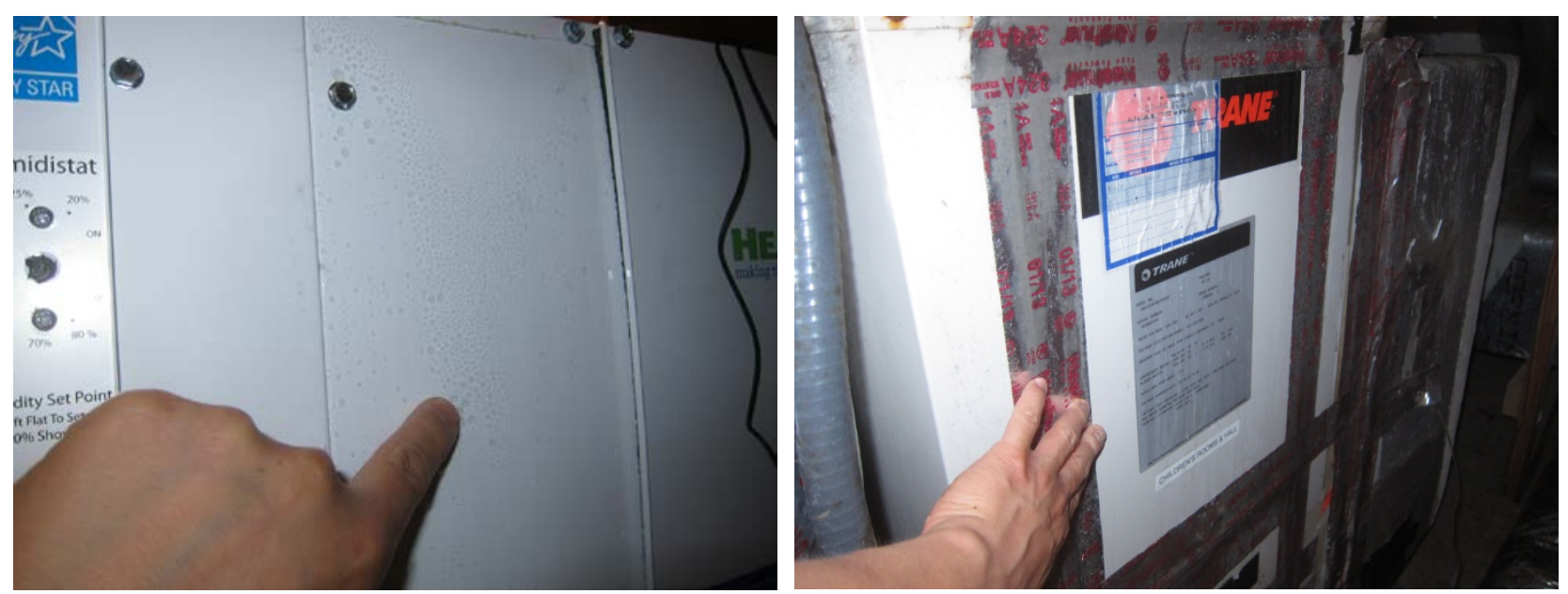

Figure 5. Condensation on HVAC equipment located in vented attic (CZ 2A) 


\section{Background Literature and Field Experience}

\subsection{Unvented Roof Background Literature}

Lstiburek (2010b) provides an overview of the use of dense-pack cellulose insulation and shows examples of the problems that can occur in compact roof assembly applications. Schumacher and LePage (2012) provide a comprehensive analysis of the use of dense-pack insulation in compact roof assemblies. They provide an overview of the problem and cite previous literature:

Many contractors and cellulose sales people falsely believe that dense-pack assemblies are "airtight". This has been shown not to be the case (Derome 2005, Schumacher 2011) - with disastrous consequences in cold and mixed climates where roof rafters have been "dense packed" with no provision for rafter ventilation (to remove moisture) or for control of condensing surface temperatures (to minimize moisture accumulation) (Lstiburek 2010b). Approximately two assemblies in ten fail - typically within 10 years (Fitzgerald 2010).

Schumacher and LePage also provide hygrothermal analysis of a variety of assemblies to show the moisture risks associated with unvented dense-pack roofs. They suggest failures are not endemic, because post-retrofit houses achieve only moderate airtightness. Thus, interior moisture generation is sufficiently diluted by wintertime air leakage to result in low wintertime interior relative humidity $(\mathrm{RH})$ levels. They provide several options for moisture-safe roof assemblies that use dense-pack cellulose:

- Exterior insulation: roof deck overclad (Figure 6, left)

- Hybrid insulation: SPF at roof deck with fibrous insulation (Figure 6, right)

- Bottom-vent decks: air space or rafter ventilation chutes under the roof deck, outboard of insulation (Figure 7)

- Top vent decks: airspace under the asphalt shingles and roof cladding. This creates a drained and ventilated cavity (Figure 8) (Lstiburek 2010a; Straube and Burnett 2005). This is not a common assembly with asphalt shingles and was considered somewhat experimental or conceptual.

Miller et al. (2006) performed field testing and simulations on roof assemblies ventilated between the cladding and sheathing. They determined that a stone-coated metal shake roof on a batten/counterbatten ventilation space reduced cooling season heat flux by $40 \%-50 \%$ (including ventilation and emissivity effects) compared with a direct-applied dark asphalt shingle roof. Simulations indicated that the ventilated air space case has enhanced sheathing (oriented strand board $[\mathrm{OSB}]$ ) drying relative to the case with no ventilation above the sheathing. 

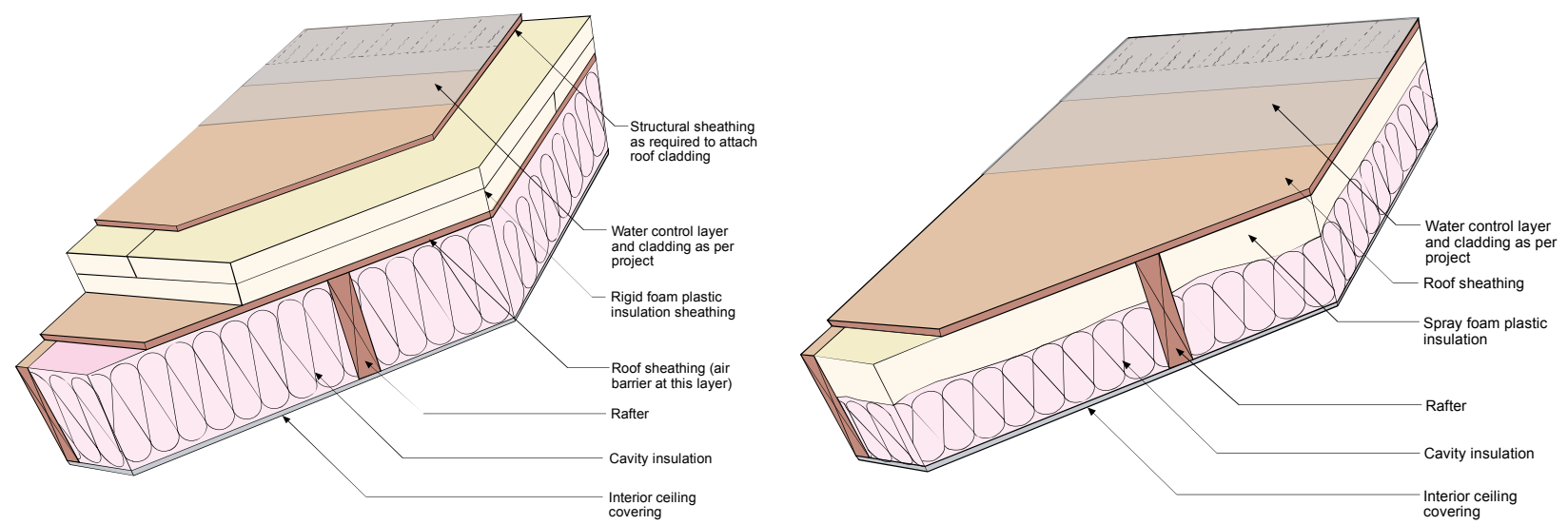

Figure 6. Unvented roof hybrid insulation options: rigid foam overclad (left); SPF (right)
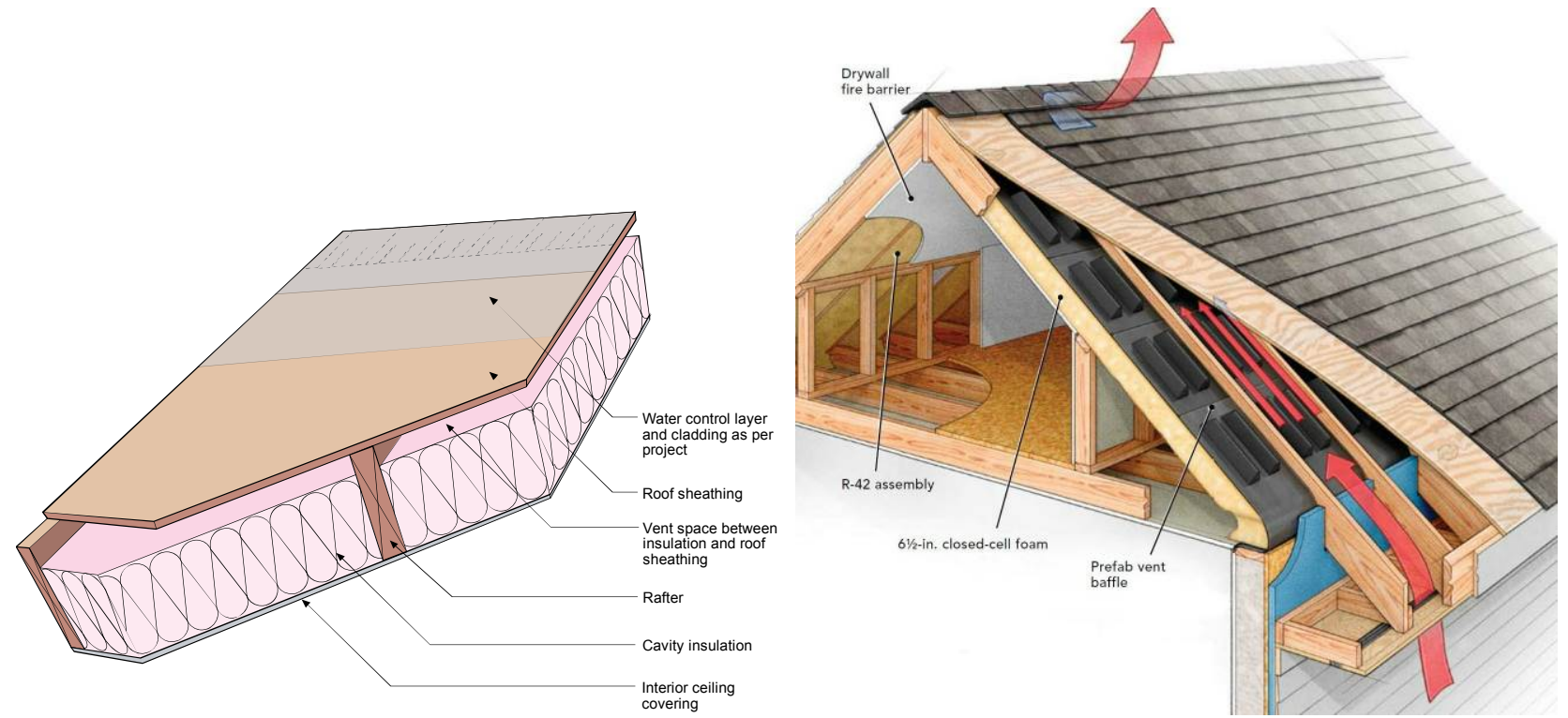

Figure 7. Bottom vent roof deck

Source of right figure: Lstiburek (2011) 


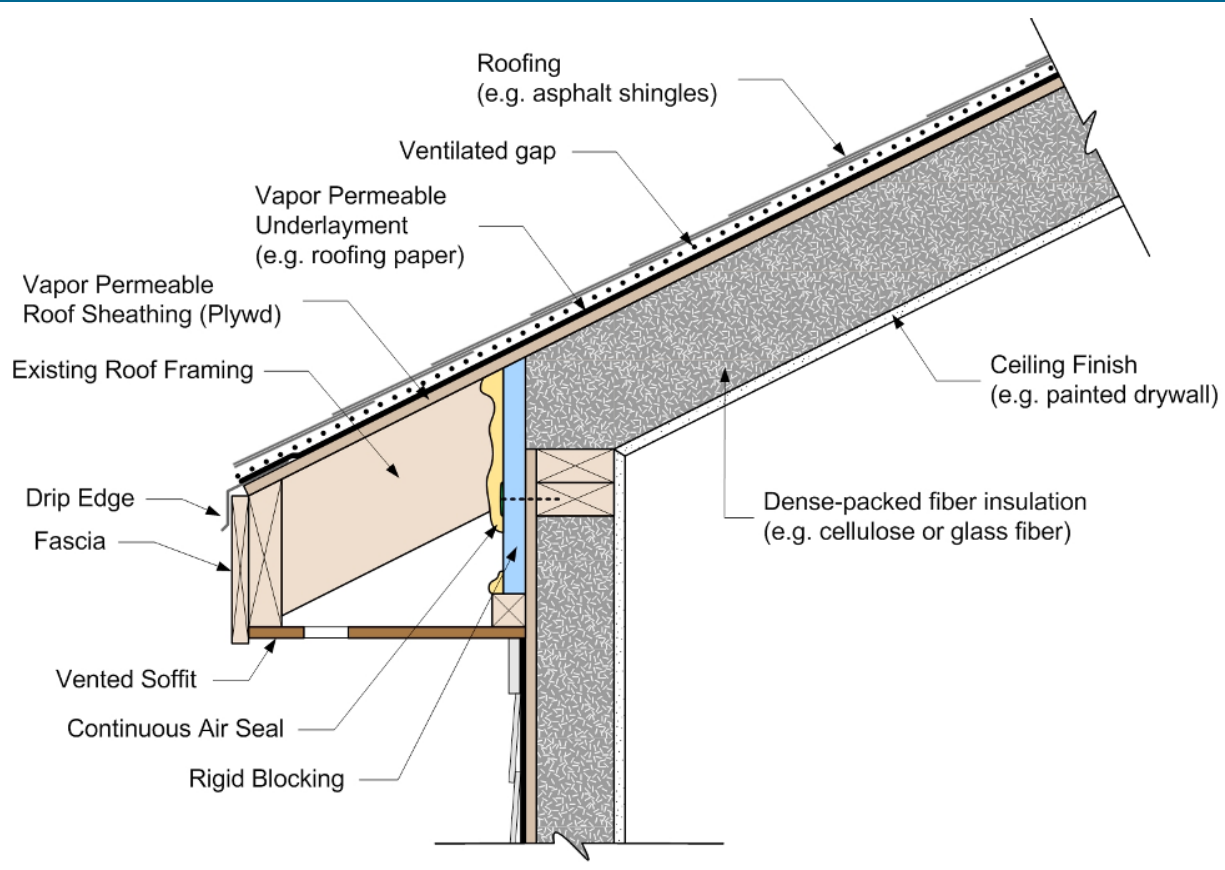

Figure 8. Top vent dense-packed roof assembly

Source: Schumacher and LePage (2012)

The top vent deck warrants further explanation; Schumacher and LePage (2012) describe the design and provide recommendations for implementation.

A number of low-rise residential roofing systems incorporate ventilated gaps between the roofing and the roof deck (e.g., clay roof tiles, concrete roof tiles \& slate tiles installed on strapping; cedar shakes installed over drainage/ventilation mat). The top-ventilated deck strategy might be considered for dense-pack insulation retrofits where the existing ceiling must be kept but exterior insulation cannot be added (e.g., due to historical preservation considerations, spatial limitations or cost constraints).

When a ventilation gap is incorporated above the roof deck, the roofing can dry to the underside. If a vapor-permeable underlayment is used, the roof sheathing can also dry to this ventilated gap; however, the rate of drying through the sheathing is limited by the vapor permeance of the sheathing and the drainage plane installed on top of the sheathing.

Top-ventilated retrofit roofs may provide better moisture performance than common retrofit roofs; however, further research is needed to better understand and establish the sensitivity to sheathing and underlay vapor permeance. At this point in time the likely moisture performance of top-ventilated retrofit roofs is not expected to be as good as the other three retrofit strategies: exterior insulated, hybrid-insulated and bottom-ventilated retrofits. Builders are encouraged to employ one of the first three strategies. If a topventilated retrofit must be implemented, it should be completed using plywood sheathing and high vapor permeance underlayment. 


\subsection{Field Experience in Houston, Texas, and Jacksonville, Florida (Climate Zone 2A)}

Building Science Corporation observed unvented roof behavior in hot-humid climates during field implementation; several of these roofs were built in the Houston, Texas, area circa 2001 (CZ 2A). The typical roof assembly was asphalt shingles, roofing felt, OSB sheathing, and netted and blown cellulose insulation (Figure 9, left). Netting was attached to the underside of the dimension lumber $(2 \times 8$ to $2 \times 12)$ rafters.

During the first fall of operation, the homeowner reported seeing reflections of moisture condensation and dripping from the ridge of the unvented attic from the interior. Site investigations (Figure 9, right) revealed elevated wood MCs at the ridge and evidence of previous condensation (such as rusted staples).
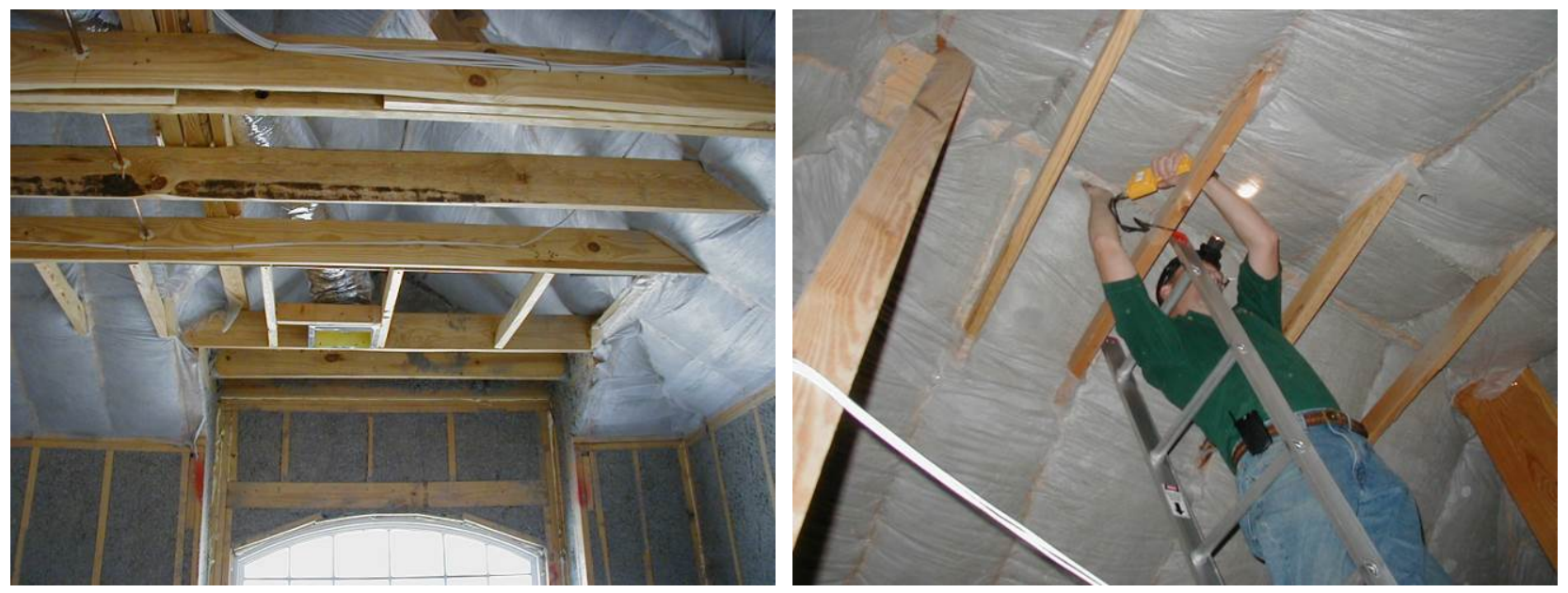

Figure 9. Netted and blown cellulose roof insulation in Houston (left); MC at the roof ridge (right)

The cellulose insulation at the peak had a noticeably packy or compactable texture as opposed to the fluffy texture of dry cellulose. This failure was localized at the peak of the roof. These moisture issues were remediated by removing the insulation at the roof ridge; of course, a thermal penalty ensued from this modification.

A similar issue arose in two production homes in Jacksonville, Florida (CZ 2A), circa 2000. Again, the roof assembly was asphalt shingles, roofing felt, OSB sheathing, and netted and blown cellulose insulation (Figure 10, left). The house was relatively airtight for the climate (2.5 ACH 50).

During a site visit, the cellulose and roof sheathing were wet to the touch, and the steel truss plate was corroded; however, the wood had not decayed. In response, the insulation was removed near the ridge (roughly $2 \mathrm{ft}$; Figure 10, right) to increase surface temperatures at the condensing roof sheathing surface. This roof has been rechecked over time (circa 2003 and as recently as March 2014); roof sheathing conditions remained dry with this assembly. 

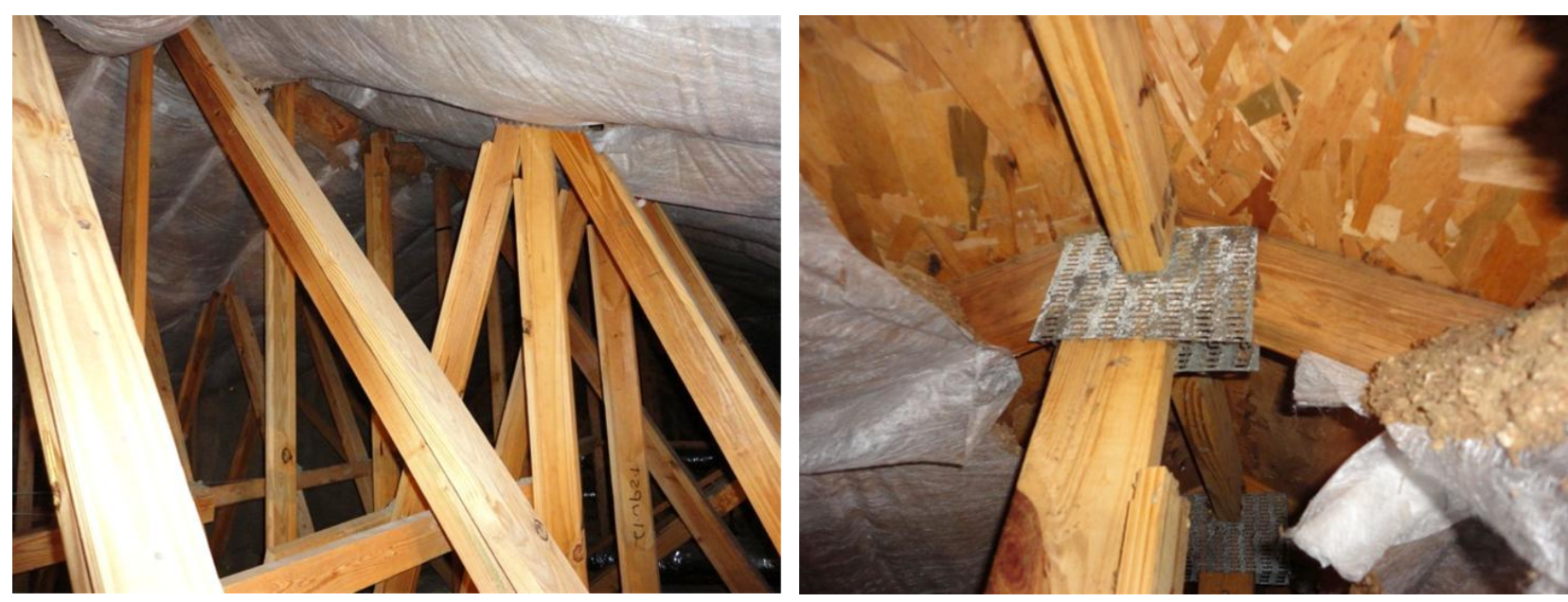

Figure 10. Cellulose roof insulation in Jacksonville (left); corrosion of ridge truss plate (right)

\subsection{Field Experience in Northern California}

Moisture issues in unvented roof assemblies often manifest in the form of damage to the sheathing at the ridge of a sloped roof, colloquially known as ridge rot. An example is shown in Figure 11, which was a dense-pack cellulose roof in a northern California location (CZ 3C).
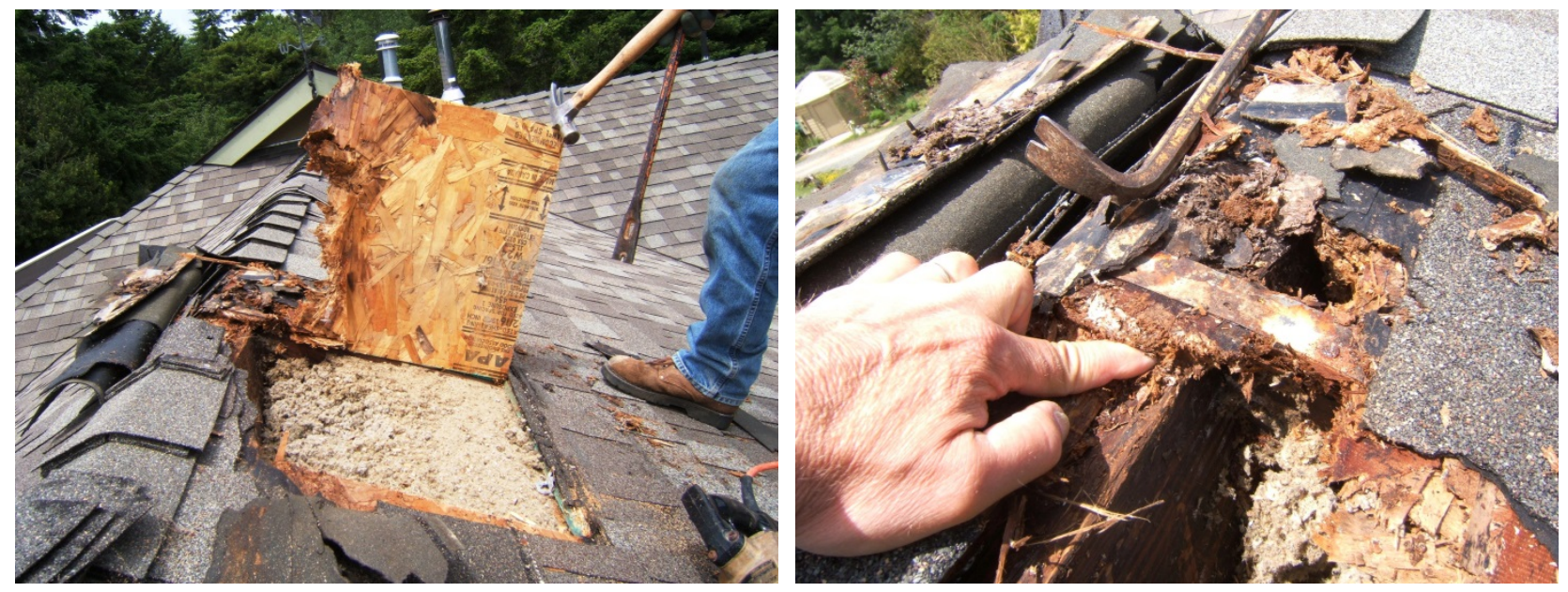

Figure 11. Ridge sheathing degradation with dense-pack cellulose in northern California

These issues arose soon after construction (during the first winter); the problems were manifested as paint blistering at the interior gypsum wallboard (GWB) near the roof (Figure 12, right), because the accumulated condensation dripped. The issue was definitely localized at the ridge of the roof; disassembly at a lower section of the roof showed dry sheathing conditions (Figure 12, left). Air barrier imperfections at the interior GWB (especially at the ridge board interruption) were contributing factors.

The pattern of moisture accumulation seen here and in CZ 2A influenced the experimental design: sensors were concentrated near the roof ridge, where problems appeared to be prevalent. 

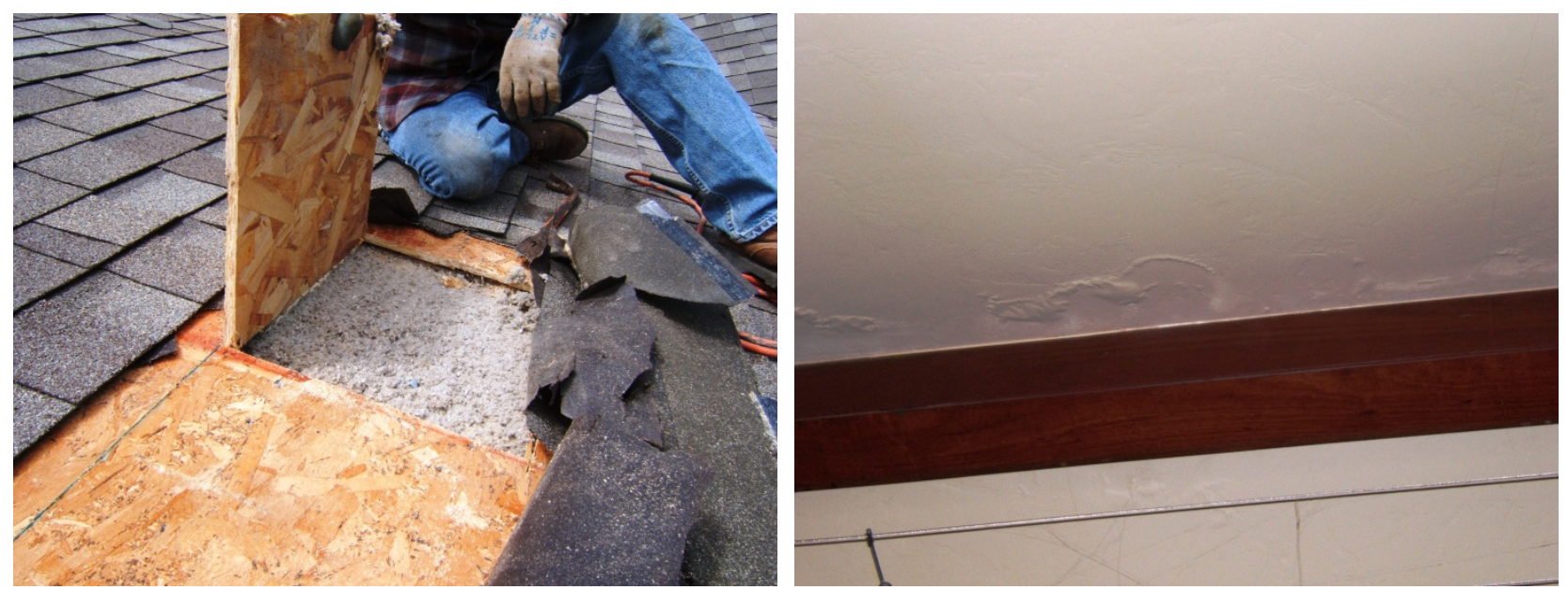

Figure 12. Dry sheathing lower at roof (left); interior ridge conditions (right)

\subsection{Salonvaara et al. (2013): Modeling Unvented Roofs in Climate Zones 1-4}

Salonvaara et al. (2013) studied unvented attics with simulations in CZs 1-4. They first presented an overview of unvented (or sealed) attics with the positives and negatives of this design compared to conventional vented attics.

The authors calibrated their models against field monitoring results from Boudreaux et al. (2013). One factor noted when comparing modeled and monitored results was the difference between the high-temperature $\left(60^{\circ} \mathrm{C}\left[140^{\circ} \mathrm{F}\right]\right)$ sorption isotherm (relationship between $\mathrm{RH}$ and $\mathrm{MC}$ ) compared with the room-temperature isotherm. Slightly better correlation was achieved by using a temperature-dependent sorption response.

The authors then ran hygrothermal simulations (WUFI Pro) models of vented and unvented roof assemblies in various configurations in CZs 1-4. Interior RH levels were set at design conditions (higher than average or typical conditions); this exacerbates wintertime interstitial condensation risks. The roof assemblies consisted of asphalt shingles, felt paper, OSB sheathing, and insulation (ocSPF or fiberglass). Cases were run for no water intrusion and for a rainwater leak ( $1 \%$ of incident rain hitting the surface bypasses the water-resistive barrier) to the roof sheathing. The results are summarized in the form of peak roof sheathing MCs for the various cases in Table 1; peak MCs higher than 20\% are highlighted in red. CZs 1, 3, and 4 results are shown to provide a range.

The authors concluded from these simulations that a vented attic assembly has better drying ability than unvented assemblies in all climates. Most unvented ocSPF assemblies had safe MCs without rain leakage, but in colder climates (CZ 4) with very vapor-open ocSPF (54 perm-in.), peak MCs reached risky levels. With the addition of rain leakage, MCs were substantially higher; these likely constitute failure in most CZs. The addition of a 1-perm coating (intumescent paint with 1-perm dry cup and 3-perm wet cup) on the interior side of the ocSPF resulted in lower MCs without rain leakage (the interior-sourced vapor flow was reduced) but higher MCs with rain leakage (reduced ability to dry inward). 
Table 1. Summary of Simulation Results (roof sheathing MCs)

Source: Salonvaara et al. (2013)

\begin{tabular}{|c|c|c|c|c|c|c|}
\hline \multirow{2}{*}{ Case } & \multicolumn{3}{|c|}{$\begin{array}{l}\text { No Rain Leak } \\
\text { (Peak MCs) }\end{array}$} & \multicolumn{3}{|c|}{$\begin{array}{l}\text { 1\% Rain Leak } \\
\text { (Peak MCs) }\end{array}$} \\
\hline & CZ 1 & $\mathbf{C Z 3}$ & $\mathbf{C Z 4}$ & CZ1 & $\mathbf{C Z 3}$ & $\mathrm{CZ4}$ \\
\hline Vented Attic & $8 \%$ & $7 \%$ & $7 \%$ & $12 \%$ & $12 \%$ & $12 \%$ \\
\hline Unvented, ocSPF (23 perm-in.) & $8 \%$ & $12 \%$ & $15 \%$ & $16 \%$ & $24 \%$ & $29 \%$ \\
\hline Unvented, ocSPF (54 perm-in.) & $8 \%$ & $16 \%$ & $22 \%$ & $14 \%$ & $27 \%$ & $35 \%$ \\
\hline $\begin{array}{c}\text { Unvented, ocSPF (23 perm-in.) + } 1 \text { Perm } \\
\text { Coating }\end{array}$ & $6 \%$ & $8 \%$ & $9 \%$ & $25 \%$ & $49 \%$ & $37 \%$ \\
\hline Blown Fiberglass, No Interior Vapor Retarder & $8 \%$ & $19 \%$ & $30 \%$ & $13 \%$ & $30 \%$ & - \\
\hline $\begin{array}{c}\text { Blown Fiberglass, } 10 \text { Perm Interior Vapor } \\
\text { Retarder }\end{array}$ & $8 \%$ & $14 \%$ & - & $15 \%$ & $26 \%$ & - \\
\hline
\end{tabular}

The two final cases used blown fiberglass insulation (100 perm-in.) instead of ocSPF; only CZs 1-3 were plotted. These results show that when vapor-open interior netting was used for installation, acceptable MCs were found in CZs 1 and 2, but riskier conditions were seen in CZs 3 and 4 . Adding netting with a vapor permeance of 10 perms reduced risks to reasonable levels in CZs 1-3. The authors recommended that the current code requirement (International Residential Code §806.4) for R-5 air-impermeable insulation in CZs 1 and 2 be dropped based on these results.

The authors then used whole-house energy simulations (WUFI-Plus) to study airflow issues between the interior conditioned zone, unvented attic, and exterior. They noted that a house can have overall low enclosure air leakage; however, stack effect will act downward during the summer, and exterior air will be drawn predominantly into the attic if air leaks to the outdoors. Thus, infiltration of hot-humid air can have a disproportionate effect on attic humidity conditions. In the simulations, air leakage resulted in high enough attic humidity to cause concerns about mold growth. Although the common solution is to add some space conditioning (summertime cooling and dehumidification) to the attic, the authors are wary of this solution for indoor air quality reasons (connecting uncleaned attic space with interior air). The authors conclude that air sealing the attic to the exterior is critical.

\subsection{Boudreaux et al. (2013): Sealed Attic Monitored Performance (Climate Zones 3A and 4A)}

Boudreaux et al. (2013) presented data collected at eight houses in CZs 3A and 4A-four with vented attics and four with sealed attics - to understand their moisture performance. The authors noted that multiple practitioners and online sources have reported high humidity problems in unvented attics.

Their data showed that attic absolute MCs (vapor pressures) were consistently higher in the sealed attics than in the vented attics. Similarly, the vapor pressures in the main spaces were higher in the sealed attic houses. When the individual house data were plotted, the two groups overlapped. The worst-performing unvented attic had the highest air leakage (10 ACH 50) of the sample; the authors described other factors that influenced interior moisture levels, including occupant density and set point. 
Plots of vapor pressure at various sections of the roof assembly indicated that the sealed attic roof typically had patterns of daytime drying (desorption into the attic) and nighttime wetting (adsorption from the attic air). Similar cycling was seen in the vented attic houses but with a much smaller vapor gradient given roof sheathing temperatures. The authors noted that the spikes in vapor pressure were associated with high solar gain days or roof sheathing temperature, or both.

Vapor pressure measurements were combined with differential pressure $(\Delta \mathrm{P})$ and air leakage measurements to estimate moisture flow to and from the attic. Their calculations showed the strongest vapor drives (from attic to interior) during the afternoons and early evenings and airflow downward (attic to interior) during the day and upward at night.

The authors theorized that seasonally, moisture accumulates in the roof sheathing from summer to fall and is then desorbed in the winter and spring.

Several sources of moisture for the sealed attic were discussed, including roof sheathing storage, solar-driven moisture from moisture stored in asphalt shingles (judged unlikely by the authors), exterior air leakage (likely, especially given the downward stack effect during the summer).

The authors used collected HVAC data to estimate the penalty associated with controlling interior humidity to comfort levels. They estimated a 7\% increase in cooling energy consumption when the HVAC system is used in a higher sensible heat ratio mode to control humidity. This operation would cut into the performance improvement associated with bringing the ductwork within the conditioned space. The authors recommended that alternatives other than sealed attics be used to bring ductwork within the conditioned space.

\subsection{Lstiburek (2014): Humidity Behavior of Unvented and Sealed Attics}

Lstiburek (2014) clarified some background and terminology for unvented attics. He proposed the alternative, more descriptive term conditioned attic. In earlier construction, attic ductwork was typically leaky, and supply leakage would slightly pressurize the attic. This would cause air leakage from the attic to the main space (air leakage communication, see Figure 13, left). This air communication would dehumidify the attic space; the moisture load in the attic was driven primarily by interior sources. Moisture would concentrate in the attic because the moisture-laden air was more buoyant and less dense than dry air.

The author cites Houston-area field research about the effect of vapor-permeable and vaporimpermeable shingle underlayments on inward vapor drives (Figure 13, right); the study found no measurable differences between these roof test bays. Therefore, he notes that shingle inward drive issues are not a significant moisture source.

As airtight HVAC ductwork became more common, incidental space conditioning provided to unvented attics and communication between the attic, and the main space was reduced. The resulting problem has been higher humidity levels in unvented and sealed attics, especially with vapor-open insulation materials such as ocSPF. Interior moisture is adsorbed and desorbed from the roof sheathing with daily warm and cold cycles; without communication to remove the moisture, it accumulates due to moisture buoyancy. 

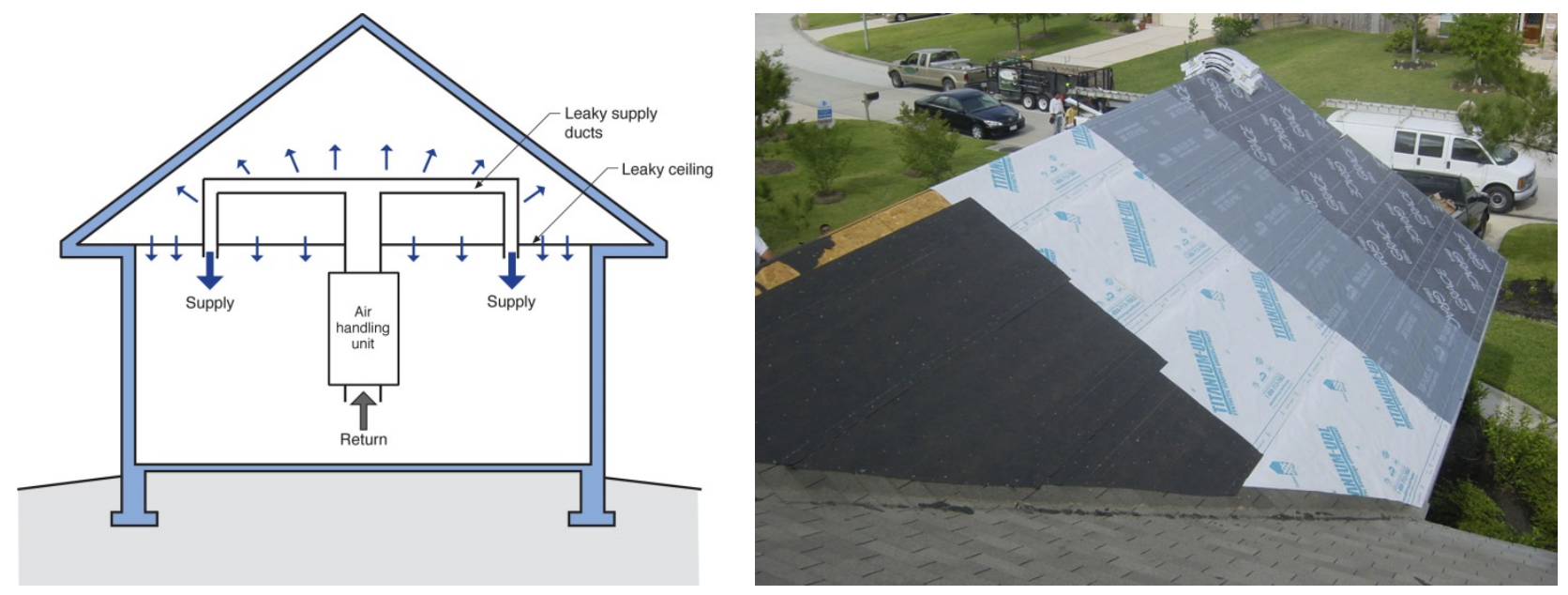

Figure 13. Air leakage communication from unvented attic to main space (left); Houston-area roof underlayment study (right)

Source: Lstiburek (2014)

The proposed resolution to this issue is to add supply and return space conditioning to the attic space at $50 \mathrm{CFM}(24 \mathrm{~L} / \mathrm{s})$ per $93 \mathrm{~m}^{2}\left(1,000 \mathrm{ft}^{2}\right)$ of ceiling area. However, this may conflict with code fire separation requirements. One option is to add a return duct smoke detector that shuts down the attic air handling unit when smoke is detected.

\subsection{Smegal and Straube (2014): Monitoring and Simulation of Spray Polyurethane Foam-Insulated Roofs (Climate Zone 6)}

Smegal and Straube (2014) covered more than 2 years of monitoring data (2010-2012) for seven vented and unvented roof assemblies installed in a test hut in Waterloo, Ontario (CZ 6). Interior conditions were set at $20^{\circ} \mathrm{C}\left(68^{\circ} \mathrm{F}\right)$ and $50 \% \mathrm{RH}$, which is a high moisture level that stresses assemblies because of wintertime condensation.

All assemblies were cathedralized (compact) roofs with roughly R-30 insulation, OSB roof sheathing, black asphalt shingles, tar paper, and latex paint on GWB as an interior finish. The roof assemblies are described in detail in Table 2 . All roofs face east.

Table 2. Test Roof Assemblies Monitored in Smegal and Straube (2014)

\begin{tabular}{c|c|c|c}
\hline Assembly & $\begin{array}{c}\text { Short } \\
\text { Name }\end{array}$ & $\begin{array}{c}\text { Vented/ } \\
\text { Unvented }\end{array}$ & $\begin{array}{c}\text { Vapor Control } \\
\text { (lowest perm interior layer) }\end{array}$ \\
\hline Unvented ccSPF & NCC & Unvented & ccSPF \\
\hline Vented ccSPF & VCC & Vented & ccSPF \\
Vented Fiberglass & VFG & Vented & Latex paint and GWB \\
Unvented Painted ocSPF & NOCP & Unvented & Paint on ocSPF, latex paint, and GWB \\
Vented ocSPF & VOC & Vented & Latex paint and GWB \\
Unvented ocSPF & NOC & Unvented & Latex paint and GWB \\
\hline
\end{tabular}

The vented roof assemblies were ventilated with a polystyrene foam baffle installed under the roof sheathing, which connected to soffit and roof vents low and high. Sensors were installed to 
measure assembly temperatures, $\mathrm{RH}, \mathrm{MC}$, and boundary conditions (interior and exterior). Wetting systems were installed between the roof sheathing and the shingle underlayment to determine the drying ability of the assemblies after a wetting event.

Sheathing MCs were plotted: most roofs had a seasonal swing with drier (5\%-10\%) MCs in summer and wetter $(8 \%-13 \%)$ MCs in winter; all these levels are well within the safe range for durability. However, the MCs for unvented ocSPF (NOC) and painted unvented ocSPF (NOCP) exceeded $20 \%$ each winter. In the first winter, the interior was at $40 \% \mathrm{RH}$, and $20 \%-28 \% \mathrm{MC}$ peaks were seen. The second winter had 50\% RH conditions, and higher $(20 \%-34 \%)$ MCs were seen. However, in each following summer, sheathing MCs in these ocSPF roofs fell to safe levels. This indicates that ocSPF roof assemblies in CZ 6A face some durability risks, even with the addition of a painted vapor control layer on the ocSPF.

RH levels within the roof assemblies were examined:

- In the ccSPF roofs (NCC/VCC), RHs within the foam were in the safe range. In the vented ccSPF roof (VCC), the ventilation chute RH levels were similar to outdoor conditions.

- In the fiberglass roof(VFG), ventilation chute RH levels were similar to outdoors. Cavity RHs fluctuated daily and showed moisture movement through the assembly (convective looping, diurnal heating/moisture drive, or air leakage).

- In the unvented ocSPF roofs (NOCP, NOC), RHs on the exterior side of the cavity rose and fell seasonally, similar to sheathing MCs. The latex painted foam had a slightly drier exterior-side RH (by 5\%), which might be insignificant; however, it might reflect the slight increase in vapor resistance in the unvented painted assembly NOCP.

- In the vented ocSPF roof (VOC), the RH on the exterior side of the cavity was very high (peaks at $95 \%$ and $100 \%$ ) during the two winters) with possible condensation risks. The low vapor permeance of the polystyrene foam chute and the lack of moisture storage (compared to OSB sheathing) may contribute to these high RHs.

The wetting system was used in the summer and fall of 2010; the applied wettings (multiple 30to 60 -mL wettings; $240 \mathrm{~mL}$ total) caused only small increases in sheathing MCs and remained well within the safe range.

The monitoring work was followed by hygrothermal simulations (WUFI 5.1 Pro) of the assemblies; the modeled and measured data correlated reasonably well. The roof assemblies were simulated in other Canadian CZs and various interior RH levels (low/medium/high) using worst-case (north/12:12 roof pitch) orientation.

The ccSPF roof assemblies worked well under most conditions; the cases that were at risk of failure were high interior $\mathrm{RH}(50 \%)$ in colder climates. These risks are seen for worst-case orientation; at a south orientation, these assemblies have no risk.

The vented ocSPF roofs worked well under all conditions; however, this assumed no vapor resistance for the baffle/chute, which seemed to affect conditions in the monitored data. 
The unvented ocSPF roofs showed risks in many CZs with latex paint (Class III) as interior vapor control. Polyethylene (Class I) reduced risks substantially, but at the cost of eliminating inward drying. An ocSPF roof with a Class II (1 perm) vapor retarder worked in conditions as cold as Ottawa with medium RH levels.

The vented fiberglass roof showed excellent performance in the simulation; however, this simulation did not include the effect of air bypass leakage from the interior, which is likely in practice and will add significant moisture load to the roof assembly.

The authors provided overall recommendations for construction and for further research on the permeance effects of ventilation baffles and chutes.

\subsection{Pallin et al. (2014): Unvented Attic Indoor Climate and Moisture Durability Simulations (Climate Zone 4A)}

Pallin et al. (2014) built on field work in Boudreaux et al. (2013) using simulations; the authors performed two sets of simulations:

- Simulations of interior temperature, humidity, and comfort levels, using an EnergyPlus whole-house simulation with added modules for multizone airflow and moisture storage of hygroscopic materials. The model was validated using test house data from previous work; the coefficient of variation of the root-mean-squared error was $\pm 2 \%$ on dry bulb temperature and $\pm 18 \%-23 \%$ on humidity ratio (within target guidelines).

- These conditions were used as inputs for a one-dimensional hygrothermal model (WUFI), introducing interior air leakage into the roof assembly, in an effort to understand moisture durability risks. The assembly was comprised of asphalt shingles, \#15 felt, $1 / 2$-in. OSB, 1 in. ccSPF, and 5- to 6-in. ocSPF.

- The inputs to these simulations included variations of enclosure leakage area (living-toexterior, attic-to-exterior, attic-to-living/attic floor), supply duct to the attic, and interior latent heat gain/moisture generation. All variable combinations would total 486 scenarios; 411 scenarios were run in this work.

The comfort analysis showed wintertime outliers outside the comfort range; these low temperature excursions showed the effect of high enclosure leakage and a resulting undersized heating system, which could not meet heating set point and demand. Attic-to-exterior leakage had the greatest negative impact on comfort; supply duct leakage and living-to-exterior leakage had the next-highest effects. Attic floor leakage had a minimal effect on these wintertime comfort excursions.

Summertime comfort outliers were caused by high humidity ratios (absolute air moisture content). These cases were all linked to high interior moisture generation rates and exacerbated by greater enclosure airtightness. This relationship was explained by the fact that greater airtightness results in less cooling system runtime and reduces dehumidification in the cooling season. The authors cautioned against extrapolating this conclusion outside this mixed-humid (Knoxville, Tennessee, CZ4) climate; in climates with higher humidity, outdoor air leakage might increase latent loads. 
The moisture durability simulations used exterior and attic temperature/humidity conditions from the previous simulations in WUFI models that introduced interior air at the insulation-sheathing (outboard side) interface, to induce wintertime condensation failures.

The authors describe direct (short) and diffusive (long) leakage paths through building assemblies. Short paths are less likely to cause wintertime condensation issues, due to the warming effects of the air leakage on surfaces. Long paths cool the leakage air, which increases the risk of depositing condensation within the assembly. The authors also noted that low airflow leakage rates have low risks of condensation (little transported moisture), as do high airflow rates (surfaces warmed by heat loss). However, intermediate air leakage levels have the highest moisture risks.

The simulation results indicate risks based on interior moisture generation rates; low generation rates present no significant risks, moderate generation rates result in some risky cases, and high generation rates result in some noticeable failure cases. Lower enclosure leakage was associated with higher risks (which retain interior moisture generation in winter), as was midrange attic-toexterior air leakage. These simulations showed no effect of duct leakage on moisture risks; these failures occurred in winter, when cooling system dehumidification would not reduce interior moisture loads.

Based on these simulations, the authors recommended that unvented attics should be built to be as airtight as possible, and interior moisture generation rates should be controlled. They stated that a supply duct to the attic can reduce (but not completely eliminate) comfort problems. They noted that higher air attic-to-exterior air leakage rates - as occur in practice - have moisture risks, raising the importance of controlling interior moisture generation. 


\section{Experimental Setup}

\subsection{Overview}

The test home is located in Winter Park, Florida, roughly 6 miles northeast of downtown Orlando (CZ 2A); it was provided by David Weekley Homes. The house is a two-story, slab-ongrade structure $\left(3,600 \mathrm{ft}^{2}\right)$; overview images are shown in Figure 14 and Figure 15. The builder's typical production has vented attics with mechanical systems (ductwork) in the attic. The front of the house faces west (Figure 15 right). The site is an existing neighborhood: the previous house was demolished, and the new house was built as infill. Instrumentation was completed in November 2014; the house was largely completed by February 2015 and occupied by homeowners in May 2015.
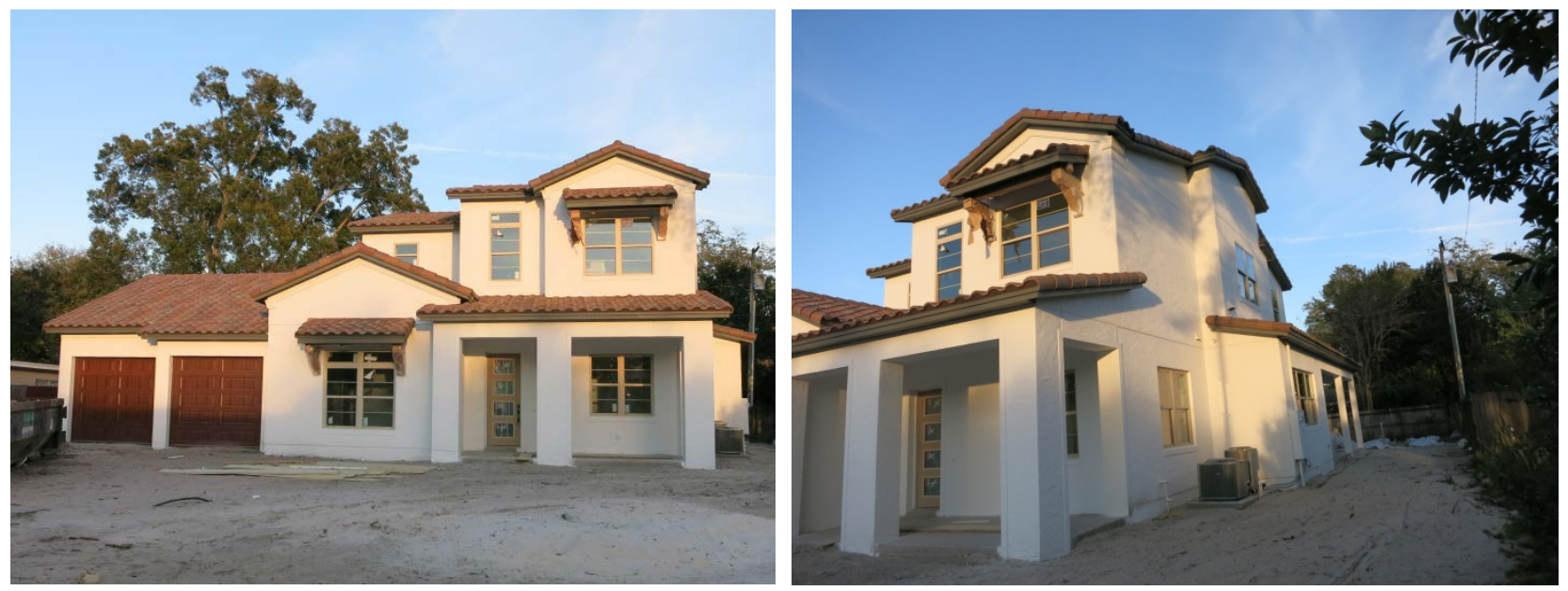

Figure 14. Front and side views of Orlando-area test house
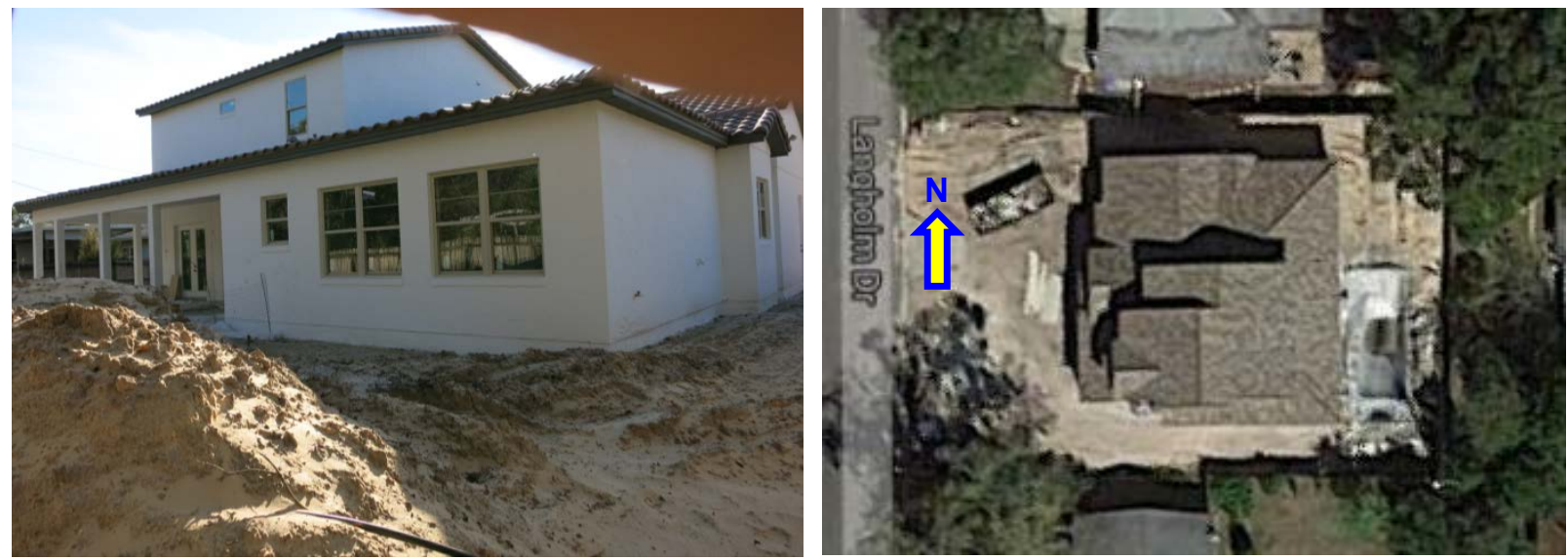

Figure 15. Rear and overhead views of Orlando-area test house

\subsection{Unvented and Conditioned Roof Assembly}

The entire roof was configured as an unvented roof with loose-blown netted fiberglass insulation at the roof deck. 
The roof assembly consists of:

- Concrete barrel tiles screwed down to sheathing

- Self-adhered modified asphalt 60-mil roofing underlayment with a woven polyester surface

- $\quad 1 / 2$-in. plywood sheathing

- Blown fiberglass insulation (R-38/ 9-1/2 in.) supported by netting stapled to the roof truss top chords.

The roof was insulated with a prototype insulation system called boxed netting. This netting system hangs down from the roof truss top chords and allows full depth insulation (i.e., not limited by the depth of a 3-1/2-in. truss top chord). The netting is first stapled to the truss top chords, then the segments are joined into a continuous layer with additional staples (Figure 16 left).

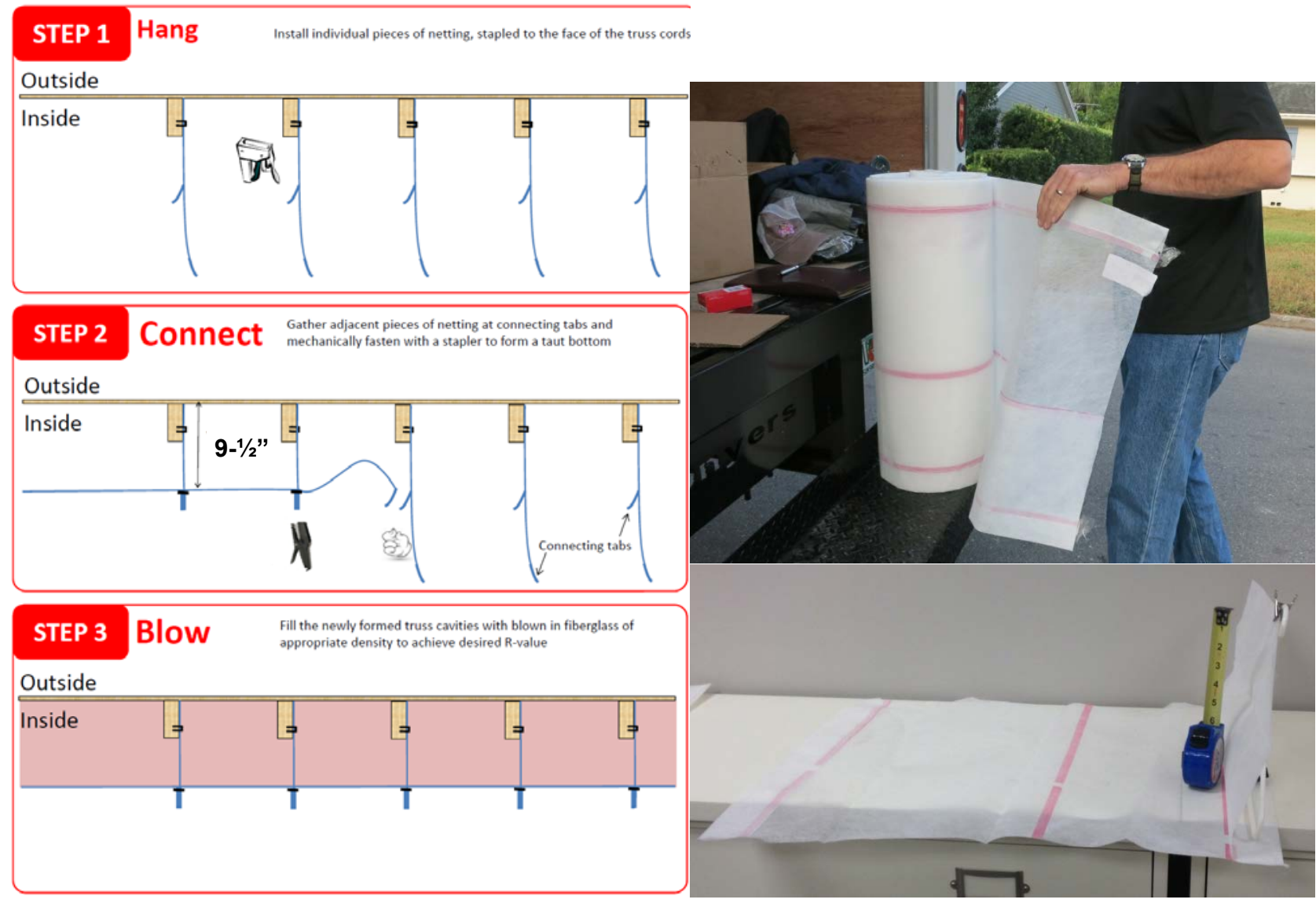

Figure 16. Installation sequence for boxed netting system (left) and images of netting product (right)

(Left-hand images courtesy of Owens Corning)

The netting is an open-weave, air- and vapor-permeable material that is similar to cellulose densepack installation netting. Images of the roof and netting before and after insulation installation are shown in Figure 17. Adapting this system to the roof's hip geometry presented no issues. 

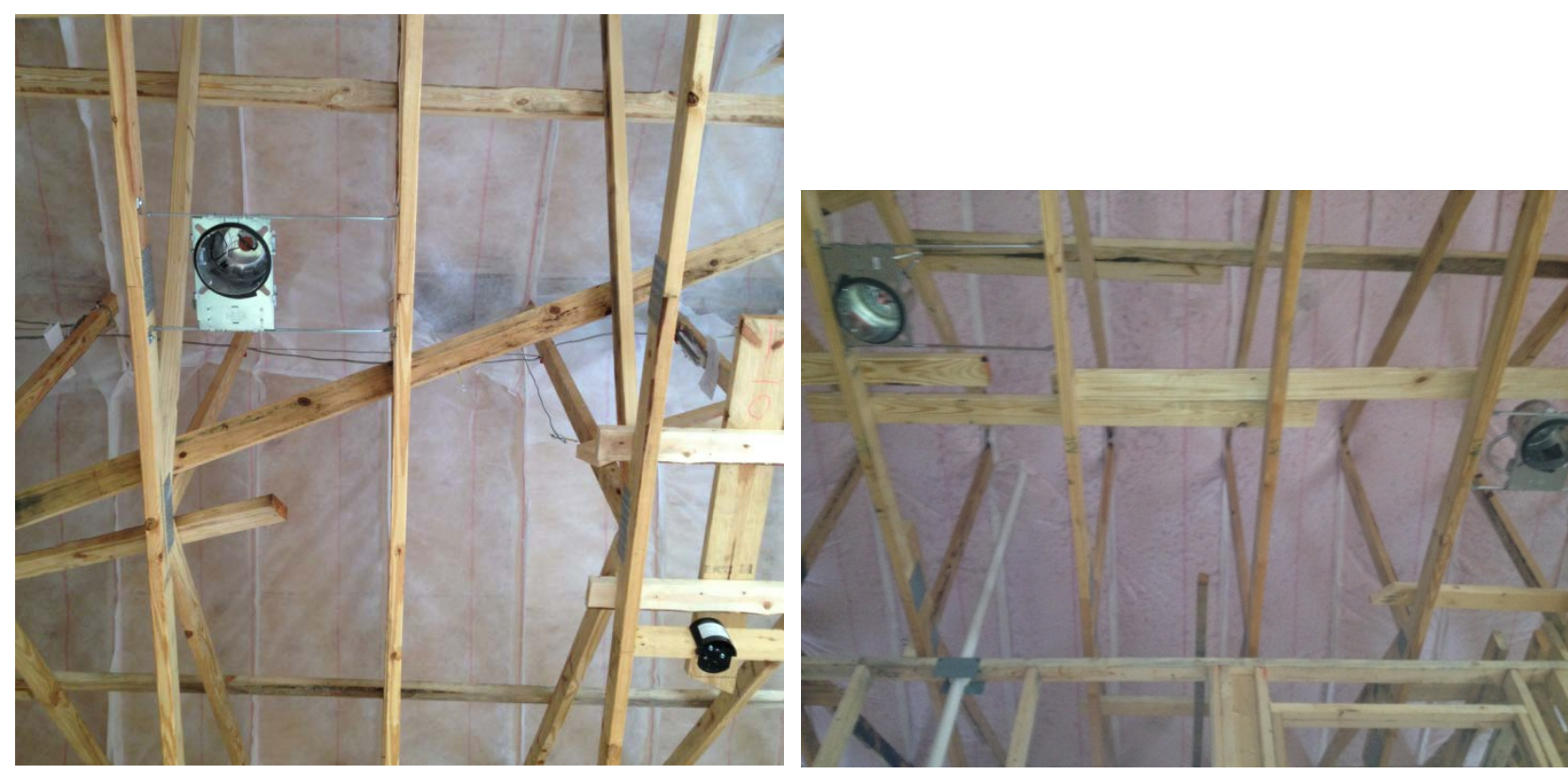

Figure 17. Boxed netting insulation system before (left) and after (right) insulation blowing
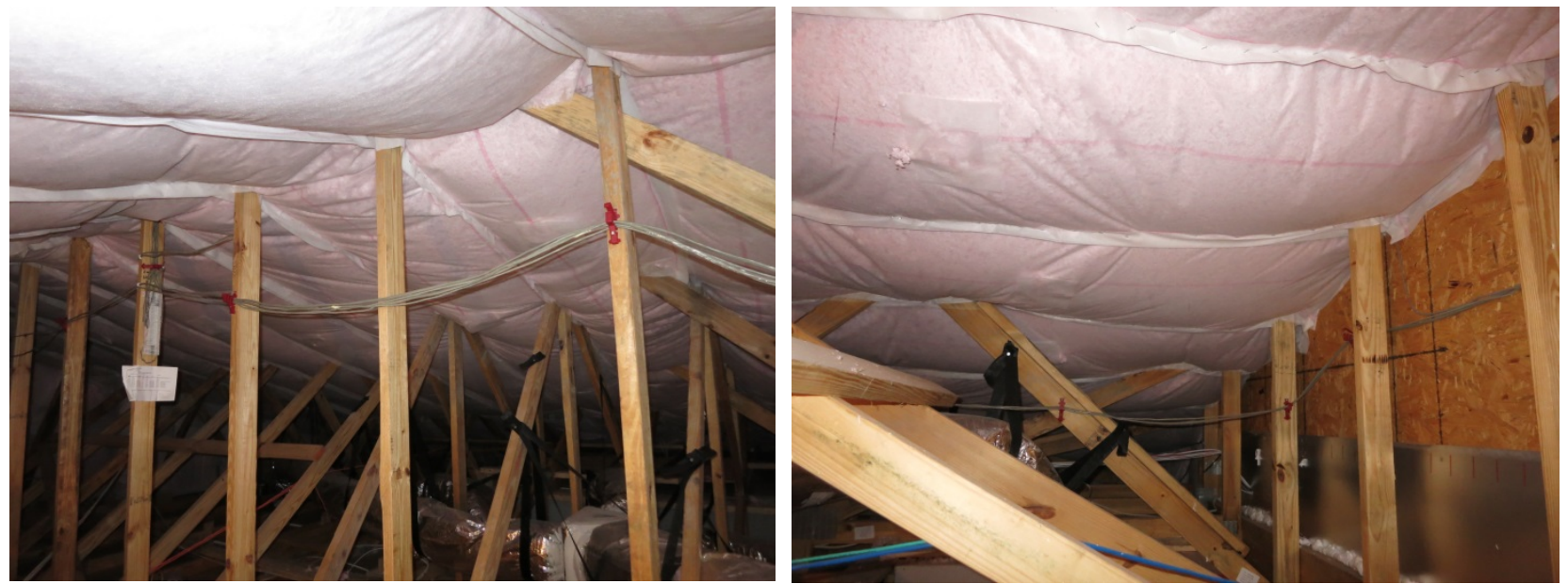

Figure 18. Typical completed attic conditions at ridge (left) and roof-to-wall (right)

This roof assembly does not meet 2009 International Residential Code (ICC 2009) code requirements (§R806.4 "Unvented attic assemblies"); however, the local authority having jurisdiction granted permission for this experimental installation.

No intentional space conditioning was provided in the unvented attic space; the space will be run at conditions between interior set point and exterior conditions, which is common for this type of roof assembly. This was done to look at worst-case conditions in terms of humidity buildup (per Boudreaux et al. 2013 and Lstiburek 2014).

\subsection{Unvented Roof Geometry and Air Barrier Details}

One challenge of using fibrous insulation for unvented roofs (instead of SPF) is that the air barrier layer requires more attention to detail. In this project, the self-adhered membrane (roof 
underlayment) provides the air barrier at the field (main body) of the roof deck. Air barrier continuity at the ridge is discussed in Section 3.4.

At the roof-wall (eave/overhang) interface, the air barrier connection was made using $2 \mathrm{x}$ wood blocking between the wall top plate and roof sheathing; gaps were filled with single-component urethane foam (Figure 19). Two-component SPF was used at this connection in other projects, which would have provided more effective coverage and air sealing and possibly more resistance to long-term movement.
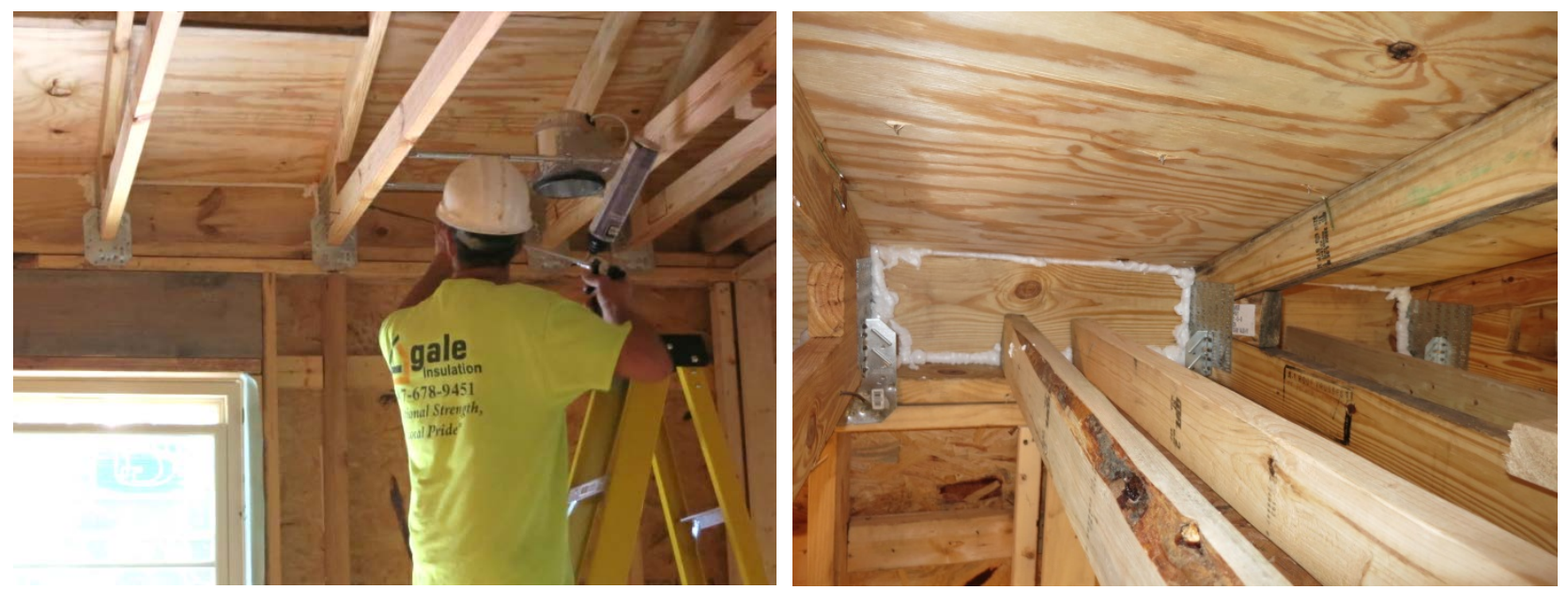

Figure 19. Air sealing roof-to-wall connection; note $2 x$ blocking and single-component foam

This air barrier connection was completed at roof-wall interfaces throughout the house, including gable ends. The gable ends of the attics were detailed as exterior walls with netted and blown insulation (but no GWB, per Figure 20 left). In addition, all penetrations (such as plumbing boots and vents) were sealed in an airtight manner to the roof sheathing/membrane layer (Figure 20 right).
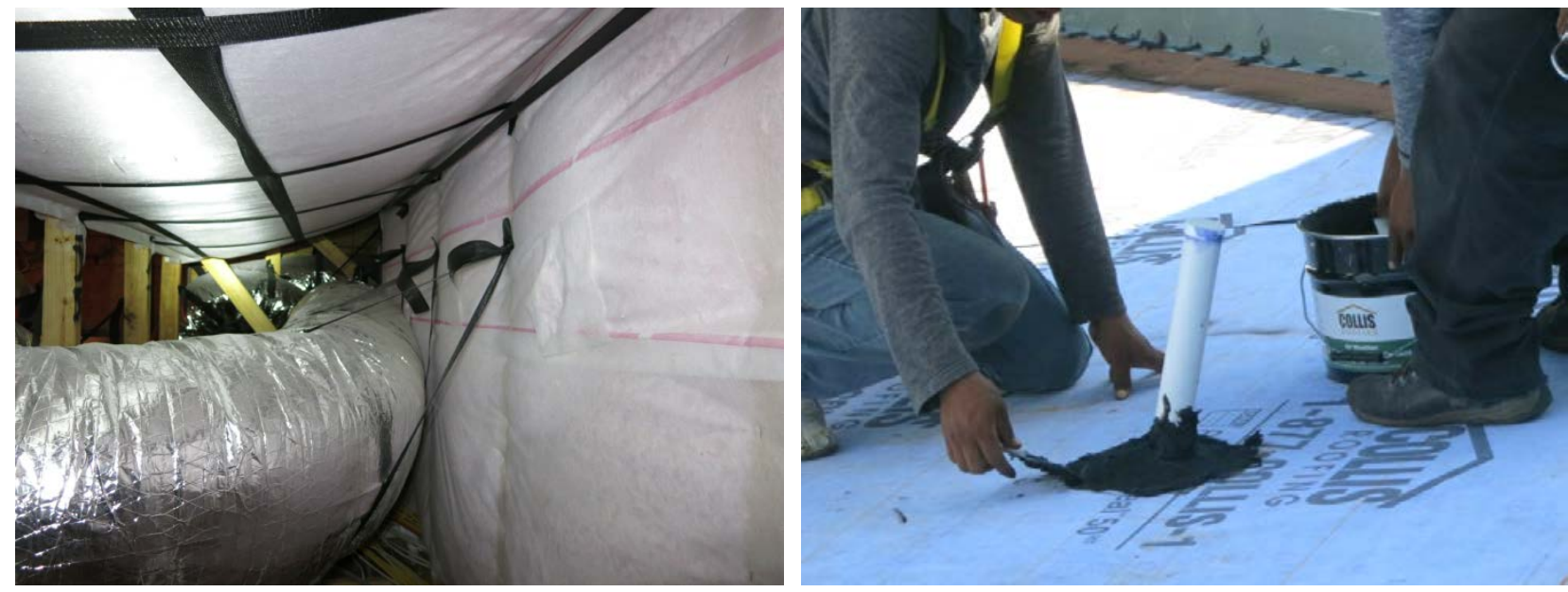

Figure 20. Insulated attic knee wall (left) and waterproofing/air barrier at roof penetration (right)

The attic over the garage is unconditioned, so the main/conditioned attic (over the first floor) and the garage attic were separated by a frame wall (red line in Figure 21 and Figure 22). This 
separation wall runs up to the roof sheathing; it is sheathed (with OSB on one side), insulated, and air sealed. Similarly, the connections from conditioned attic to unconditioned attic (e.g., over outdoor space) were similarly walled and air sealed (blue lines in Figure 21 and Figure 22).

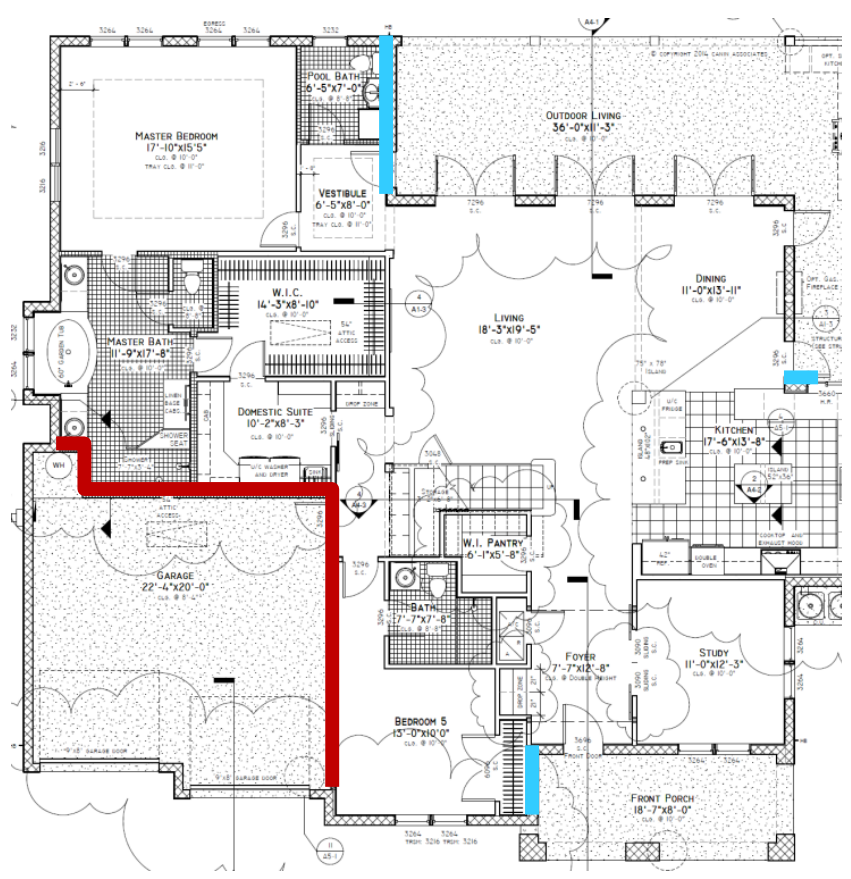

Figure 21. First floor with separation walls

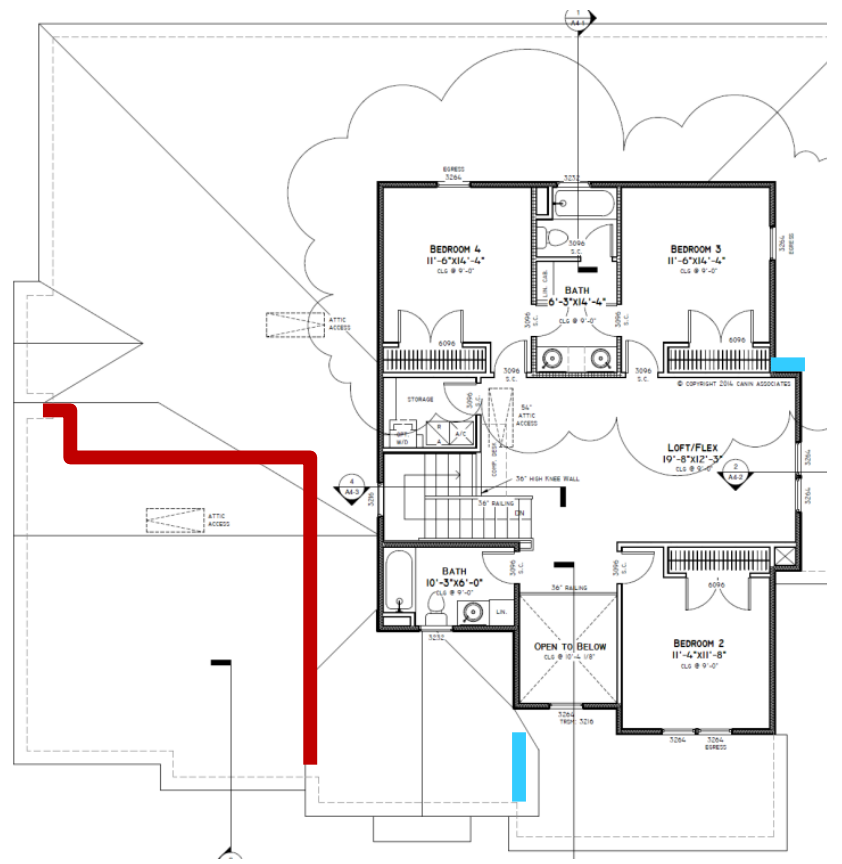

Figure 22. Second floor with separation walls

\subsection{Diffusion Vent at Ridge}

Given the localized moisture accumulation and failures seen in previous work with fibrous insulation and unvented roof assemblies, the researchers theorized that a diffusion vent (water vapor open, but air barrier closed) at the highest points in the roof assembly might allow for the wintertime release of moisture (to safe levels). Therefore, the experimental assembly included a diffusion vent at the peak of the roof rafter cavities (at both the ridge and hip conditions) as shown in Figure 23. It was not used at the roof valleys or roof-wall connections, because they are more vulnerable areas for bulk water (rainwater) penetration; the self-adhered membrane used at the field of the roof was installed at these conditions.

The components and details of the diffusion vent follow:

- At the ridge or hip, the sheathing stops short of the ridge by roughly 7 in. At the ridge or hip, a $1 \times 4$ supports the tile roof ridge metal, leaving a \pm 3 -in. slot in the sheathing and creating a diffusion port that allows moisture to escape at the top of the roof Figure 24 left).

- The diffusion ports are covered with a strip of a highly vapor-permeable roof membrane (tear-resistant polyethylene terephthalate fabric with a diffusive, waterproof dispersion coating; 214 perms dry cup, 550 perms wet cup; Figure 24 right). This material is Cosella-Dörken Delta-Foxx (shown in brown, supplied by manufacturer). 
- The field of the roof is dried in using the underlayment normally used on the roof (60-mil modified-asphalt self-adhered roofing underlayment with a woven polyester surface for construction foot traffic durability and slip resistance; Boral TileSeal).

- The edges of the permeable roof membrane (Delta Foxx) are taped to main roof membrane to create an air barrier (while allowing vapor diffusion; Figure 25 left). A 6in.-wide 25-mil rubberized asphalt self-adhered flashing membrane tape is used. The length and the end caps of the diffusion vent are sealed.

- The concrete roof tiles are attached to the roof deck using screws.

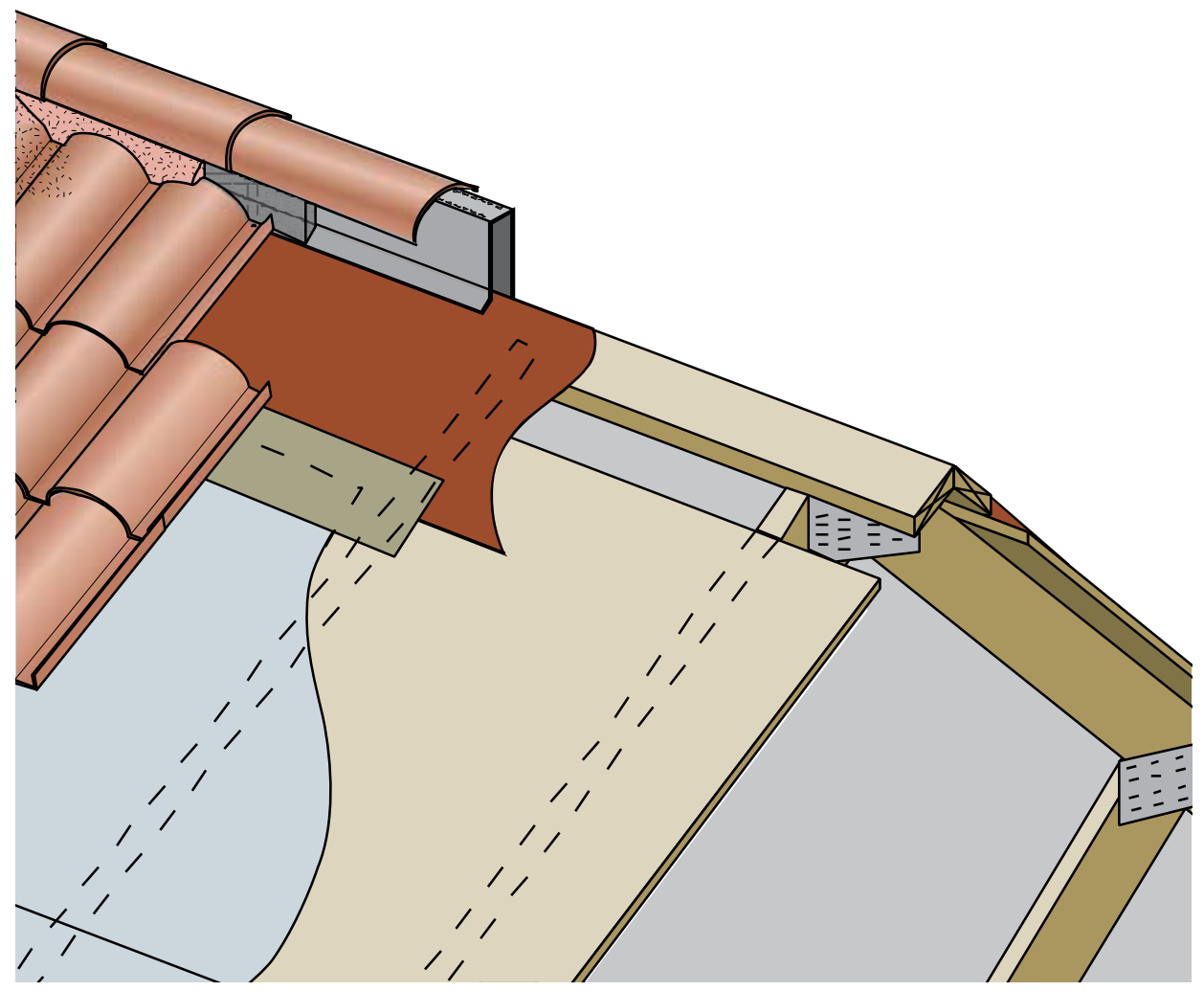

Figure 23. Diffusion vent detail at roof ridge and hip
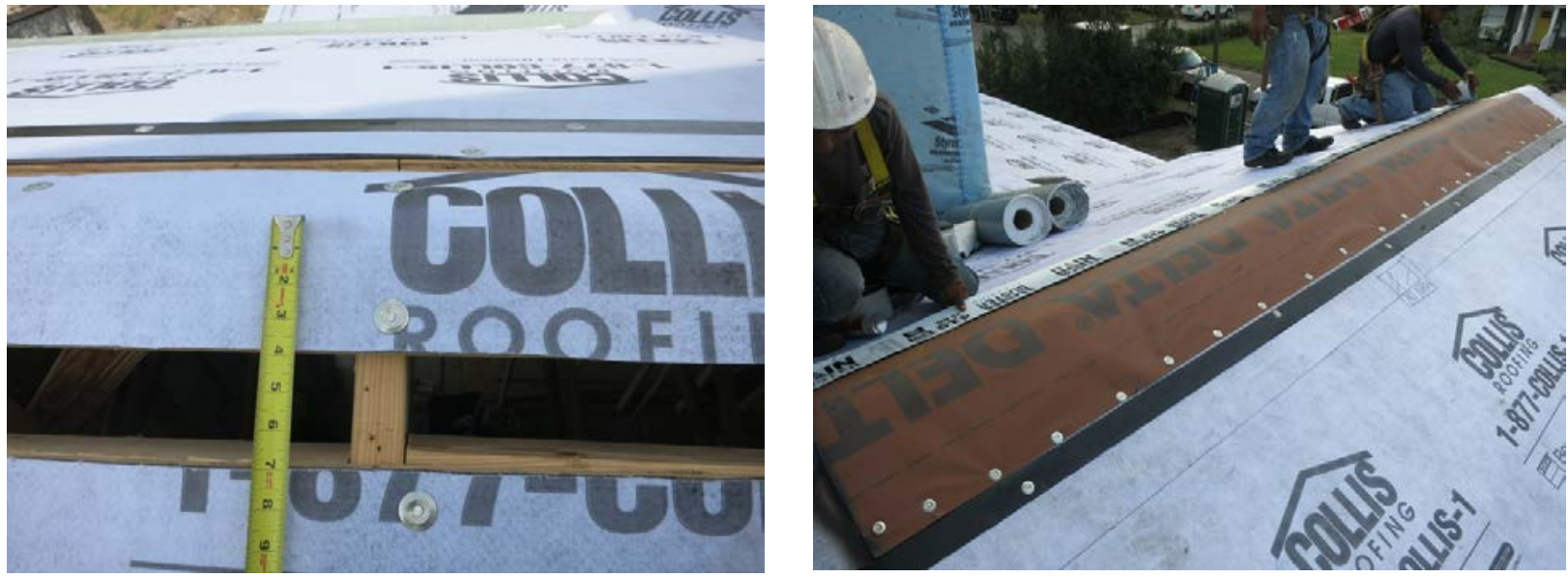

Figure 24. Open slots for vapor diffusion vent (left), diffusion vent membrane (right) 
At the ridge metal channel (Figure 25 right), some type of open-weave mortar mesh was placed between the metal and the roof tile to ensure an open air channel for lateral airflow. Air flows under the roof tiles and exits through the gaps between the ridge tiles.
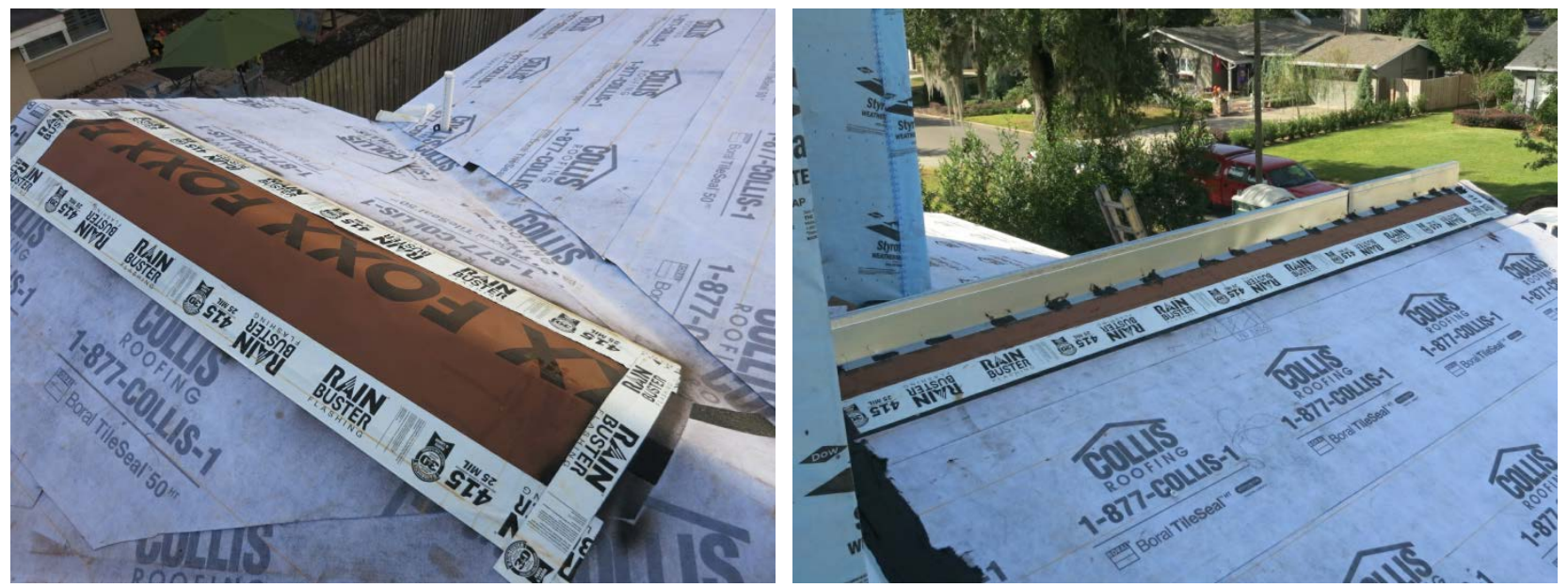

Figure 25. Completed diffusion vent (left); installation of ridge metal (right)
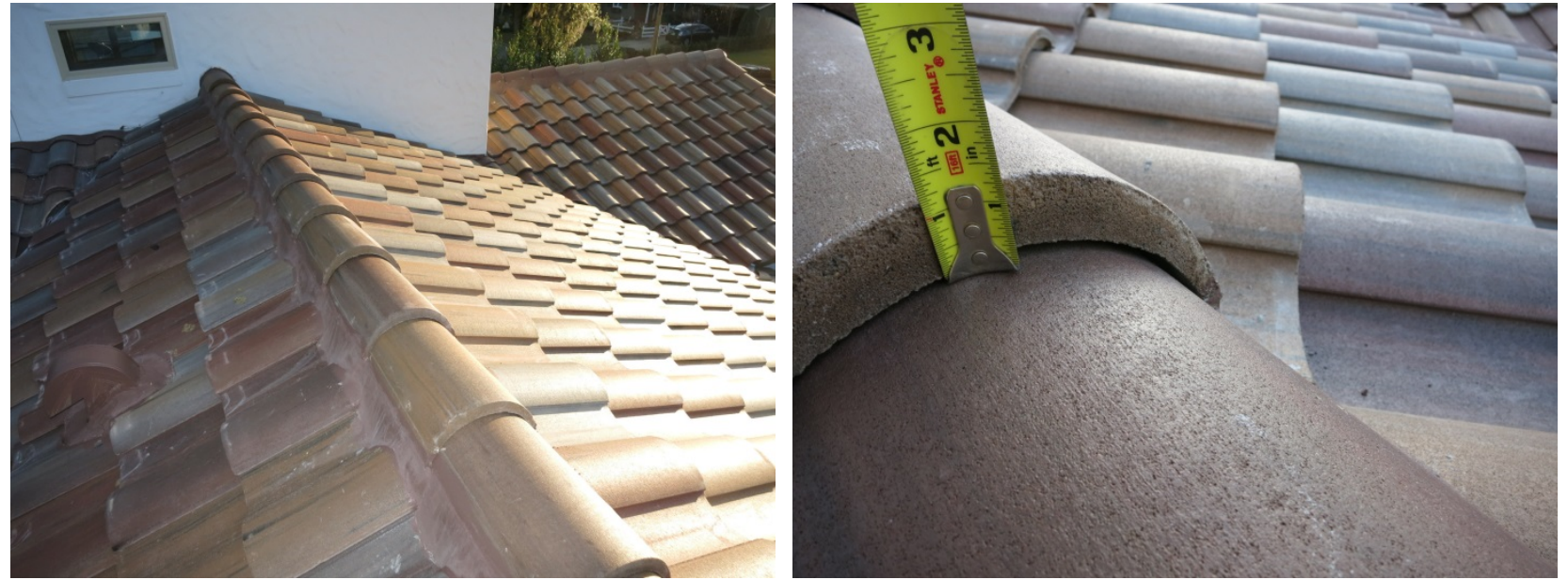

Figure 26. Completed roof ridge tile geometry (left); gaps in ridge tile (right)

As a control comparison, one section of the roof was constructed as a typical unvented roof. This type of assembly previously showed high MCs in Jacksonville, Florida (CZ 2A). This roof section had vapor-impermeable membrane (bituminous self-adhered roofing membrane) over the ridge, rather than the diffusion vent detail. The key points are (1) whether failure occurs at the control roof, and then (2) whether the experimental (diffusion vent) roofs have sufficient drying to avoid failure.

\subsection{Roof Instrumentation Setup}

The roof plan is shown in Figure 27 with the ridges, hips, and valleys marked and roof slopes noted. The area constructed as conventional unvented roof (no diffusion port) is highlighted in blue. Unconditioned attic areas are shown in gray. 
The measurement locations are also shown in Figure 27: the instrumentation is intended to capture a variety of orientations and roof conditions. Typically a ridge package contains several sensors (shown in Figure 28); the sensor package is concentrated at the ridge or highest point in the bay (orange star), because moisture typically accumulates at the peaks. In addition, at each bay with a ridge package, sheathing MC and temperature (blue squares) are measured lower on the roof sheathing. Zero, one, or two sheathing $\mathrm{MC} /$ temperature sensors are installed on each slope, depending on the roof geometry. These measure the moisture accumulation in the rafter bays with the same condition but lower on the roof.

Monitoring locations shown in the diagram include:

- DVR-1 through DVR-3 (diffusion vent-ridge): peak measurements with diffusion vent at ridge, at several roof locations (both over first- and second-floor attics).

- UVR-1 (unvented roof-ridge): unvented assembly for comparison with diffusion vent.

- DVH-1 and DVH-2 (diffusion vent-hip): measurements at the hip rafter, both high and low.

- RW-1 and RW-1 (roof-wall): measurements at the roof-wall interface, which is the top termination of a roof truss bay. However, this assembly does not receive a diffusion vent: moisture accumulation (if any) was measured here.

The ridge monitoring package is shown in Figure 28 through Figure 30. Sheathing MCs were measured at the ridge $1 \times 4$ on one orientation (left) and as high as practical on the other orientation, directly below the diffusion port slot (right). In addition, at the ridge/peak of the insulated bay, a temperature/RH sensor and MC wafer sensor were installed. The wafer sensor is a small wood sample measured for MC, which acts as a surrogate humidity sensor (see Ueno and Straube 2008). The sensor can indicate liquid water condensation. Finally, the sheathing MCs on both orientations were measured roughly 24 in. from the ridge to capture the extent of the wetting. 


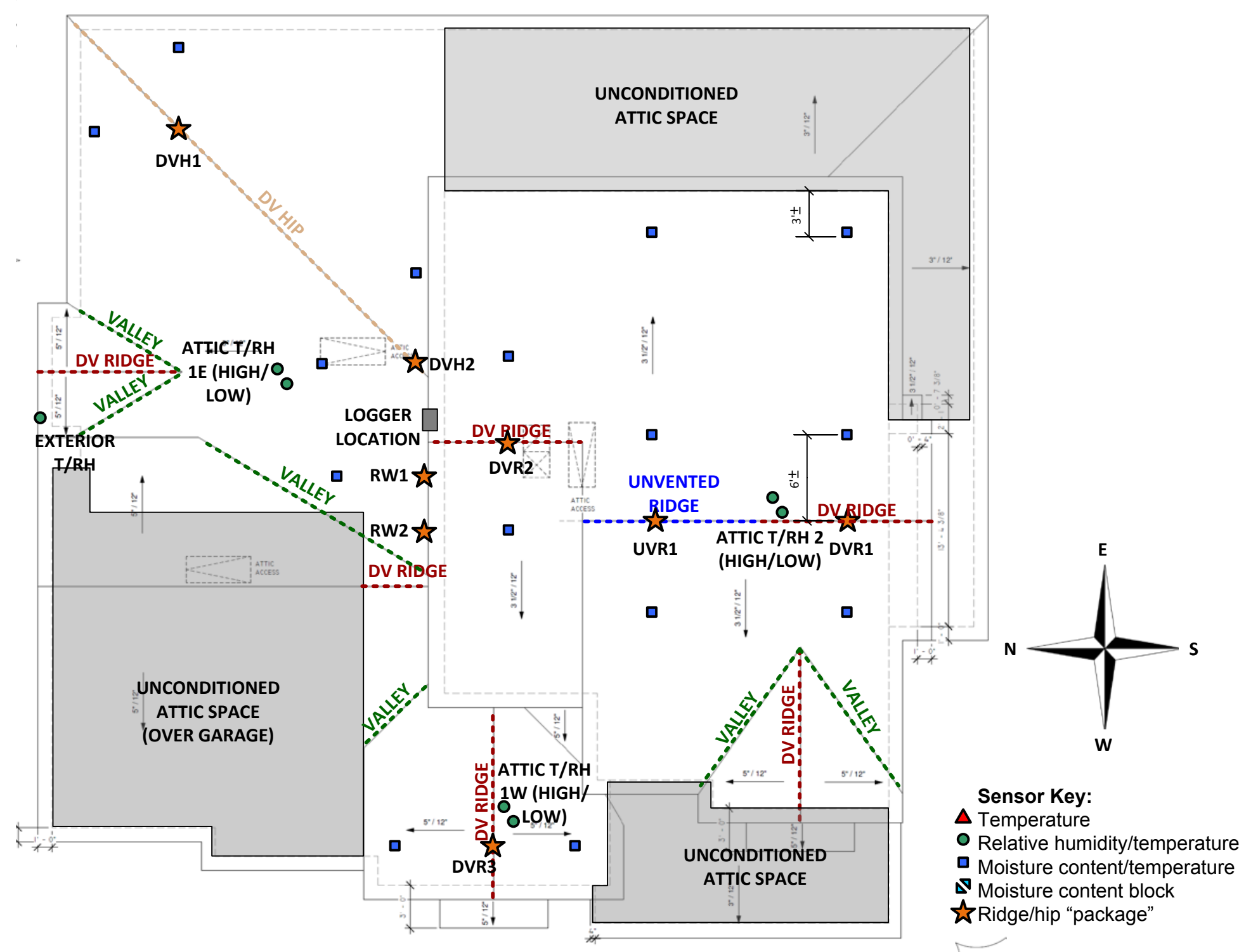

Figure 27. Orlando roof plan showing ridges, hips, valleys, and measurement locations 


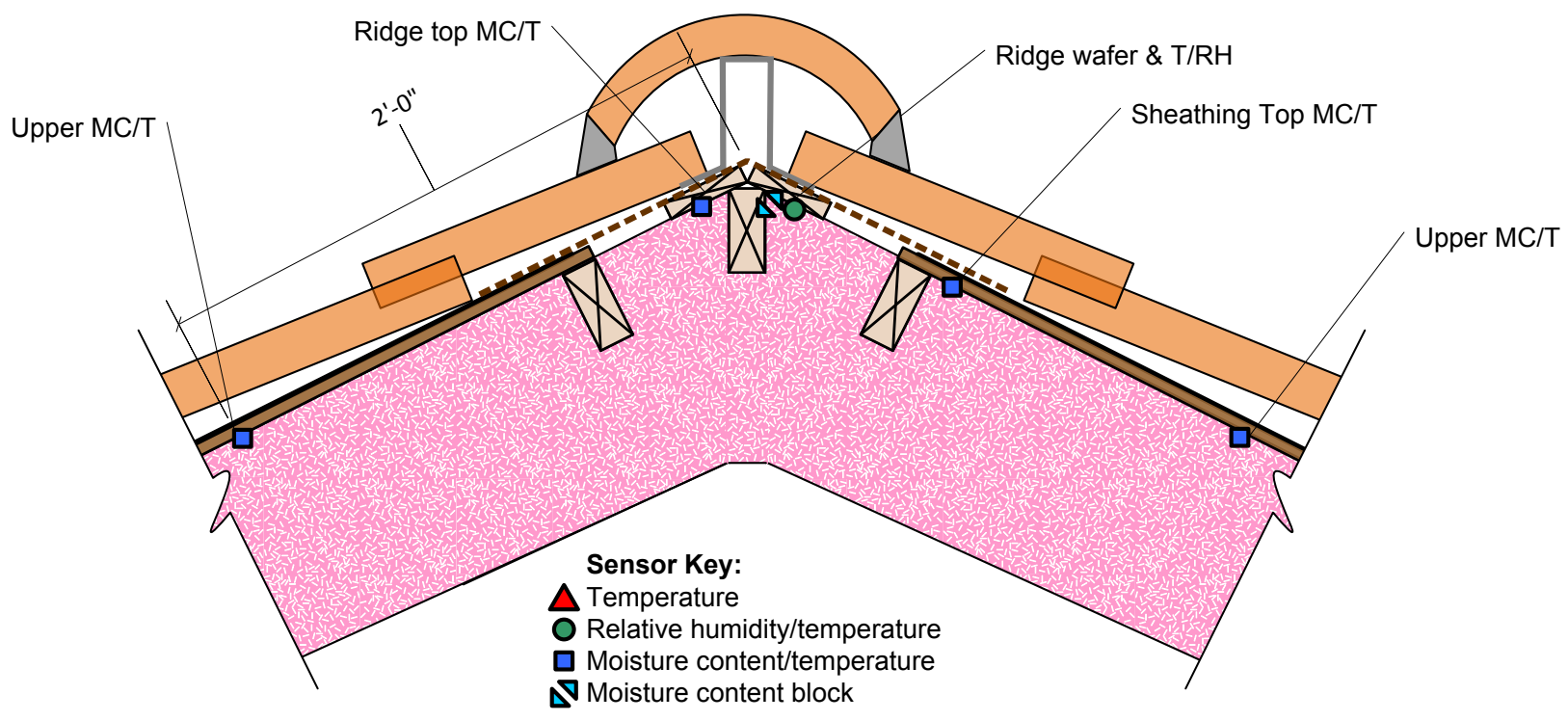

Figure 28. Ridge monitoring package (sensors at ridge and hip peaks)

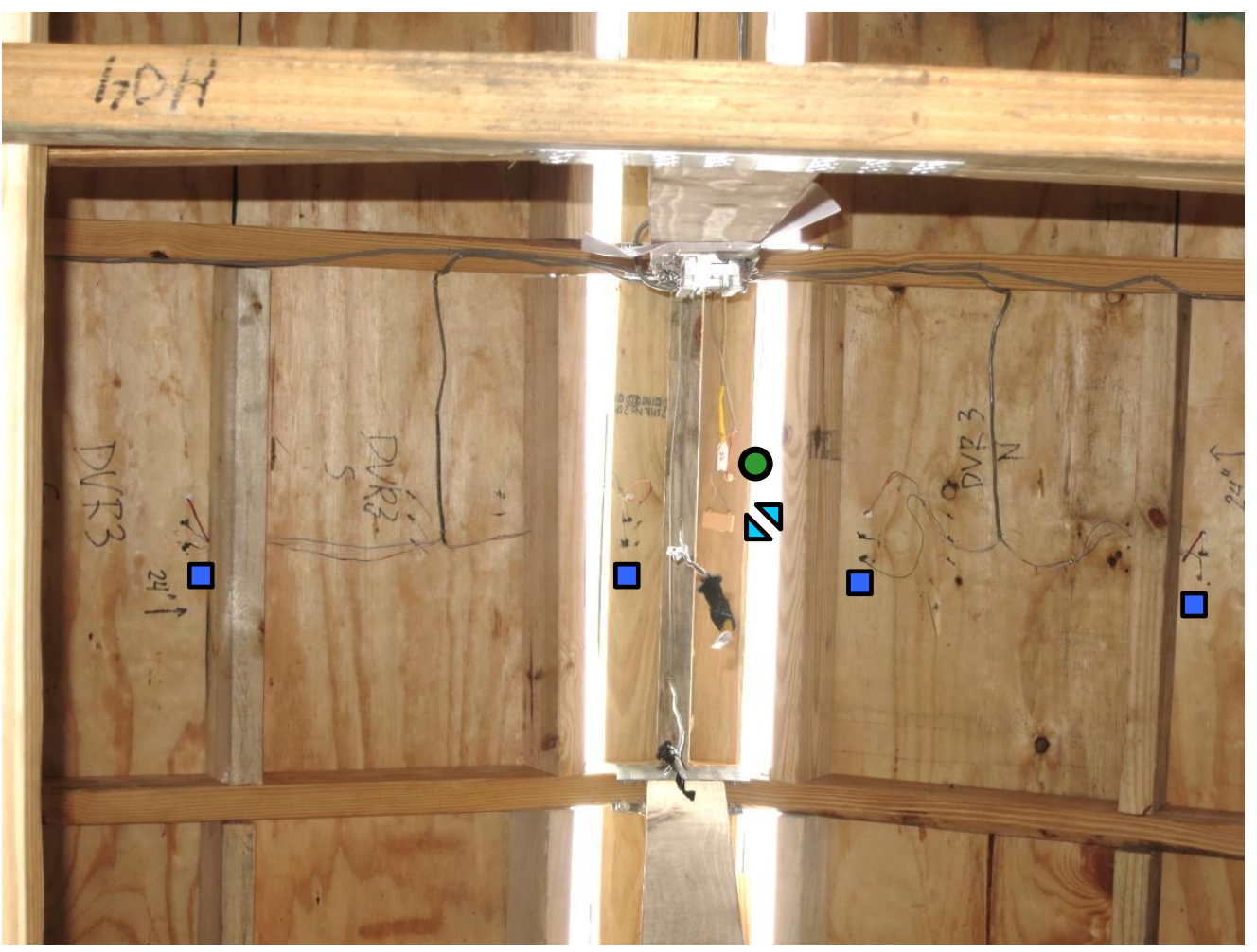

Figure 29. Typical ridge monitoring package with sensors highlighted 

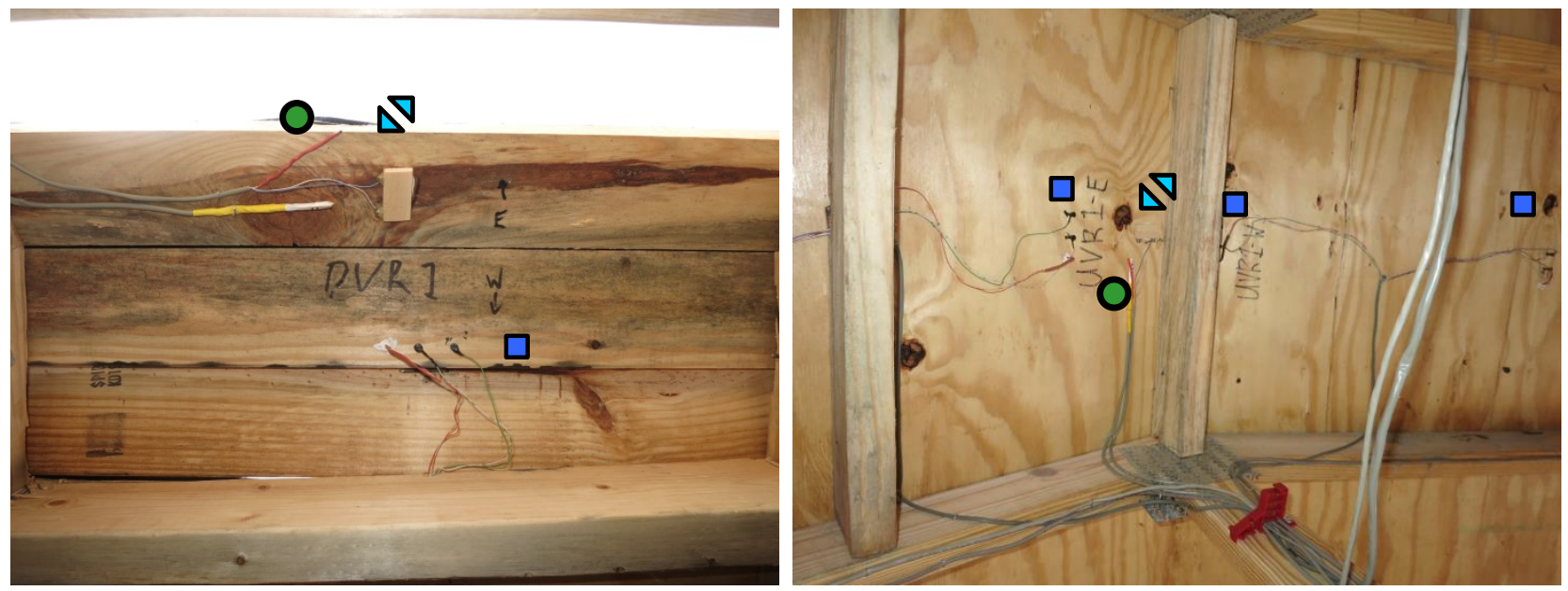

Figure 30. Close-up of ridge package (left); ridge package at unvented roof (right)

At each bay with a ridge package, sheathing temperature and $\mathrm{MC}$ are measured lower in the same rafter bay at the sheathing, in zero, one, or two locations (blue squares in Figure 27). This measures moisture accumulation in the rafter bays with the same condition but lower on the slope. The number of lower roof sheathing MC sensors varies with the roof configuration based on the presence of unobstructed rafter bays.

In addition, conditioned attic (i.e., interior) temperature and $\mathrm{RH}$ were measured at three locations within the conditioned attic (Figure 31 left and green circles in Figure 27); measurements were paired high and low (roughly the 1/3 and 2/3 vertical points) to capture the effects of thermal and/or moisture stratification in the space. Interior main space temperature and $\mathrm{RH}$ are measured via a sensor installed in the return duct of the space-conditioning system near the interior grille. Exterior temperature and humidity were recorded on site within a radiation shield (albeit unshielded by the roof overhang; Figure 31 right).
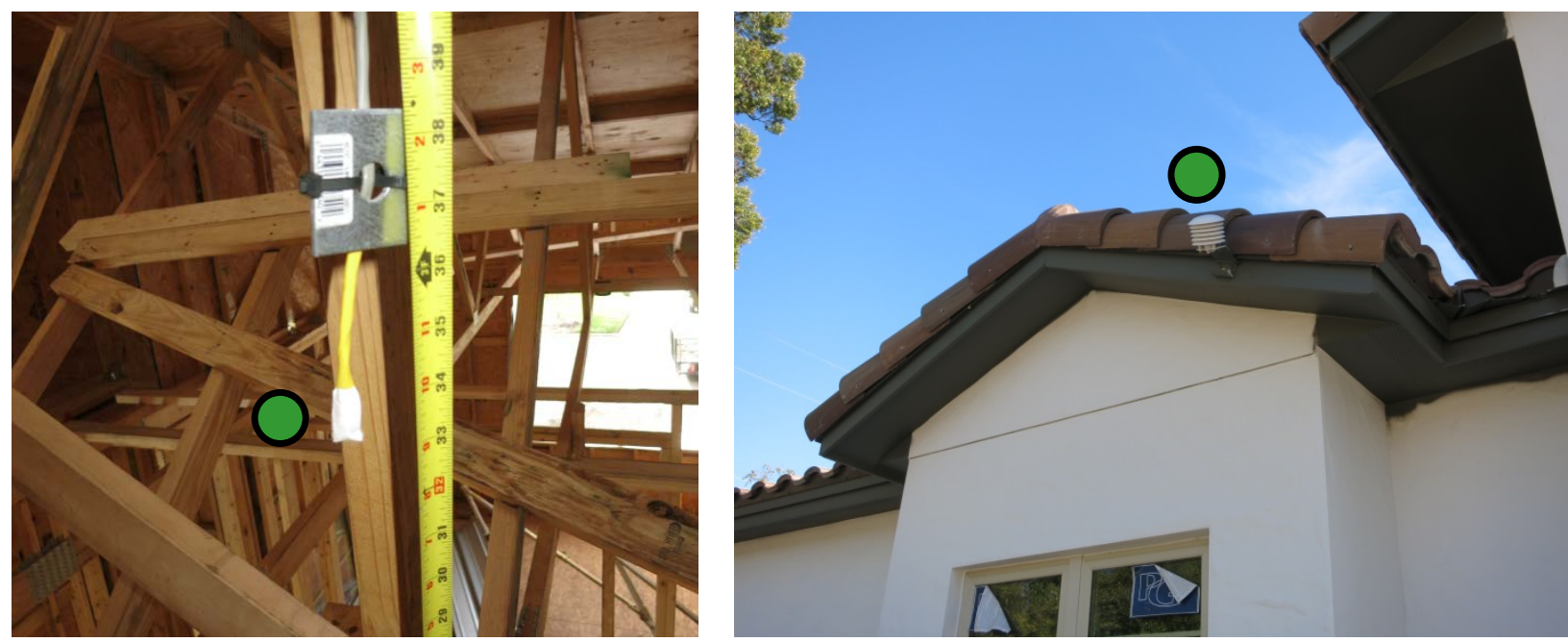

Figure 31. Typical temperature/RH sensor for attic interior (left) and exterior (right) conditions 
Instrumentation was installed as per Straube et al. (2002); measurements were taken at 5-minute intervals, and averages were recorded every hour. Instrumentation specifications are provided in Appendix A (temperature and RH sensors) and Appendix B (MC sensors). Data were recorded in a central data acquisition system and periodically downloaded remotely via cellular modem.

Exterior data were supplemented by airport (Orlando Executive Airport/KORL) weather data (e.g., precipitation and wind).

\subsection{Attic and Roof Air Leakage Testing}

As part of the commissioning process, the house and attics were tested for air leakage. The testing included $\Delta \mathrm{P}$ measurement, multifan nulling/pressure neutralization, and infrared localization of air leakage.

\subsubsection{House Geometry and Attic Configuration}

The three-dimensional geometry of the house, including the attic areas, is shown in the isometric images in Figure 32 and Figure 33. The house geometry includes:

- First and second floors (in light blue and dark blue, respectively); the second floor has a smaller footprint than the first floor.

- The lower attic (light blue), which is over the first floor where it is not under the second floor. It has a convoluted geometry and wraps around from front to back.

- The upper attic (orange) over the second floor.

- The garage attic (red), which is separated from the lower attic by a sheathed and insulated wall (per Figure 20 left, Figure 21, and Figure 22).

- The porch roofs (green), which were designed to be isolated from the lower attic (Figure 21 and Figure 22).

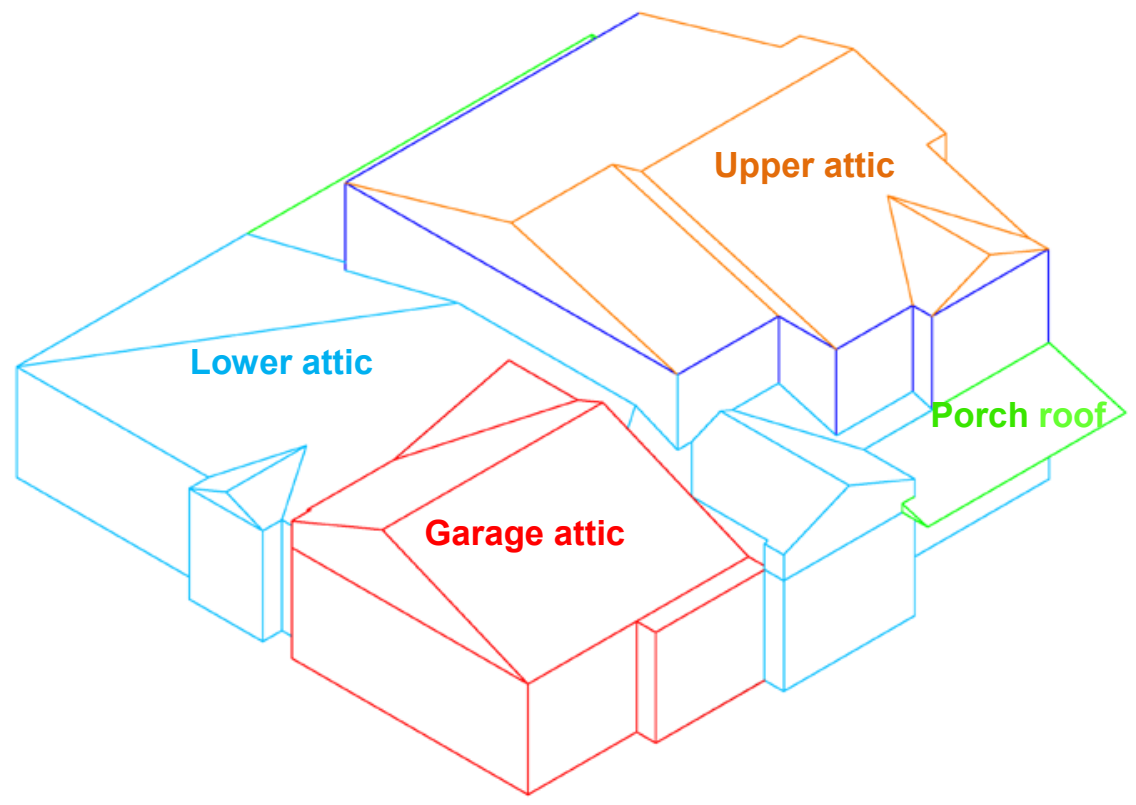

Figure 32. Front-left isometric of unvented roof geometry 


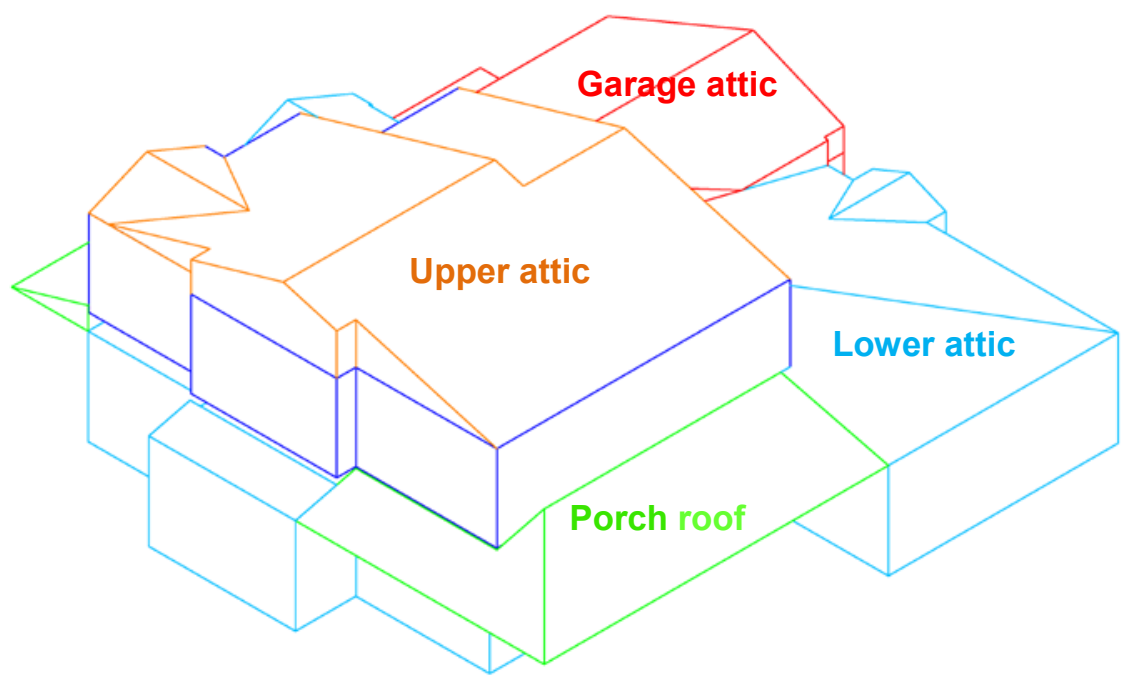

Figure 33. Rear-right isometric of unvented roof geometry

\subsubsection{Single Fan Test (Pressure Differences)}

The first set of tests involved a single blower door fan (see Appendix A for equipment) located at the front door (Figure 34) and measuring air leakage with the attic hatches open or closed.

Multipoint depressurization testing was conducted (from -50 to $-20 \mathrm{~Pa}$ ).

Configurations included:

- Both attic hatches closed

- Lower attic hatch open; upper attic hatch closed

- Upper attic hatch open; lower attic hatch closed

- Both attic hatches open.
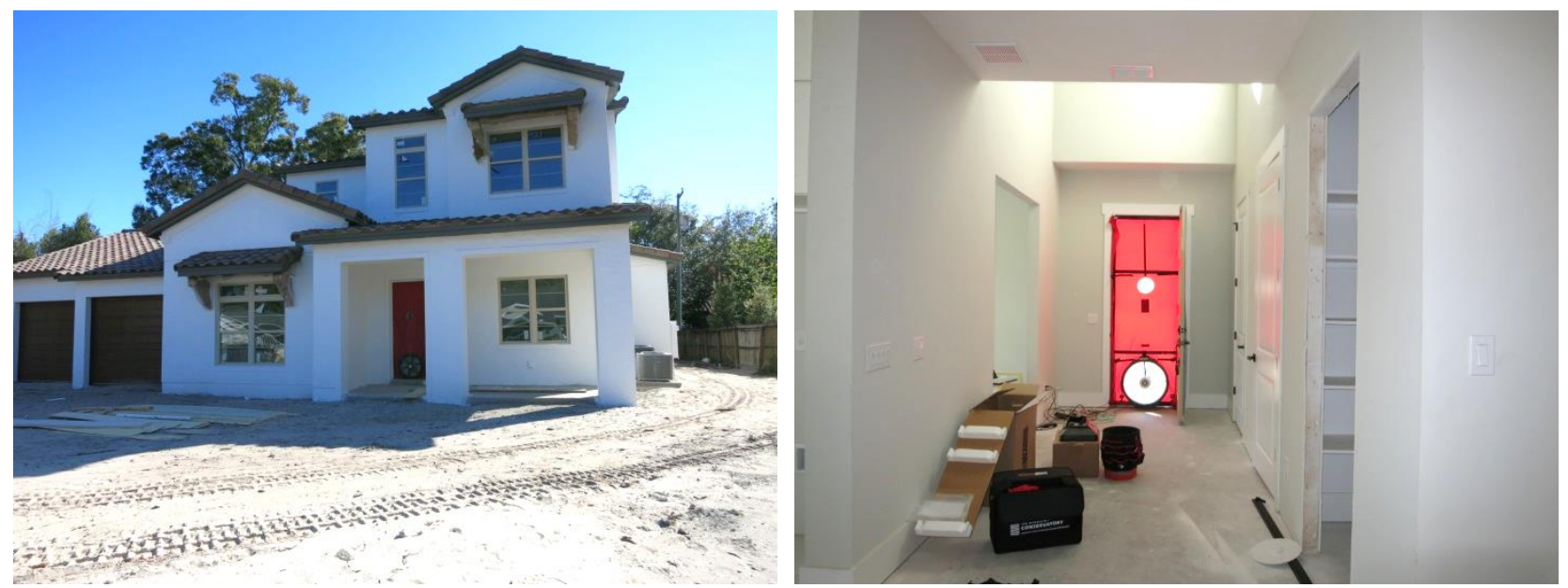

Figure 34. Air leakage (single blower door) testing of the tile roof test house 
The results of the four multipoint tests are shown in Figure 35; the exponential curve fits were used to calculate $\mathrm{C}$ (coefficient) and $\mathrm{n}$ (exponent) values.

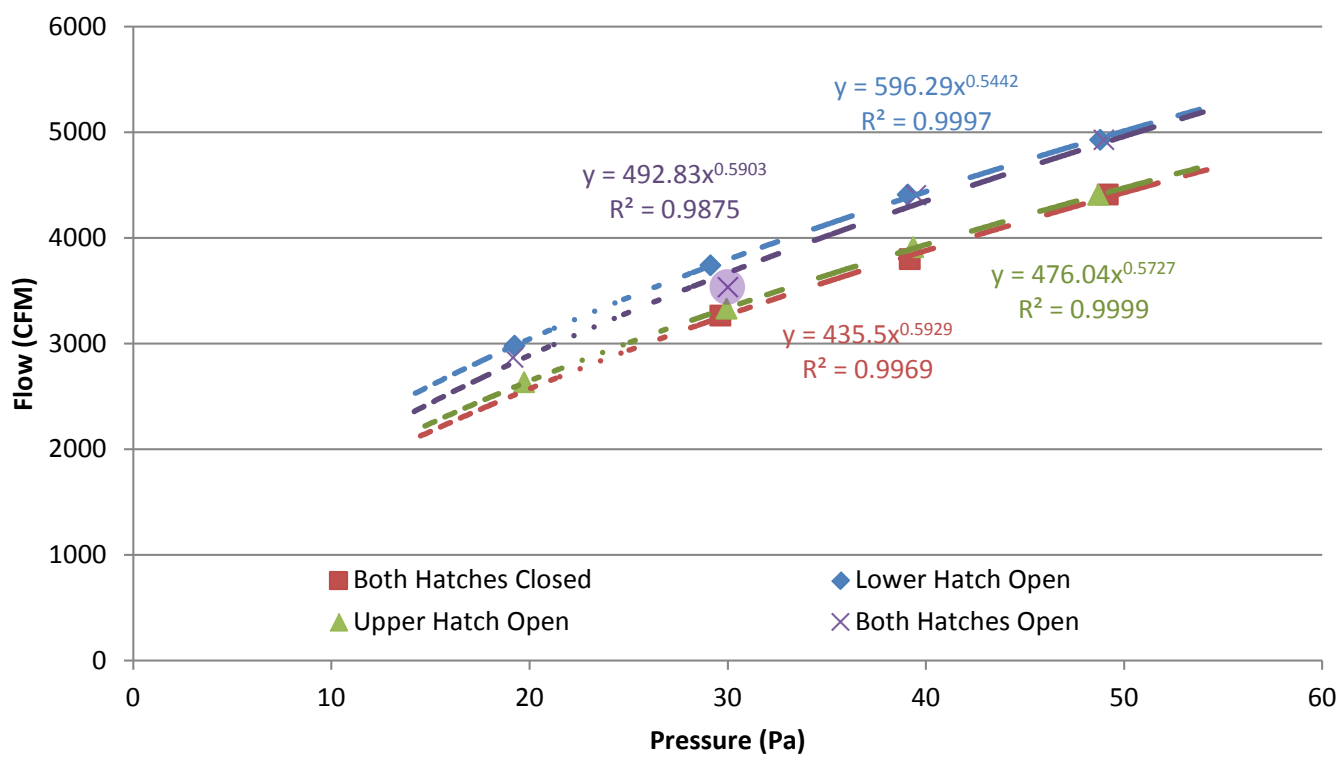

Figure 35. Hatch open/hatch closed multipoint testing with curve fits

The measured air leakage in the various configurations is shown in Table 3. The table includes CFM 50 (cubic feet per minute at 50 Pascals) air leakage, as well as the change $(\Delta)$ in CFM 50 from the initial, both hatches closed test. Normalized leakage metrics of ACH 50 (air changes per hour at 50 Pascals) and CFM 50/ $\mathrm{ft}^{2}$ of enclosure area are shown, normalizing by the full building volume/surface in all cases. Finally, the air leakage is stated in terms of equivalent leakage area (EqLA at $10 \mathrm{~Pa})$. EqLA is considered a reasonable representation of actual changes in air leakage open areas (TEC 2015). A data anomaly appears (purple circle in Figure 35; "outlier" in Table 3) in the "both hatches open" series, which is discussed below.

Table 3. Results of Hatch Open/Hatch Closed Air Leakage Testing

\begin{tabular}{|c|c|c|c|c|c|c|c|}
\hline & $\mathbf{C}$ & $\mathbf{n}$ & CFM 50 & $\triangle$ CFM 50 & ACH 50 & $\begin{array}{l}\text { CFM } \\
50 / \mathbf{f t}^{2}\end{array}$ & $\begin{array}{r}\text { EqLA } \\
\text { (in. }^{2} \text { ) }\end{array}$ \\
\hline $\begin{array}{l}\text { Both Hatches } \\
\text { Closed }\end{array}$ & 435.5 & 0.59 & 4429 & & 6.7 & 0.51 & 456 \\
\hline $\begin{array}{c}\text { Lower Hatch } \\
\text { Open }\end{array}$ & 596.3 & 0.54 & 5012 & 583 & 7.6 & 0.58 & 516 \\
\hline $\begin{array}{l}\text { Upper Hatch } \\
\text { Open }\end{array}$ & 476.0 & 0.57 & 4473 & 44 & 6.8 & 0.52 & 461 \\
\hline $\begin{array}{c}\text { Both Hatches } \\
\text { Open (w. Outlier) }\end{array}$ & 492.8 & 0.59 & 4961 & 532 & 7.5 & 0.57 & 511 \\
\hline $\begin{array}{c}\text { Both Hatches } \\
\text { Open (Select } \\
\text { Data) }\end{array}$ & 514.6 & 0.58 & 5009 & 580 & 7.6 & 0.58 & 516 \\
\hline
\end{tabular}


The overall air leakage results (6.7 to 7.6 ACH 50) are higher (worse) than typical goals for energy-efficient construction; they exceed the 5 ACH 50 target for $\mathrm{CZ} 2$ (per 2012 International Energy Conservation Code ICC 2012, §R402.4.1.2 Testing). However, the house was still being completed; door gaskets (Figure 36) and finish floors were not installed (which would have provided some gasketing).
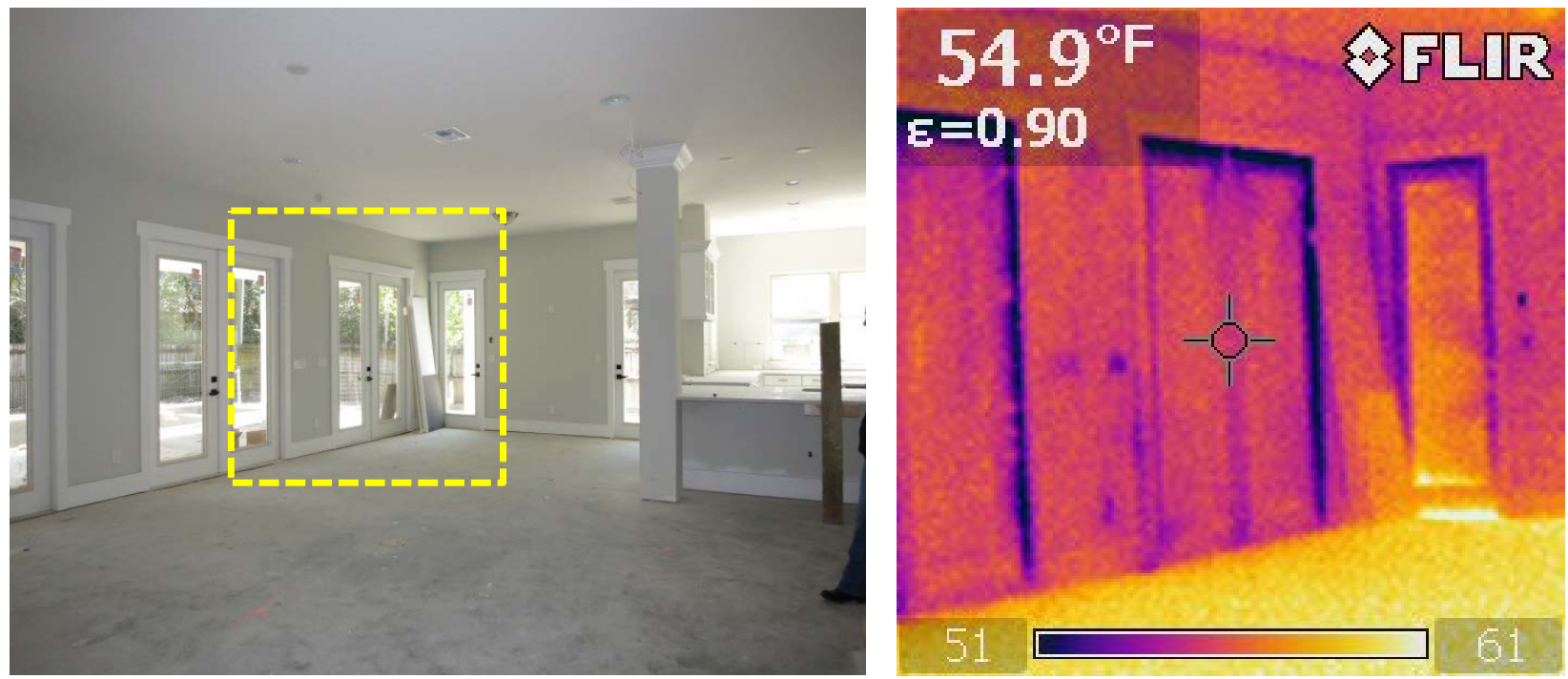

Figure 36. Visual (left) and infrared (right) image during depressurization testing, showing door leakage

Opening the lower attic hatch resulted in a substantial (+583 CFM 50/13\%) increase in leakage; opening the upper hatch caused a minimal (+44 CFM 50/1\%) increase. This suggests substantial air leakage from the lower attic to outside.

The final test (both hatches open) was first calculated to be more airtight than the one hatch open test (an unreasonable result). However, after removing an outlier data point (highlighted in Figure 35, "select data" in Table 3), the results of the two tests were almost identical.

During these hatch open/closed tests, the $\Delta \mathrm{Ps}$ to the attics were measured, as shown in Table 4, with the house at $-49.2 \mathrm{~Pa}$. The large $\Delta \mathrm{P}$ at the lower attic $(23 \mathrm{~Pa})$ is consistent with that attic being "half in-half out" of the conditioned space. The small $\Delta \mathrm{P}$ from the upper attic to the inside $(9.3 \mathrm{~Pa})$ is consistent with that attic being mostly in the conditioned space. Even with the hatch closed, more air paths remain open from the upper attic to inside than to outside.

The $\Delta \mathrm{Ps}$ were translated into hole size ratios (size of interior-to-zone versus zone-to-exterior holes), per Fitzgerald and Blasnik zone pressure diagnostic (ZPD) methods (Bohac 2002; Morin 2011). The ratio of $\Delta \mathrm{Ps}$, or $\mathrm{p}_{\mathrm{e}}$ to $\mathrm{p}_{\mathrm{i}}(\Delta \mathrm{P}$ exterior versus interior) was calculated, followed by the ratio of hole sizes $\left(c_{e}\right.$ to $c_{i}$, or exterior versus interior hole area).

These calculations indicate that the lower attic (suspected high leakage) has a 1.1:1 ratio of net hole area connecting to interior space, versus the exterior. The upper (suspected low leakage) attic has a 2.6:1 ratio of interior versus exterior hole area. 
Table 4. $\Delta \mathrm{Ps}$ at $\mathbf{- 4 9 . 2} \mathrm{Pa}$ across Closed Hatches to Attics with Hole Size Ratios

\begin{tabular}{c|c|c|c|c|c}
\hline & $\begin{array}{c}\text { Zone-House } \\
\boldsymbol{\Delta} \mathbf{P}\end{array}$ & $\begin{array}{c}\text { Zone-Out } \\
\boldsymbol{\Delta} \mathbf{P}\end{array}$ & $\begin{array}{c}\text { \% Zone- } \\
\text { House } \Delta \mathbf{P}\end{array}$ & $\begin{array}{c}\mathbf{p}_{\mathrm{e}} / \mathbf{p}_{\mathbf{i}} \\
(\boldsymbol{\Delta} \mathbf{P} \text { ratio })\end{array}$ & $\begin{array}{c}\mathbf{c}_{\mathrm{i}} / \mathbf{c}_{\mathrm{e}} \text { (hole } \\
\text { size ratio) }\end{array}$ \\
\hline Lower Attic & 23.0 & 26.2 & $47 \%$ & 1.1 & 1.1 \\
\hline Upper Attic & 9.3 & 39.9 & $19 \%$ & 4.3 & 2.6 \\
\hline
\end{tabular}

\subsubsection{Multifan Test (Nulling Testing)}

The next test was to install two additional fans in the hatches to the lower and upper attics (Figure 37). The attics were first individually tested for air leakage (with a window open to relieve pressure). Then all three fans were run simultaneously to bring all zones to the same pressure (i.e., a nulled test). Ideally, this test only measures air leakage from a given zone to the exterior.
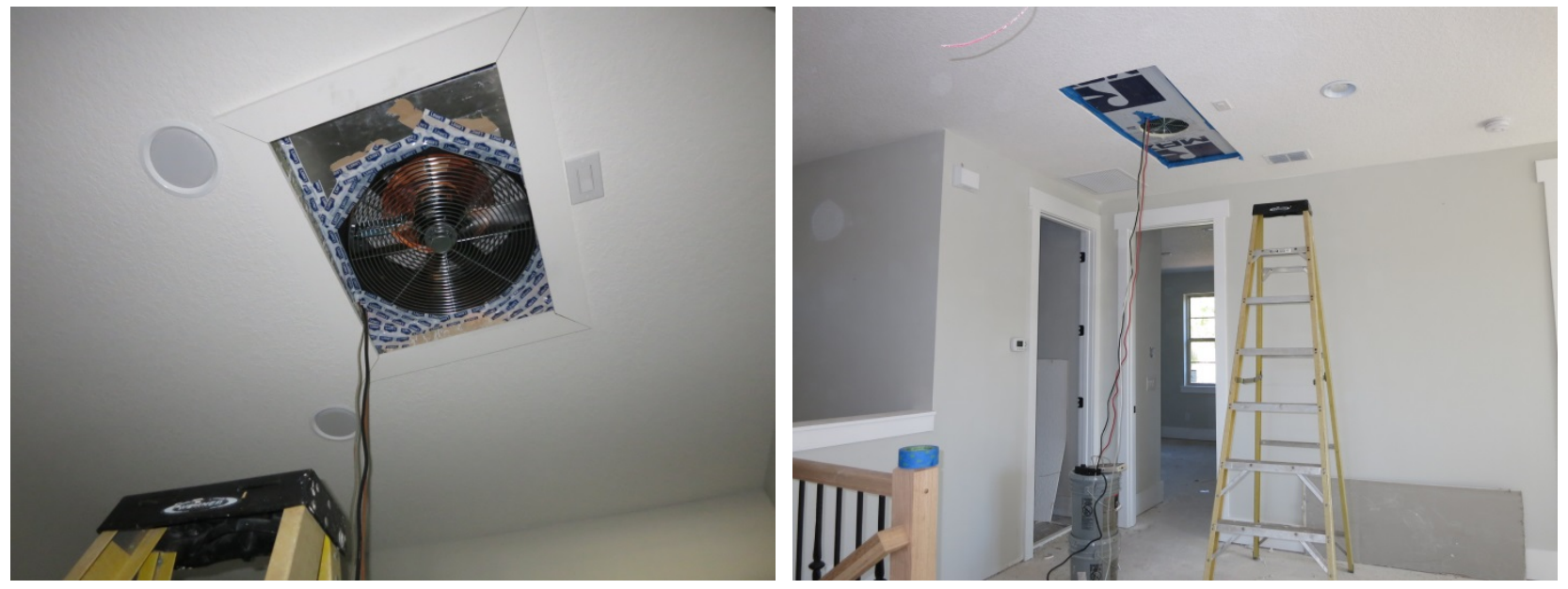

Figure 37. Depressurization fans placed in lower (left) and upper (right) attics

The results of the individual zone (nonnulled) tests are shown in Table 5; the results for "Both Hatches Open (Select Data)" (see Table 3) are reproduced for the Main Space (for reference). The multipoint test data are shown in Figure 38.

Table 5. Results of Individual Space Air Leakage Testing (nonnulled)

\begin{tabular}{c|c|c|c|c|c}
\hline & $\mathbf{C}$ & $\mathbf{n}$ & $\mathbf{C F M} 50$ & EqLA (in. ${ }^{2}$ ) & ACH 50 \\
\hline $\begin{array}{c}\text { Mane } \\
\text { Space }\end{array}$ & 514.6 & 0.58 & 5009 & 516 & 7.6 \\
$\begin{array}{c}\text { Upper } \\
\text { Attic }\end{array}$ & 104.4 & 0.69 & 1525 & 157 & 25.6 \\
$\begin{array}{c}\text { Lower } \\
\text { Attic }\end{array}$ & 363.7 & 0.61 & 3878 & 399 & 94.3 \\
\hline
\end{tabular}

Results are stated in terms of EqLA and the ACH 50 for the individual zone (based on individual zone volume). The ACH 50 for the attic zones are exceptionally high (26 and 94 ACH 50); 
however, this is a function of the small volumes of these spaces rather than a good metric of their relative leakiness.

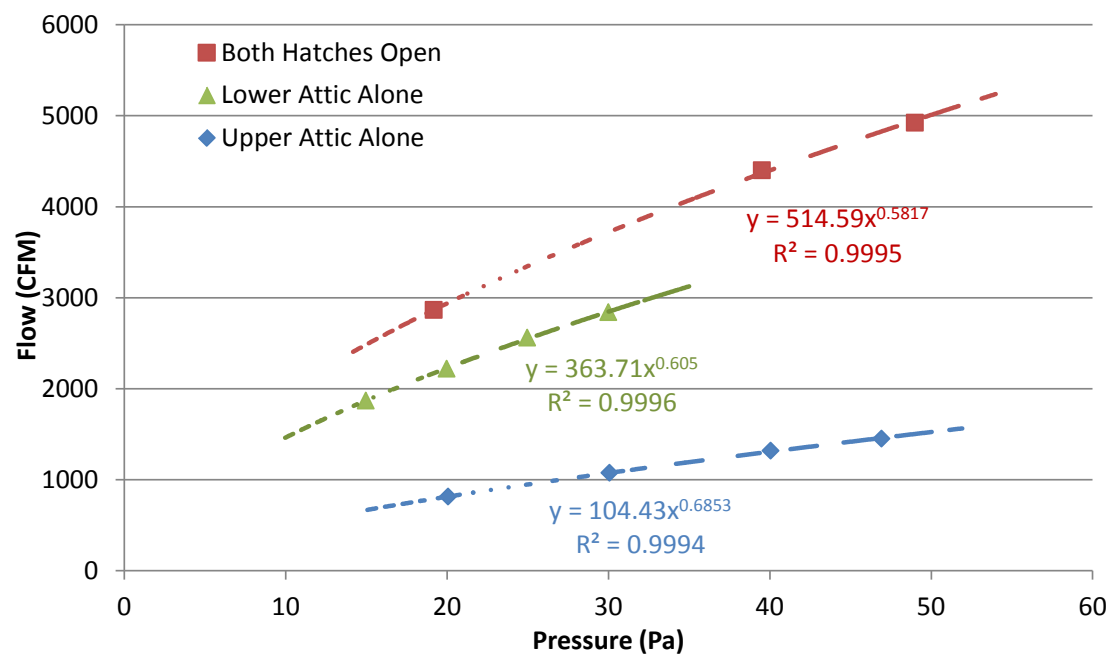

Figure 38. Multipoint testing of individual zones (main house and two attics), nonnulled

The multipoint results for the nulled testing (all three fans running simultaneously) are shown in Figure 39.

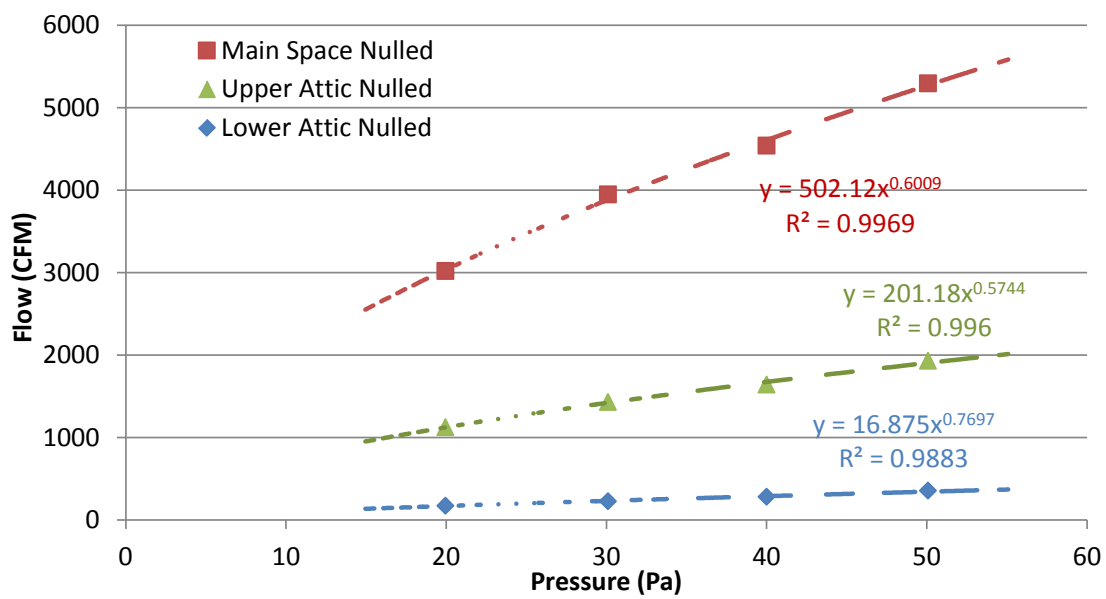

Figure 39. Multipoint testing of zones (main house and two attics) with simultaneous fans (nulled)

The calculated results are shown in Table 6; as would be expected, the air leakage through the attic zones drops significantly between these two tests, because the interior-to-attic leakage was eliminated. The upper attic drops by 1180 CFM 50 (-78\%), and the lower attic by 1975 CFM (51\%). The EqLA connected to the exterior ("Ext. EqLA") was calculated from these measurements, and then the EqLA connecting the zone to the interior ("Int. EqLA") was calculated by subtraction.

The results indicate significant leakage (196 in. ${ }^{2}$ EqLA) from the lower attic to the exterior and relatively low leakage ( $35 \mathrm{in}^{2}$ EqLA) from the upper attic to the exterior. 
Table 6. Results of Simultaneous Fans/Nulled Air Leakage Testing

\begin{tabular}{c|c|c|c|c|c|c|c}
\hline & C & $\mathbf{n}$ & CFM 50 & $\begin{array}{c}\Delta \\
\text { CFM 50 }\end{array}$ & $\begin{array}{c}\text { \% } \Delta \\
\text { CFM 50 }\end{array}$ & $\begin{array}{c}\text { Ext. } \\
\text { EqLA } \\
\text { (in.2) }\end{array}$ & $\begin{array}{c}\text { Int. EqLA } \\
\text { (in.2)* }\end{array}$ \\
\hline Main Space & 502.1 & 0.60 & 5269 & 260 & $5 \%$ & 543 & -27 \\
Main Space-Net & - & - & 3023 & - & - & 311 & - \\
Upper Attic & 16.9 & 0.77 & 343 & -1182 & $-78 \%$ & 35 & 122 \\
Lower Attic & 201.2 & 0.57 & 1903 & -1975 & $-51 \%$ & 196 & 203 \\
\hline
\end{tabular}

* Calculated value, from Ext. EqLA and Total EqLA in Table 5.

The "Main Space" test is the sum of leakage from all three zones (the attic hatch fans push air into the main space, which is then exhausted to the exterior). At first glance, this nulled test should logically be identical to the "both hatches open" test (5,009 CFM 50); instead, it is 5\% higher $(5,269$ CFM 50). However, in reality, the open attic hatches create some airflow resistance; this would result in a lower $\Delta \mathrm{P}$ in the attics (i.e., the pressure field was not welldistributed to the attic zones). In these conditions, the single fan test would have a lower airflow (consistent with measurements). Both test methods show significant upper attic air leakage.

The "Main Space" test can be used to calculate the net leakage from the main space (first and second floors) to the exterior, labeled "Main Space-Net" in Table 6. It shows that the leak from the lower attic to exterior is substantial — roughly two-thirds of the leakage from the main space to outside.

In addition, the calculated EqLA values from the nulling test can be compared with previous ZPD measurements:

- Upper attic, interior: exterior ratio: 2.6:1 ZPD versus 3.5:1 nulling

- Lower attic, interior: exterior ratio: 1.1:1 ZPD versus 1.0:1 nulling

Overall, this comparison indicates that ZPD provides reasonable and useful results. However, assuming the nulling test provides more accurate results, ZPD appears to have noticeable uncertainty.

\subsubsection{Air Leak Localization with Infrared}

Given the high leakage area associated with the lower attic, the lower attic was examined with infrared thermography with the house and attics depressurized to localize air leakage. Outdoor conditions were $\operatorname{cool}\left(\sim 50^{\circ} \mathrm{F} / 10^{\circ} \mathrm{C}\right)$ during this testing. The areas in Figure 41 through Figure 46 are keyed to the isometric in Figure 40. 


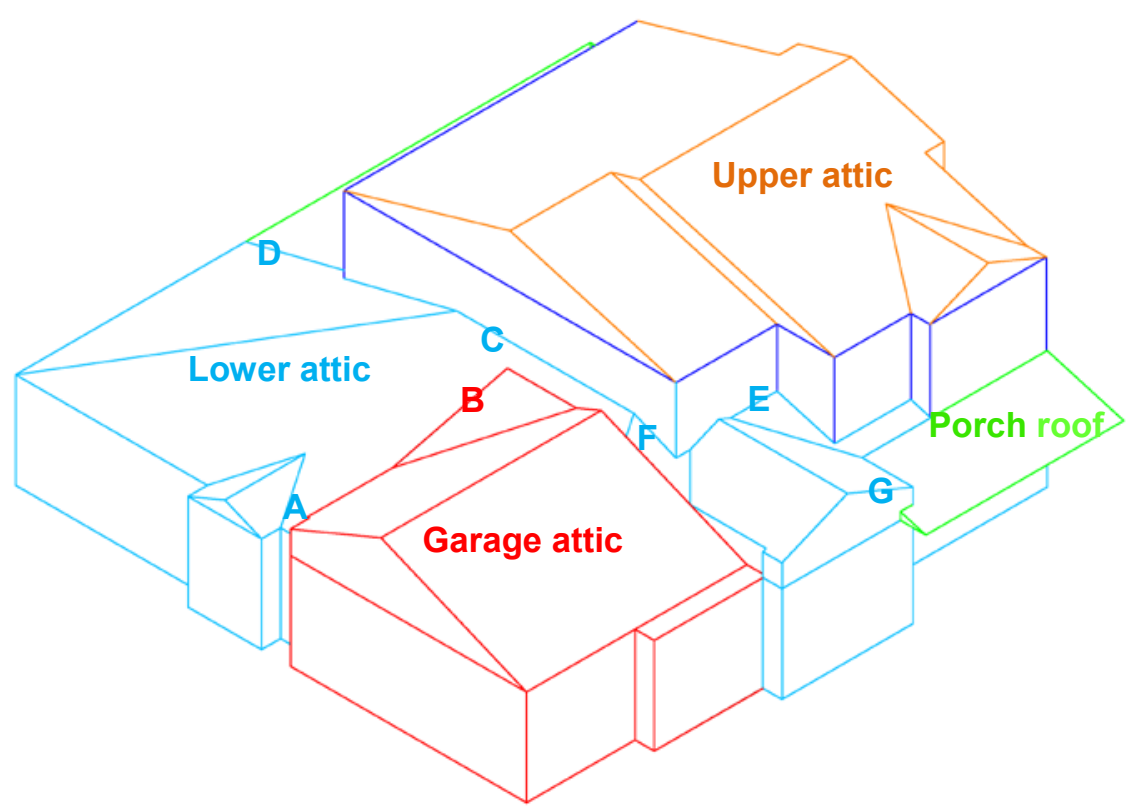

Figure 40. Front-left isometric of unvented roof geometry, keyed to Figure 41 through Figure 46

Location A is above the first floor master bathroom adjacent to the garage. Observation from below showed indications of cold air leakage at the roof-wall connection at the ceiling (Figure 41). This observation was complicated by the presence of a drying roof rainwater leak (indicated by the blue outline in Figure 41).
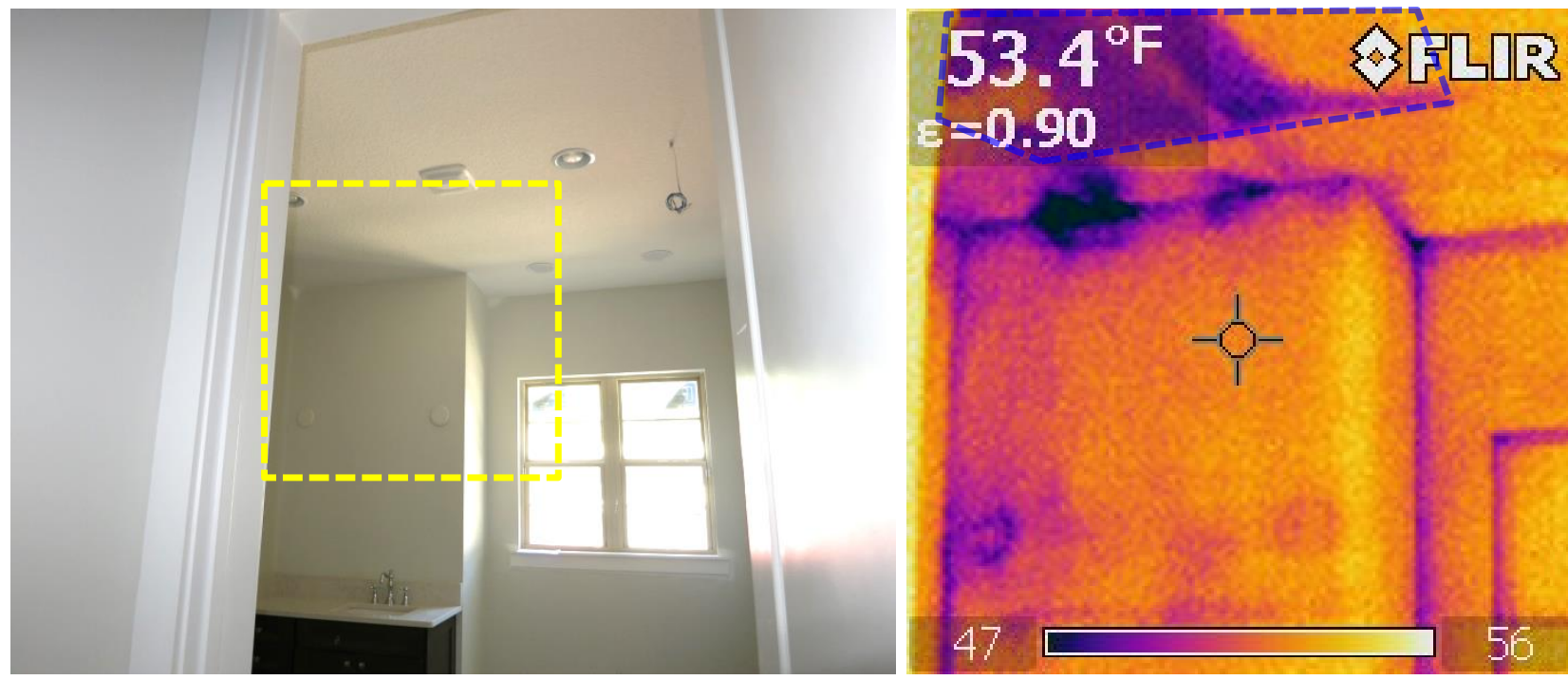

Figure 41. Bathroom ceiling air leakage at roof-wall interface; water leak in blue (Location A)

This air leakage was confirmed by attic observations (Figure 42); unfortunately, with the installation of insulation, the diffuse leak provided only the general location of the air leakage. 

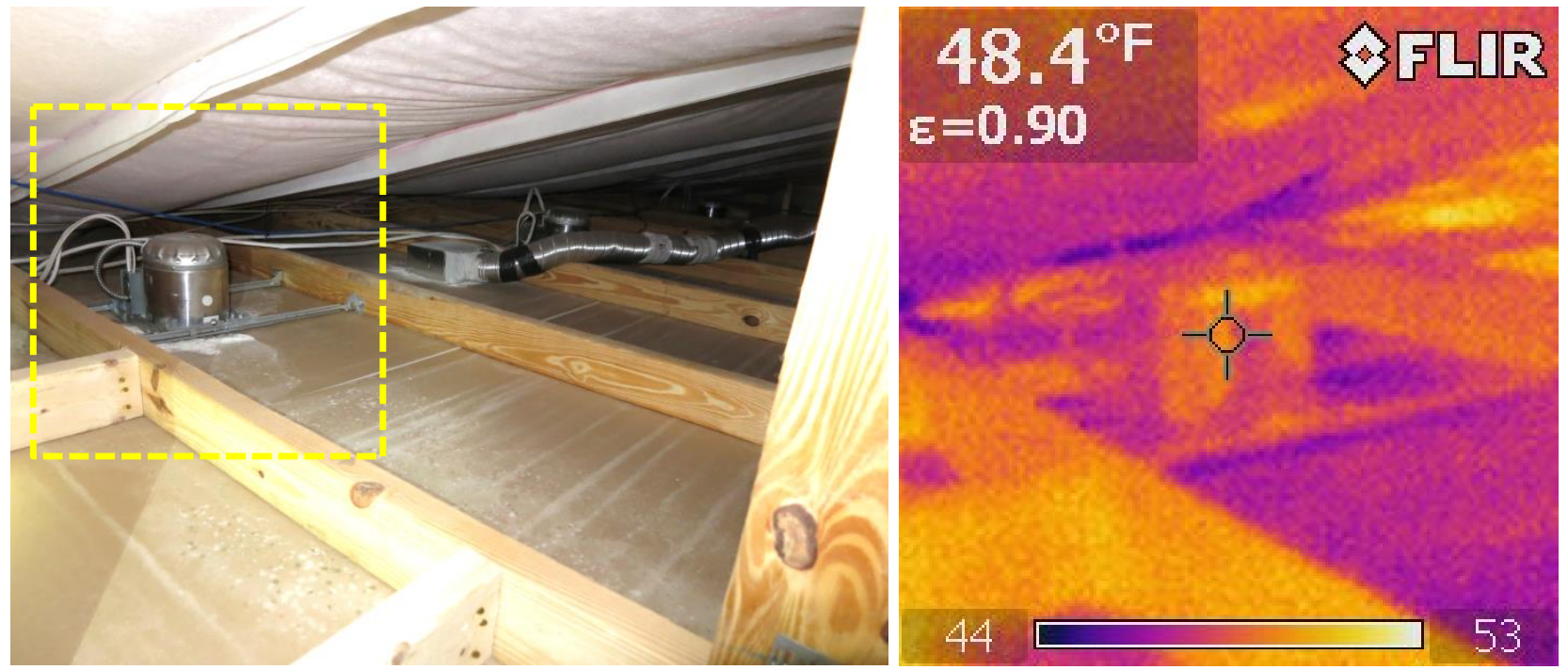

Figure 42. Roof-wall connection above bathroom; water damage at ceiling visible (Location A)

The attic was very congested (with ductwork and truss members); as a result, observations in the attic were limited, especially when combined with the low slope of the roof.

Another area with noticeable leakage was the wire penetrations from the electric service panel, at the wall to the garage (Location B), as shown in Figure 43. This leakage occurred despite the liberal use of spray foam at the wire penetrations.
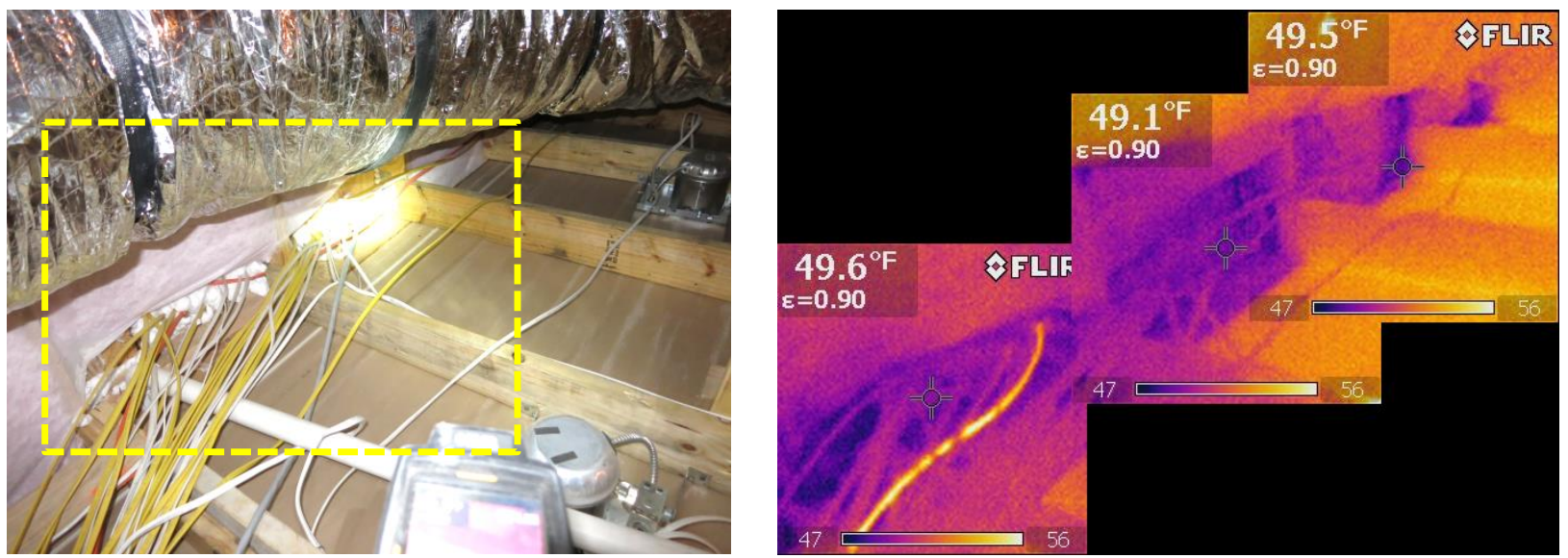

Figure 43. Air leakage at wiring penetrations at garage wall-top plate (Location B)

Observation from the attic hatch revealed some leakage occurring at the roof-wall interface (Location C), as shown in Figure 44. The leakage appeared to originate at or near a wall stud. The unusual shape of the leak in Figure 44 is roof-wall leakage, but masked by the metal plate of the cellular modem antenna attached to the wall stud. 

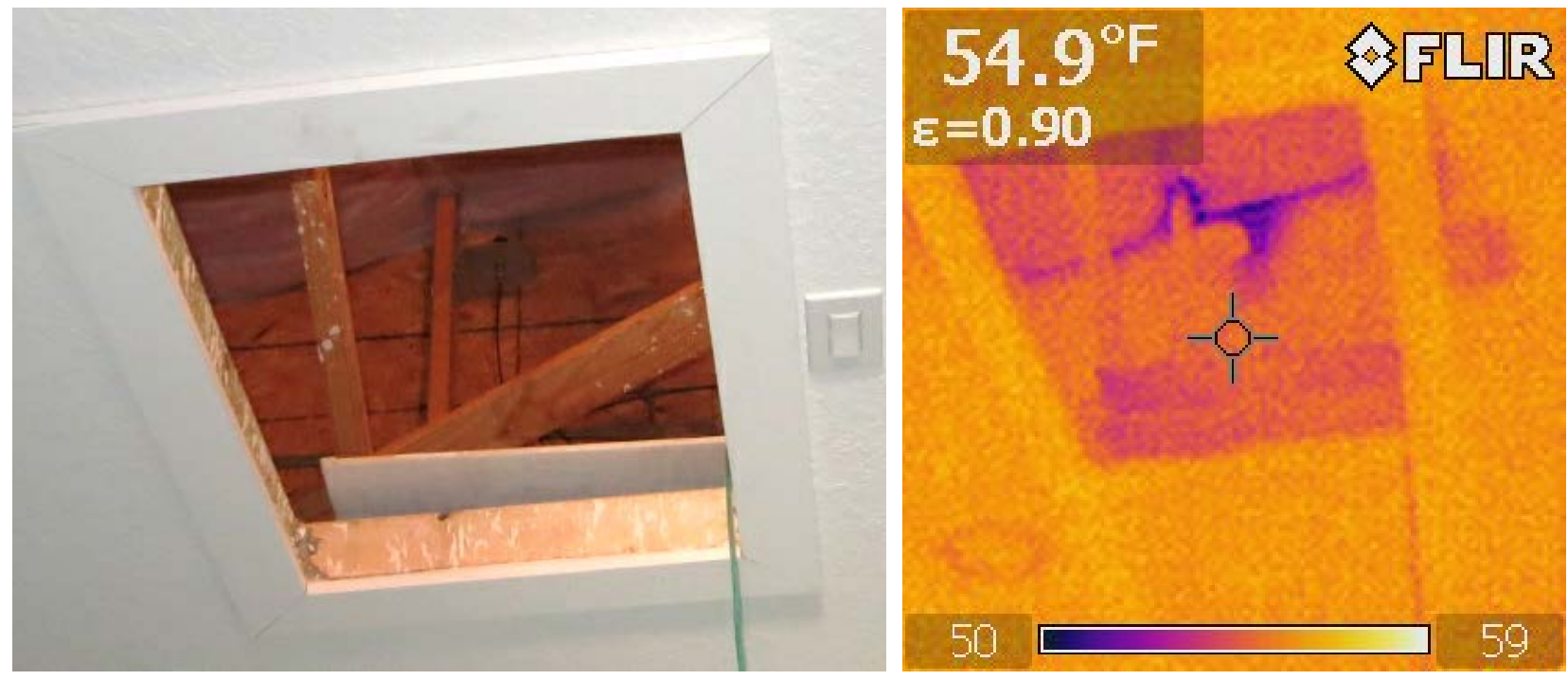

Figure 44. Air leakage at stud below roof-wall interface (Location C)

This leakage was also seen from the attic (Figure 45). In addition, Figure 45 shows air leakage at the wall to the unconditioned porch roof (Location D).
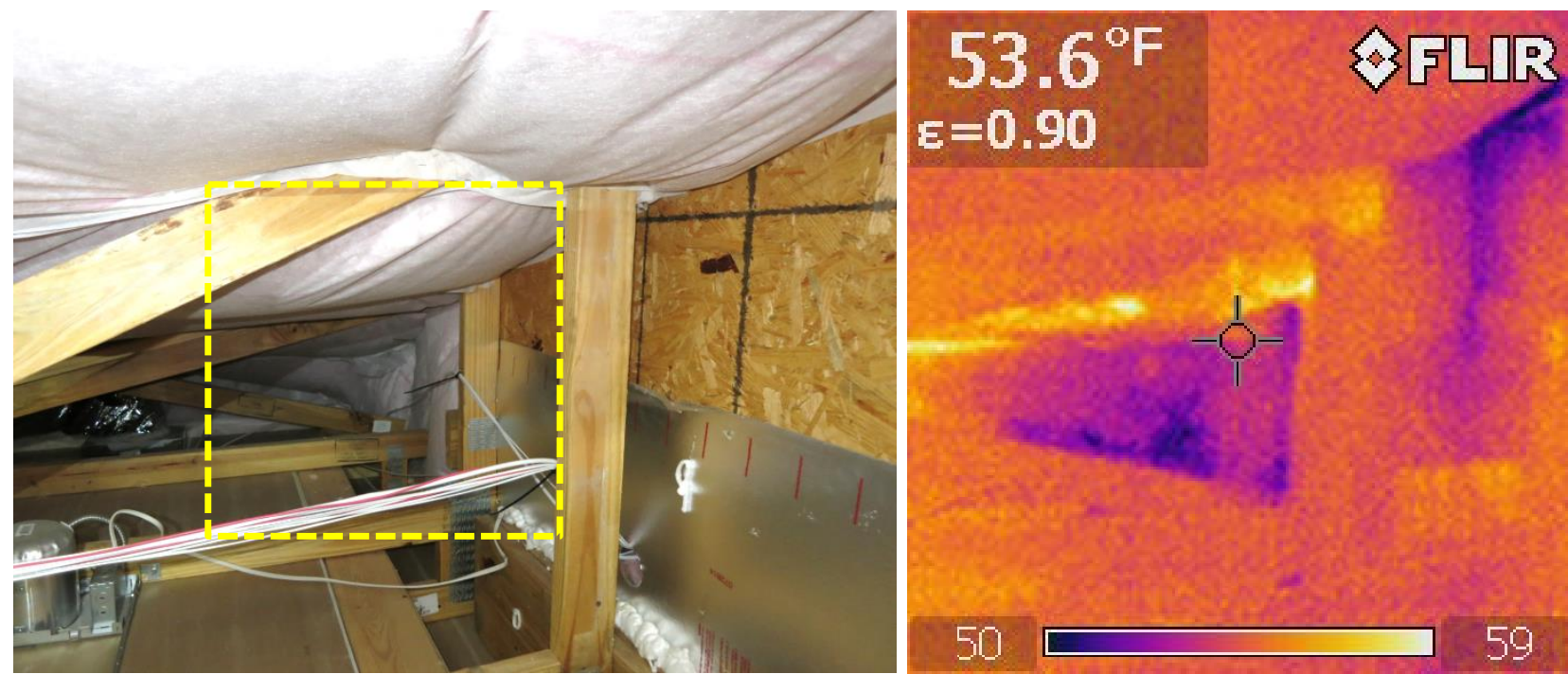

Figure 45. Air leakage at roof-wall interface, and at unconditioned porch attic (Location D)

The presence of roof-wall leakage was originally puzzling, given the use of a self-adhered roof membrane that laps onto the wall sheathing. However, examination of construction photos (taken at Location E; Figure 46) showed that membrane adhesion to the vertical wall surface was not consistent; gaps and openings sometimes occurred. Although this detail would provide excellent service for rain control (assuming shingle lapping of the house wrap onto the roof membrane), it was apparently not sufficient for air barrier detailing. 

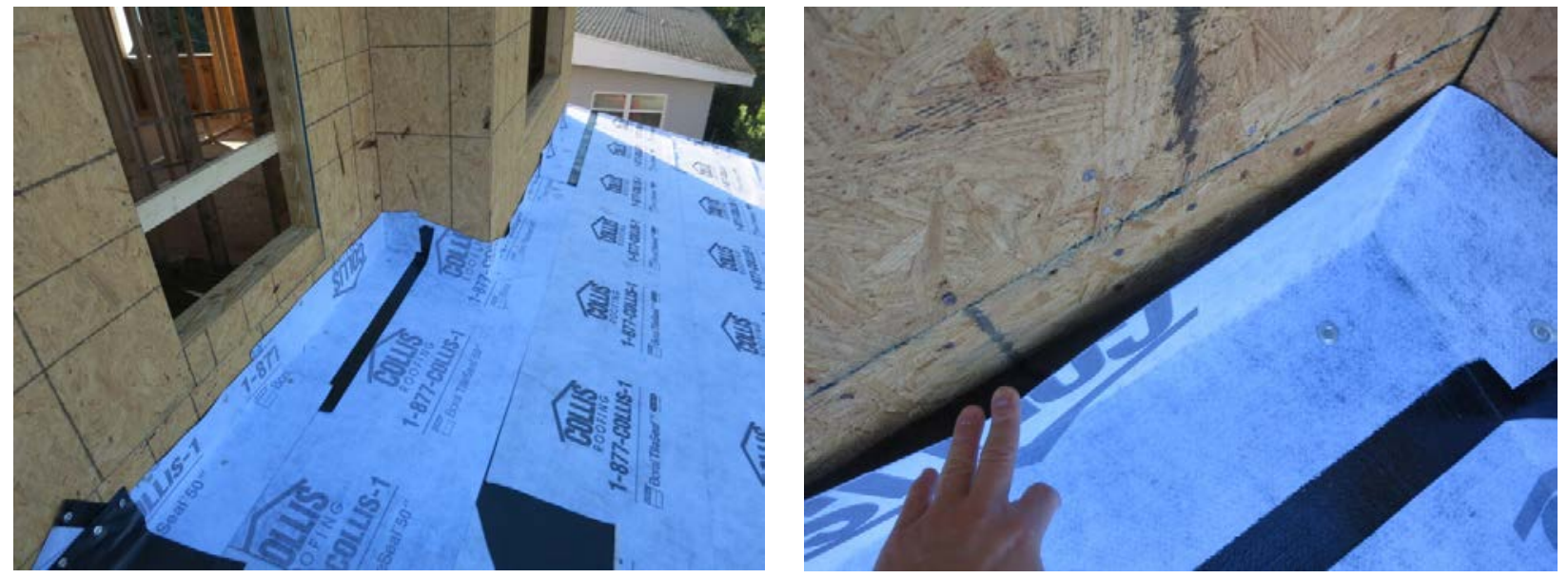

Figure 46. Construction image of roof-wall interface self-adhered membrane (Location E)

The convoluted geometry of the lower attic resulted in a bottleneck (Location F); it was not passable without possible damage to the ductwork in the finished house. Therefore, conditions above the front bedroom were not examined; significant leakage was suspected at the wall to the garage or at the connection to the unconditioned porch (Location $\mathrm{G}$ ).

Overall, the localization of air leakage indicates that more complicated attic geometries, especially roof-wall connections, can be sources of air leakage (given typical construction practices and quality control measures). For instance, the wall to the garage and the wall to the unconditioned porch roofs were sources of leakage. In addition, a self-adhered roof membrane at the roof-wall interface might not provide a robust air barrier connection, depending on adhesion and installation.

\subsubsection{Air Handling Unit Pressure Differential Effects}

Salonvaara et al. (2013) stated that one potential mechanism for transferring high-humidity conditioned attic air to the house main space is pressurization/depressurization effects of the air handling system. The pressure behavior of the upper attic was tested, measuring the $\Delta \mathrm{P}$ across the hatch (Figure 47 left). The upper attic contains the second-floor ductwork (Figure 47 right); the associated air handling unit is in the conditioned space.
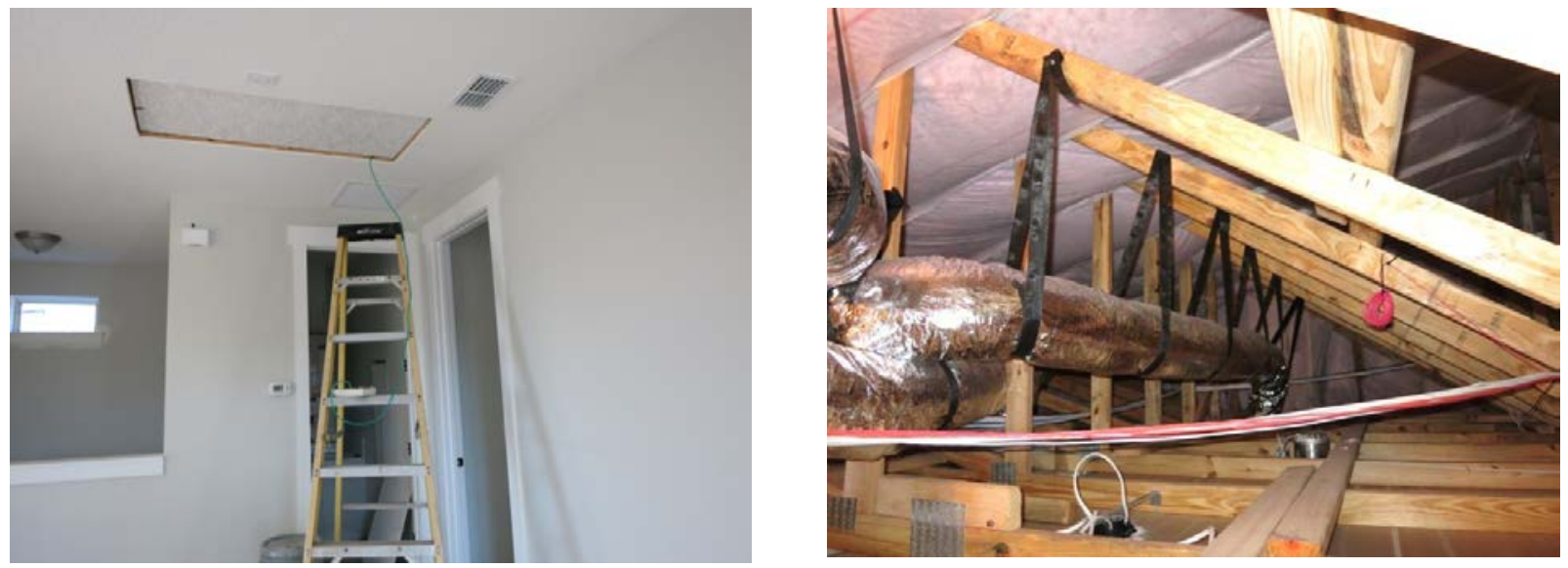

Figure 47. Upper attic $\Delta \mathrm{P}$ measurement (left); ductwork located in upper attic (right) 
The baseline (fan off) measurements of attic pressure (with respect to the main space) varied from $0 \mathrm{~Pa}$ to $-0.1 \mathrm{~Pa}$. The measurements after turning on the air handling unit were essentially unchanged ( 0 Pa typical), indicating that any pressurization or depressurization caused by air handling unit operation in this house is minor. 


\section{Monitoring Results}

\subsection{Boundary Conditions}

Data were collected from November 2014 through August 2015 (for 9 months); this captured a winter (during construction) and the following spring and summer. However, data were not collected from January to mid-February 2015 due to site power problems. Interior and exterior temperatures are plotted in Figure 48. Exterior temperatures include site-measured and airport (Orlando Executive Airport/KORL) data. Interior temperatures include six conditioned attic measurements at three vertical stack pairs and main space (second-floor HVAC return) conditions ("Interior T").

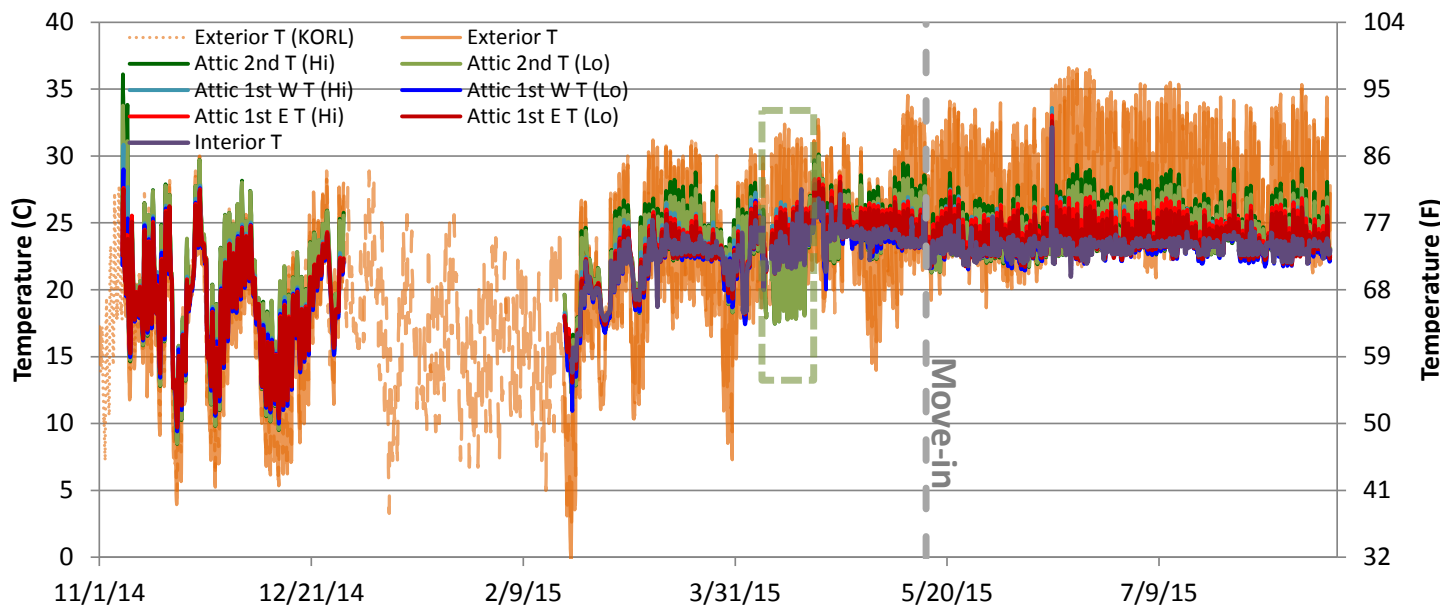

Figure 48. Exterior, attic, and main conditioned space temperatures

There was a temperature anomaly in April 2015, when the second-floor attic ("Attic $2^{\text {nd }} T$ ") temperatures dropped to near-ambient conditions (highlighted in green in Figure 48). This was ascribed to painting work with open windows and an open attic hatch (per the site supervisor).

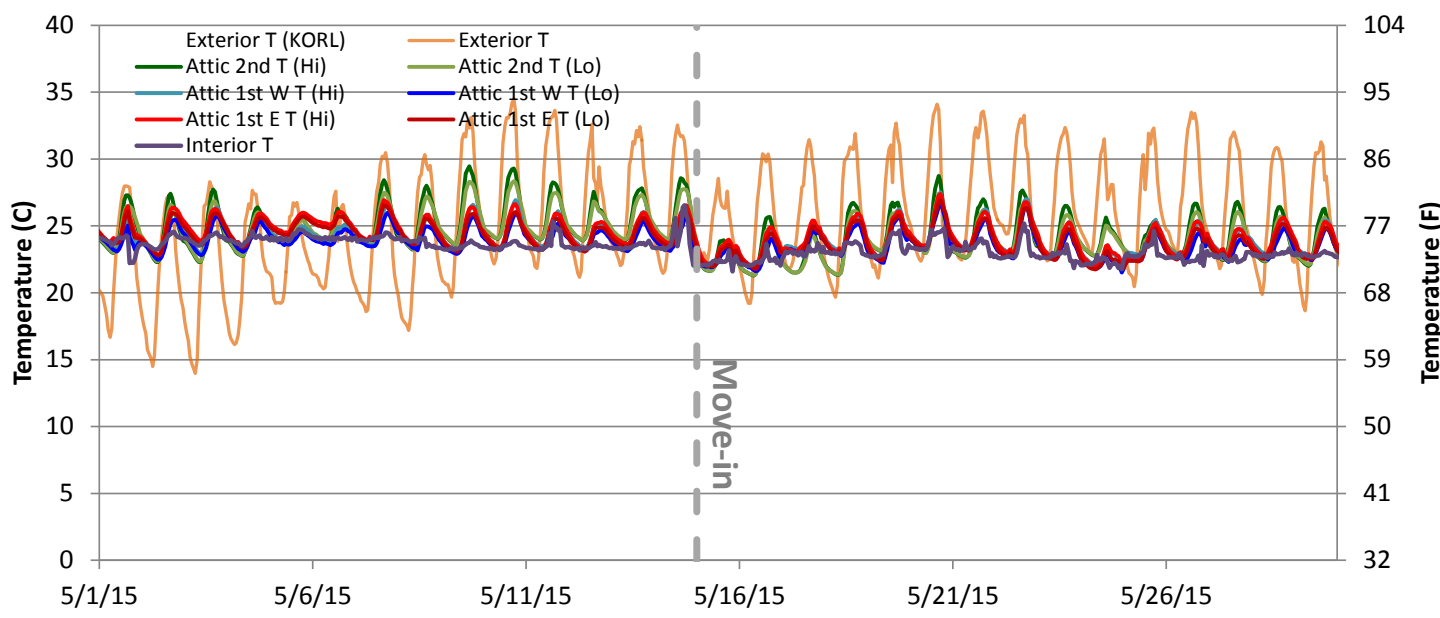

Figure 49. Exterior, attic, and main conditioned space temperatures, May 2015 
The house was unoccupied until mid-May 2015, when the homeowners moved in ("Move-In"); this was accompanied with a drop in interior set point (Figure 49). The second-floor attic ("Attic $2^{\text {nd }}$ T"; both high and low) is often warmer than the first-floor attics; this pattern is particularly pronounced on days with clear conditions during the day (per airport weather station data). This is likely solar gain at the second-floor attic; the first-floor attic is partially shaded by the second floor. Stack effect also likely plays a role.

Monthly heating degree day and cooling degree day data (Base $65^{\circ} \mathrm{F}$ ) for Orlando are plotted in Figure 50; data prior to instrumentation are faded. Winter of 2014-2015 was 497 heating degree days, which is $86 \%$ of normal (536 heating degree days); however, that period was mostly unoccupied conditions.
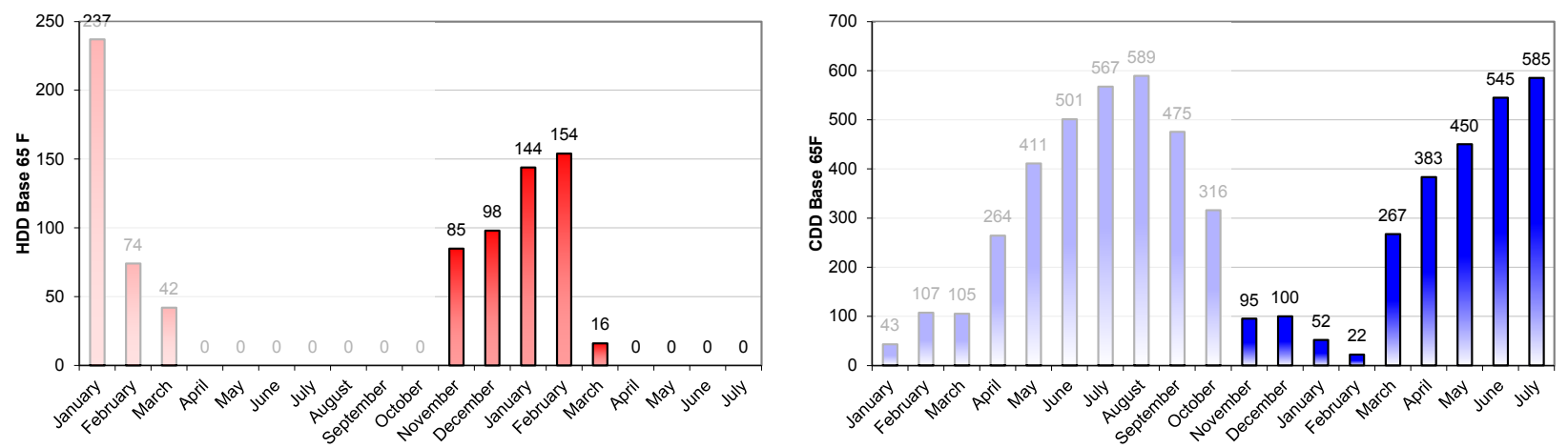

Figure 50. Heating degree days (left) and cooling degree days (right) for Orlando (MCO airport)

Interior RH is plotted in Figure 51; after the data gap (post mid-February 2015). Attic RHs oscillate between very high $(90 \%-100 \%)$ and lower $(75 \%-80 \%)$ levels on a diurnal cycle. This period includes conditioned and unconditioned periods; the thermostat was apparently set for cooling only, and the system was operated intermittently (see interior temperatures in Figure 48). After the cooling system was put in operation, interior space RH dropped slowly over time (from roughly $70 \%$ to $50 \%-60 \%$ ). However, attic peak RHs still cycled up to the $90 \%-100 \%$ range.

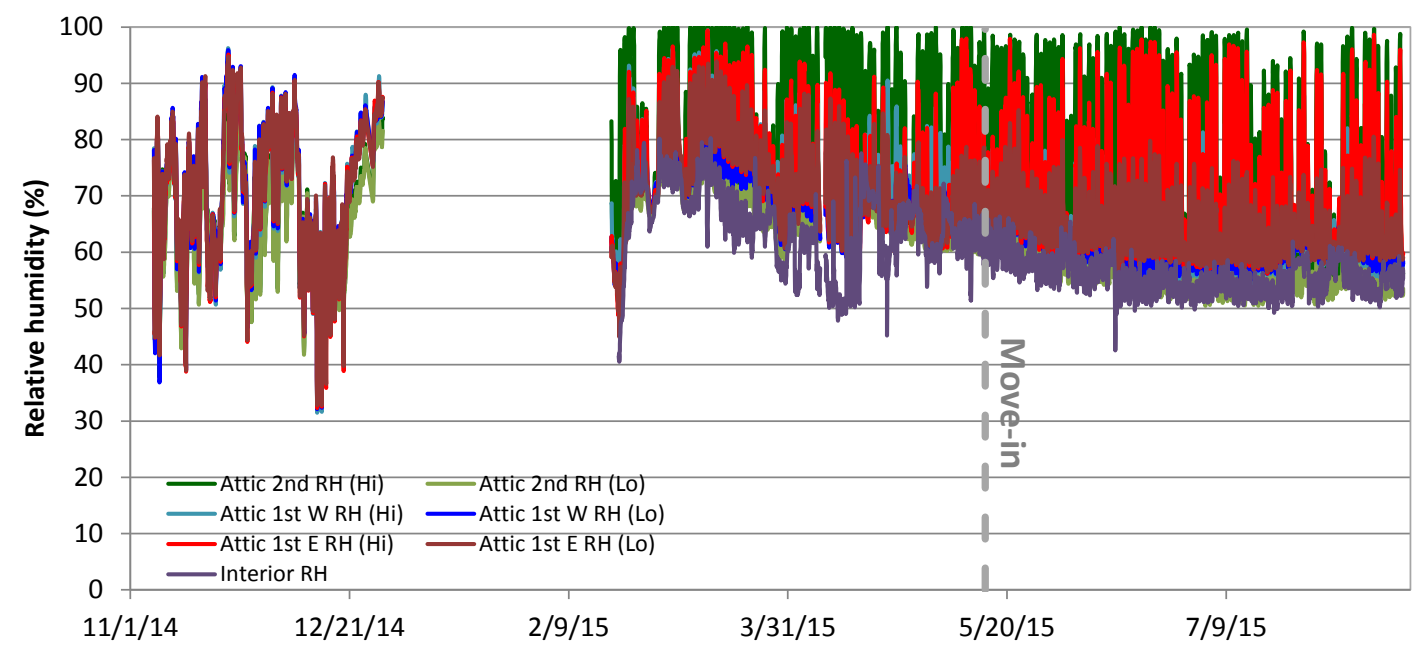

Figure 51. Attic and main conditioned space RH 
A detail of July RH data (Figure 52) shows that interior RHs are well controlled (50\%-60\%), but several attic sensors have daily peaks up to $90 \%-100 \% \mathrm{RH}$. The highest $\mathrm{RH}$ readings are associated with sensors capturing the upper one-third of attic air conditions (Hi sensors). In contrast, lower one-third (Lo) sensors have less pronounced peaks. These patterns are discussed further below.

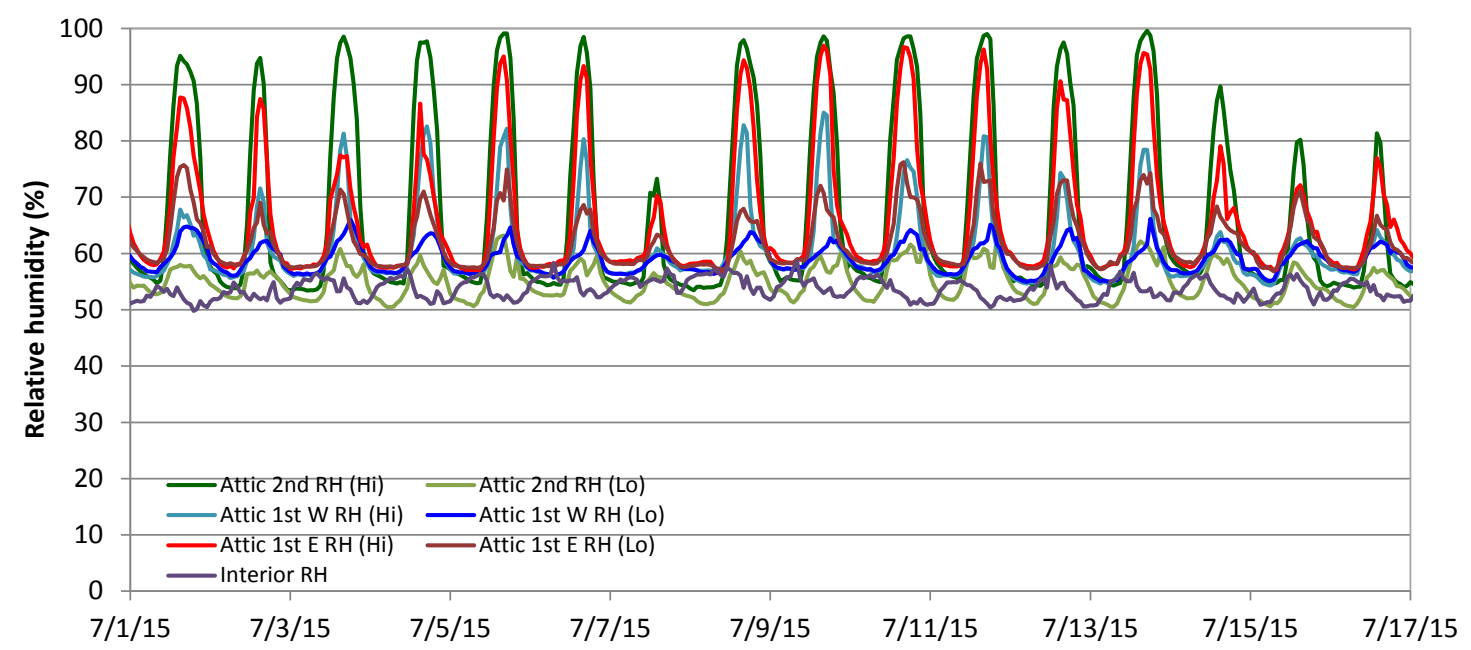

Figure 52. Attic and main conditioned space RH, July 2015 detail

Further insight can be gleaned by plotting moisture conditions in terms of absolute air moisture content (dew point), which removes temperature-RH effects, and allows comparisons with outdoor conditions (Figure 53). The initial data (pre-January 2015) show identical conditions between interior and exterior dew points; after resumption of data collection (February 2015), interior dew points are higher than exterior. The site supervisor confirmed that drywall mudding and interior painting occurred during the missing data period (i.e., construction moisture created interior moisture loads). Similar to RH plots, interior conditions are drier than attic conditions and show a gradual decline over the cooling season.

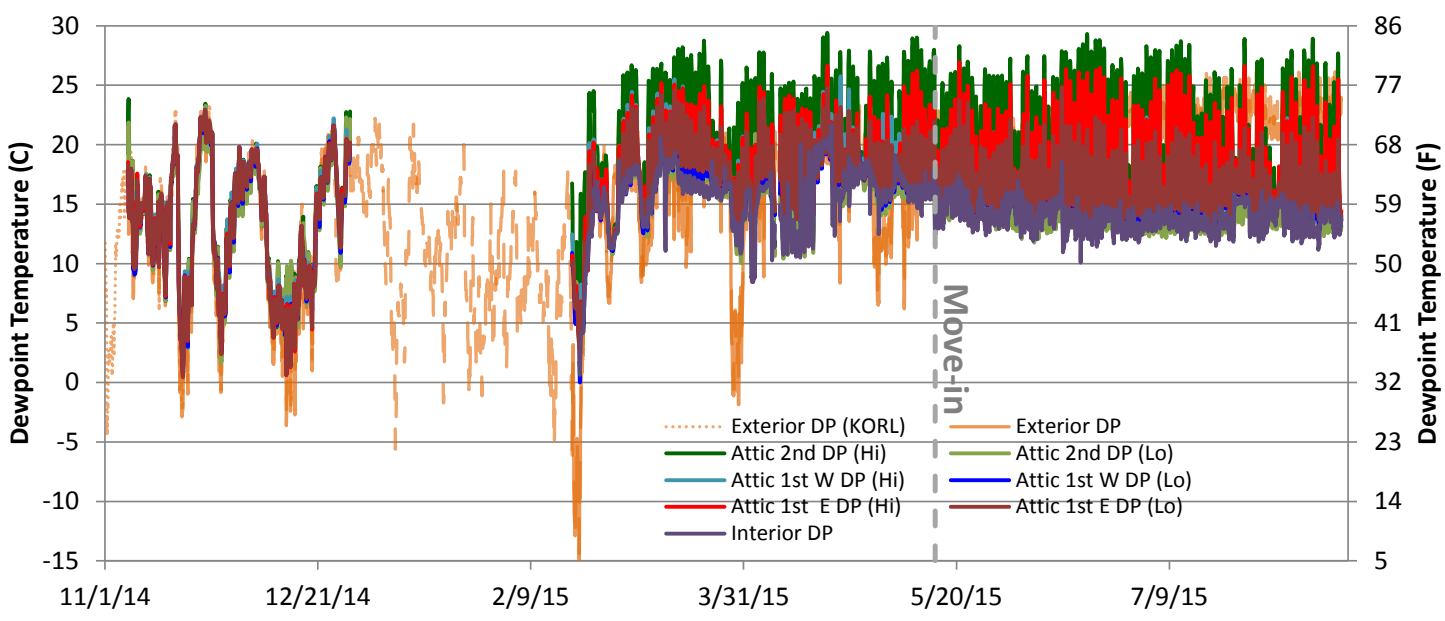

Figure 53. Exterior, attic, and main conditioned space dew point temperatures 
A close-up of March 2015 dew point data is shown in Figure 54: interior dew points exhibit a diurnal cycle; the peaks in these data are typically at 5-6 p.m., which is a rough match to sunset.

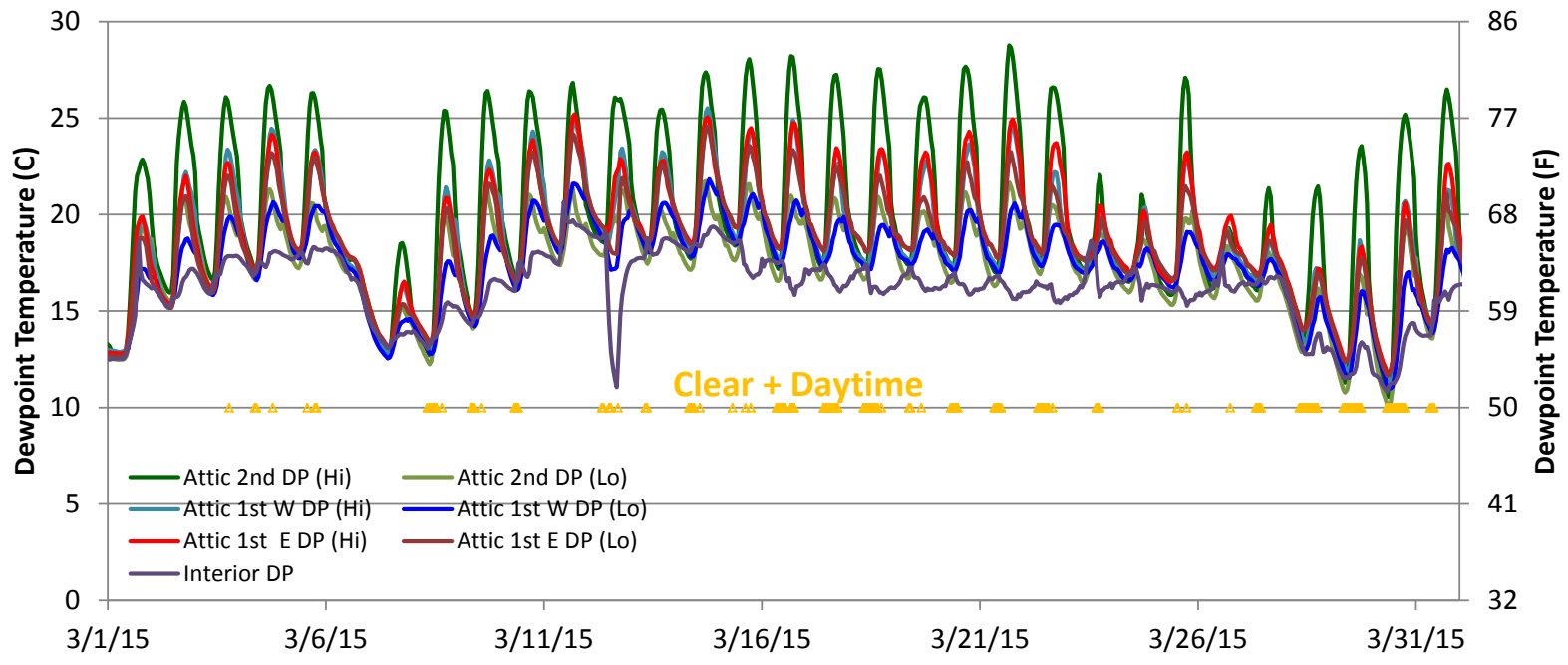

Figure 54. Attic and main space dew point temperatures (March 2015) with sky conditions

The diurnal moisture cycling also highlights differences between the three attic locations; the highest dew points are seen at attic $2^{\text {nd }}$ (high). In any given high/low pairing, the high measurement has a higher dew point. These observations are consistent with moisture stratification and buoyancy within the attics, as described by Lstiburek (2014). The high dew points in the second-floor attic are due to a combination of greater airtightness (as measured previously), and location at the highest point of the conditioned space. The dew points of attic $1^{\text {st }}$ west (W) are the lowest and show little stratification (high/low difference). It is the shortest attic, with only $19 \mathrm{in}$. between the high and low sensors. Interior dew points are the driest, because this space receives direct space conditioning (and therefore dehumidification during cooling).

The diurnal cycles are not consistent day to day; some days have much more pronounced dew point spikes. Weather data (from KORL) were plotted with marker points on hours with "Clear" sky conditions during daylight hours ("Clear + Daytime"; gold dots) in Figure 54. This figure shows days with minimal dew point spikes were typically overcast conditions (e.g., March 24 and March 25). This is consistent with dew point rise being caused by moisture driven out of the roof sheathing by solar gain and temperature rise.

This pattern is also seen in summertime data, such as an August excerpt (Figure 55). Large dew point spikes typically coincided with clear daytime conditions. The same relative attic dew point patterns are seen. The effect of solar gain could also be gauged by plotting roof sheathing temperature.

Overall, the boundary condition measurements show that the upper/second-floor attic has the highest risk of cold-weather condensation issues, because it has the highest dew points (air moisture content) from construction moisture. This is consistent with the upper/second-floor attic being (a) a relatively airtight and (b) located at the top of the conditioned space (i.e., moisture 
stratification). In addition, interior moisture loading is minimal before the data gap but is then significant (some 100\% RH conditions) after the gap due to construction moisture.

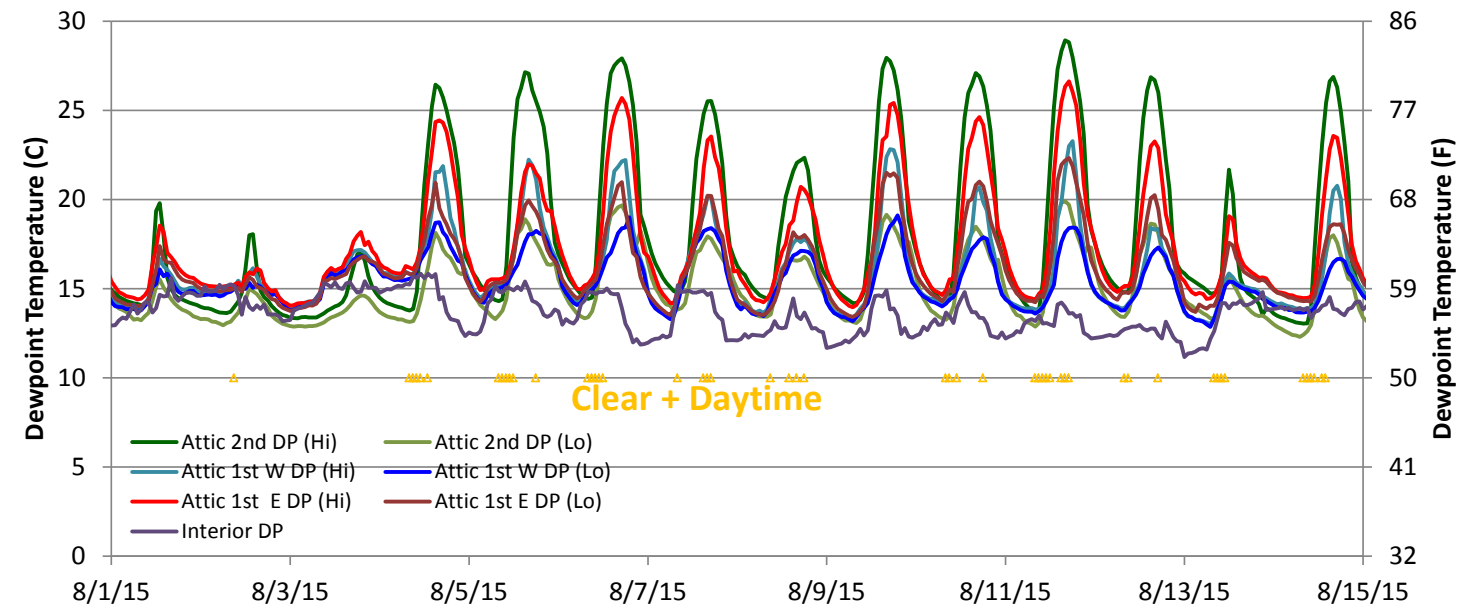

Figure 55. Attic and main space dew point temperatures (August 2015) with sky conditions

\subsection{Dew Point and Vapor Pressure Gradients}

Interior and exterior absolute air moisture contents (in the form of dew point temperature) were graphed in Figure 56 to demonstrate the direction of the moisture vapor pressure gradient. Representative periods from the spring and summer are also plotted in the figure.

Figure 56 shows typical March dew point conditions, including the previously described diurnal cycling and attic stratification. Exterior dew point is consistently lower than interior conditions, but there is significant overlap. March 2015 was early after close-in, so interior dew points likely reflect construction moisture retained inside.

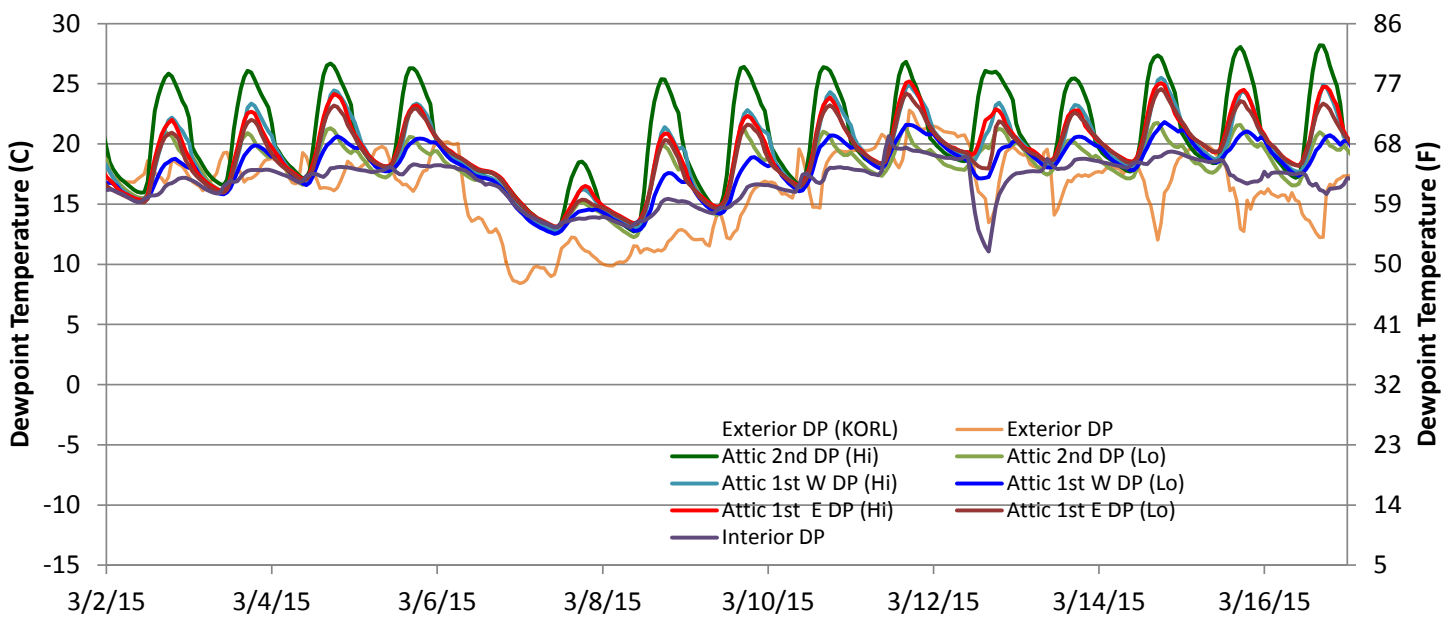

Figure 56. Interior and exterior dew point temperatures, March 2015 detail

Typical August dew point conditions are shown in Figure 57; exterior dew point is consistently higher (wetter) than interior main space conditions and typical attic conditions. However, the 
daily dew point spikes are higher than exterior conditions. This indicates that high moisture in unvented attics is not solely due to air leakage; interior-sourced moisture and adsorbing and desorbing moisture play an important role.

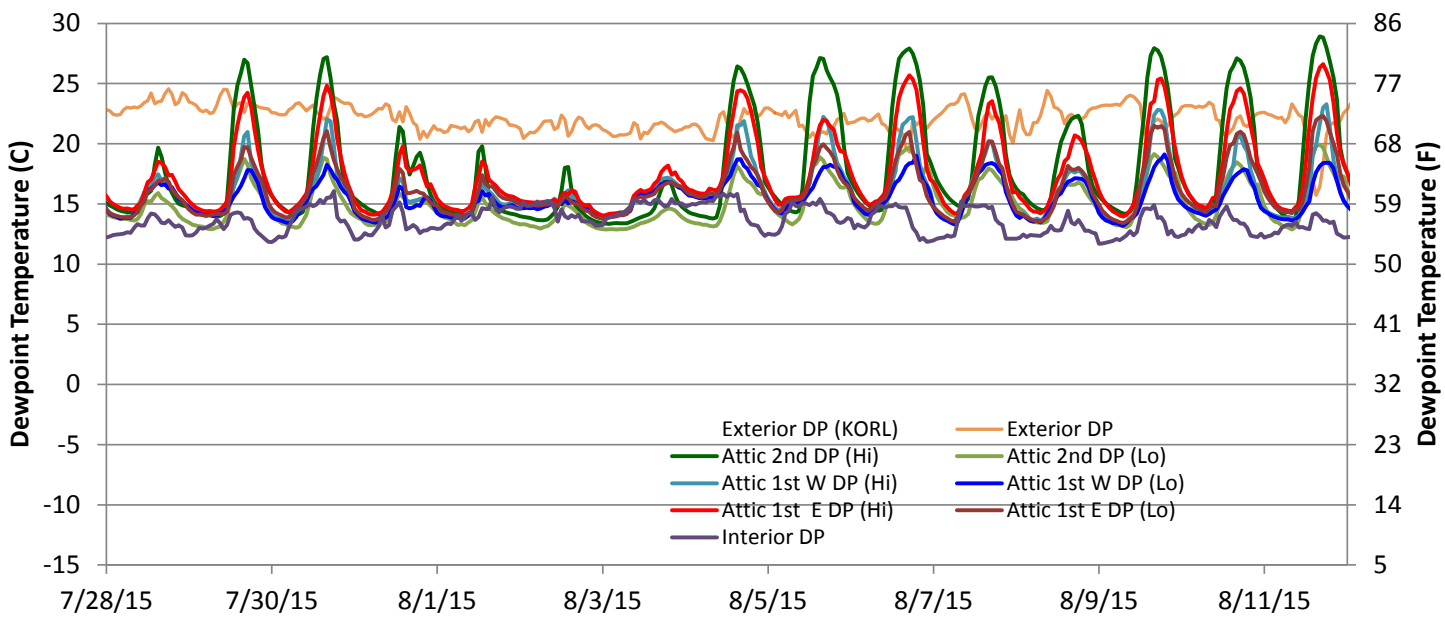

Figure 57. Interior and exterior dew point temperatures, August 2015 detail

The air leakage measurements showed that the second-floor attic is much more airtight than the first-floor attic (35 in. ${ }^{2}$ EqLA versus 196 in. $^{2}$ EqLA). This relationship suggests that the firstfloor attic could be at risk of gaining exterior-sourced moisture in the summertime. However, the summertime dew point comparisons do not show any distinct signal; the diurnal cycling of moisture adsorbing and desorbing from the roof sheathing dominates interior dew points. The second-floor attic shows the highest dew points (upper/high sensor location).

\subsection{Roof Monitoring Location Summary}

Although the instrumentation setup was described previously, the monitoring locations are shown again for reference in Figure 58 on a house isometric. 


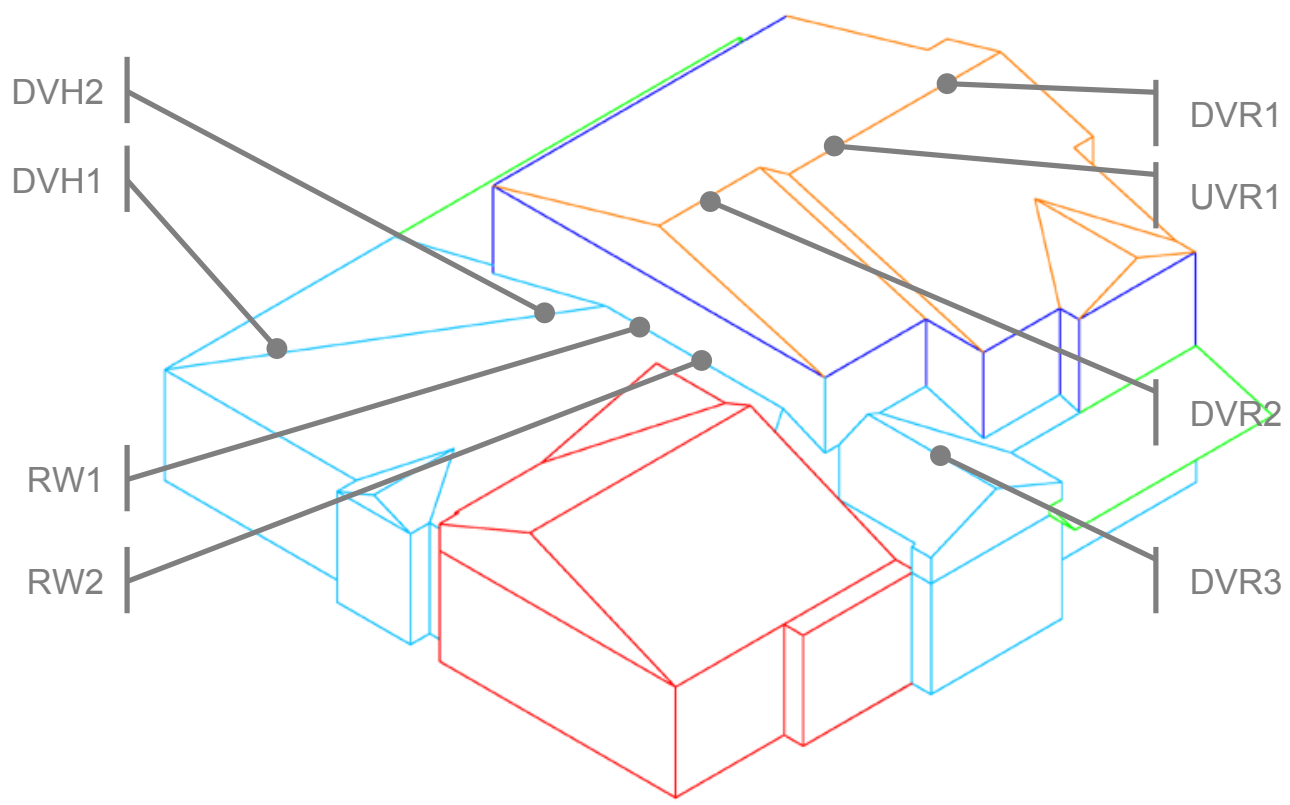

Figure 58. Roof instrumentation locations on isometric of house

Table 7 cross-references the short names to the full assembly names and notes the attic where the monitoring package is located.

Table 7. Roof Instrumentation Location Summary, with Attic Location

\begin{tabular}{c|c|c|c}
\hline Assembly & Short Name & Attic & Notes \\
\hline Unvented Ridge 1 & UVR1 & Upper/2 & Unvented comparison \\
\hline Diffusion Vent Ridge 1 & DVR1 & Upper $/ 2^{\text {nd }}$ & \\
Diffusion Vent Ridge 2 & DVR2 & Upper/2 & \\
Diffusion Vent Ridge 3 & DVR3 & Lower $\left(\right.$ West) $/ 1^{\text {st }}$ & Small west-facing attic \\
Diffusion Vent Hip 1 & DVH1 & Lower (Main) $/ 1^{\text {st }}$ & Lower hip location \\
Diffusion Vent Hip 2 & DVH2 & Lower (Main) $/ 1^{\text {st }}$ & Upper hip location \\
Roof-Wall 1 & RW1 & Lower (Main) $/ 1^{\text {st }}$ & Downhill area \\
Roof-Wall 1 & RW2 & Lower (Main) $/ 1^{\text {st }}$ & No downhill area \\
\hline
\end{tabular}

\subsection{Unvented Ridge Measurements}

Measurements for the unvented (nondiffusion vent) roof ridge (UVR1) are plotted in Figure 59; the ridge is located in the second-floor/upper attic. In this plot and those that follow, roof sheathing and wafer sensor MC measurements are plotted on the left-hand axis; RH measurements at the ridge/peak are plotted on the right-hand axis in dark green. 


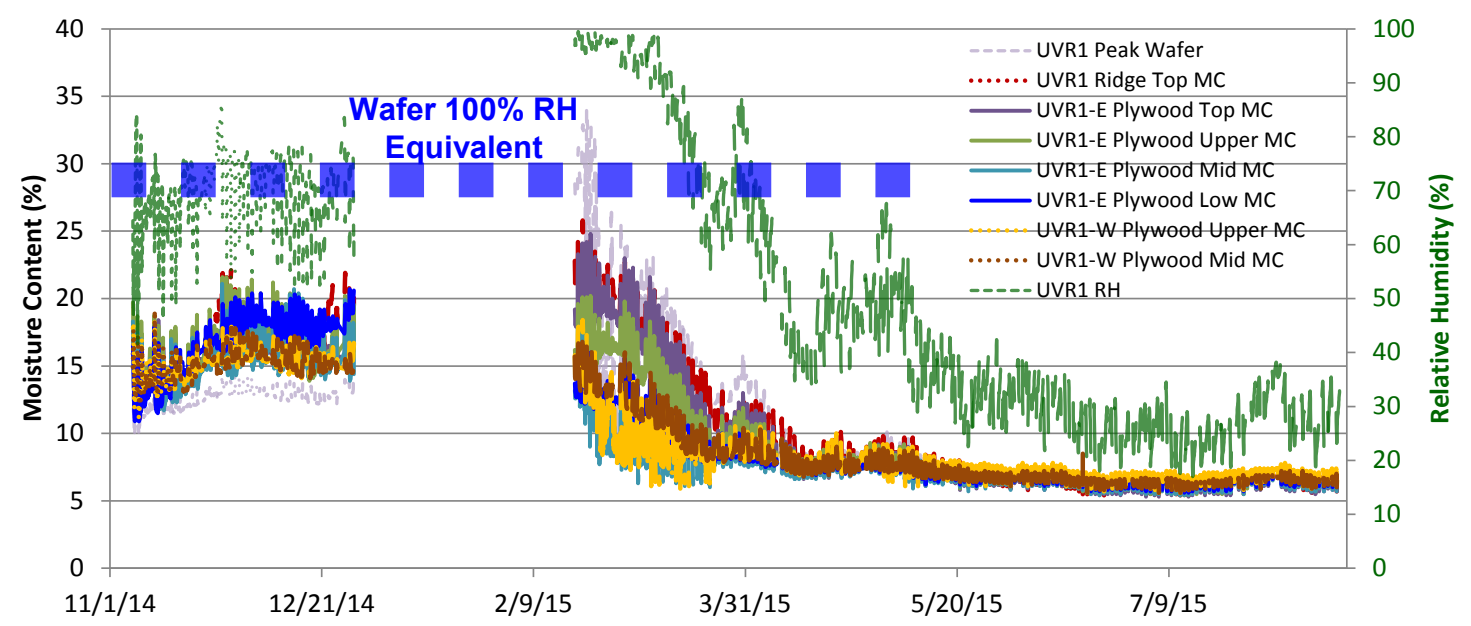

Figure 59. Unvented roof (UVR1) MC and RH measurements (second-floor attic)

Prior to the data gap (with low interior moisture conditions), wood MCs remained mostly below $20 \%$ with corresponding RHs. But after the gap (high interior moisture), significant moisture accumulation occurred at the ridge. This is indicated by wood MCs near the ridge in the $20 \%-$ $25 \%$ range, wafer measurements higher than $30 \% \mathrm{MC}$, and ridge $\mathrm{RH}$ in the $95 \%-100 \%$ range. These high moisture conditions correlate with some of the coldest days of the winter (Figure 48). As outdoor temperatures increased, all these MCs fell. By early May 2015, all wood MCs were lower than $10 \%$ (completely safe range), and RHs were in the $30 \%-50 \%$ range. Dry conditions were seen throughout the remainder of the summer.

The ridge wafer measurements can be related to qualitative moisture conditions. In a previous calibration (Ueno and Straube 2008), the wafer sensors came to equilibrium with $100 \% \mathrm{RH}$ conditions (air in a closed container over water) at 28\%-30\% MC (blue dotted line in Figure 59). However, immersing the sensors in liquid water increased their MC to the $40 \%-45 \%$ range. Therefore, measurements higher than the 100\% RH-equivalent range (28\%-30\%) may have indicated liquid water condensation, and higher than $40 \%$ strongly indicated liquid water wetting. The measurements in the unvented roof showed possible condensation followed by drying in the springtime.

\subsection{Diffusion Vent Ridge Measurements}

$\mathrm{MC}$ and RH measurements for the diffusion vent roof ridges are plotted in Figure 60 (DVR1, upper attic), Figure 61 (DVR2, upper attic), and Figure 62 (DVR3, lower attic).

Although the MCs increased after the data gap (i.e., cold weather; addition of interior construction moisture), accumulation was nowhere near levels seen in UVR1 (almost all were lower than 20\%). Peak RHs were also drier: they did not hit the 95\%-100\% levels seen in UVR1. The MCs dropped in the spring, correlating with warmer weather; all were much lower than $10 \%$ during the summer. The RH levels did not show such a steep drop into the spring as UVR1. RH levels oscillated noticeably at the ridge compared to UVR1. 


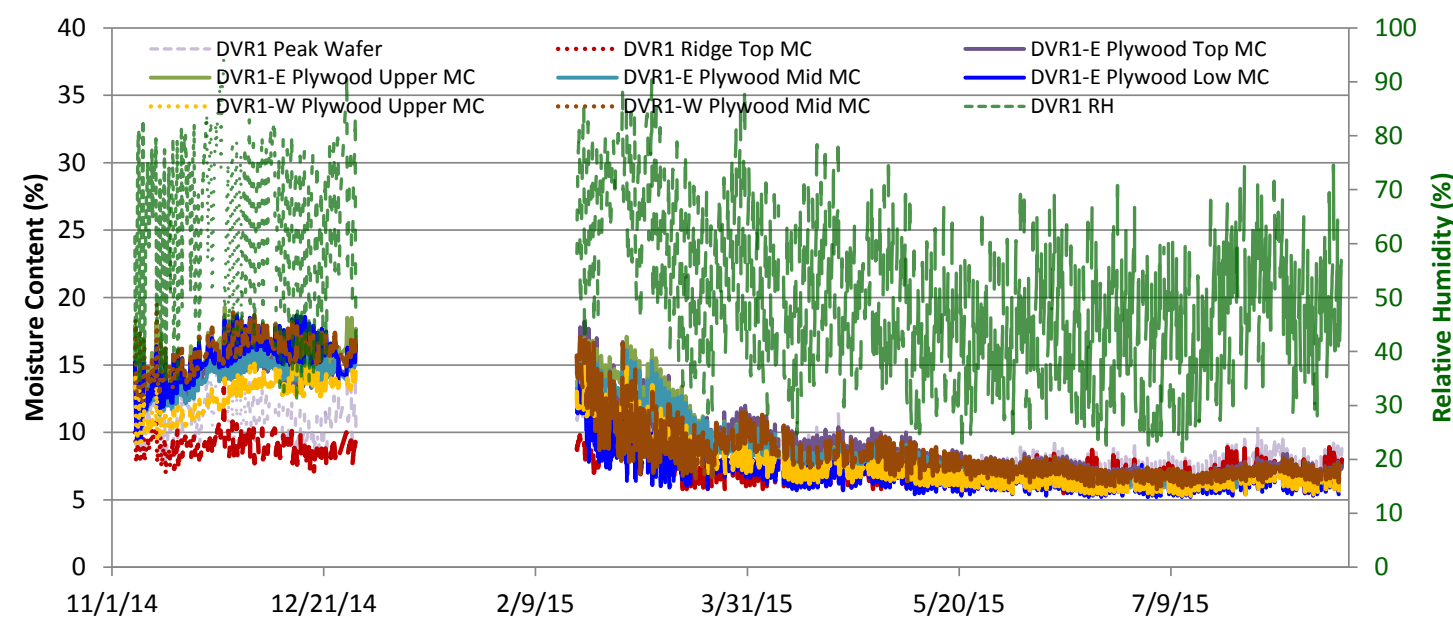

Figure 60. Diffusion vent ridge (DVR1) MC and RH measurements (upper/second-floor attic)

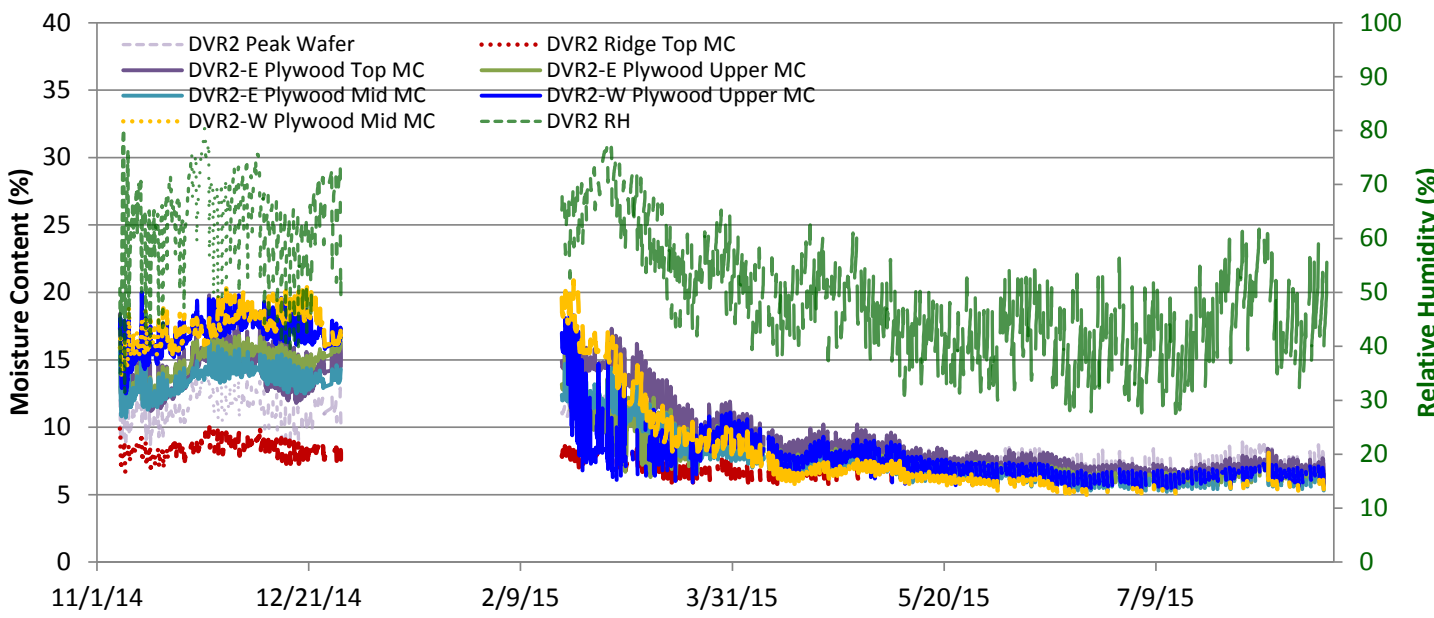

Figure 61. Diffusion vent ridge (DVR2) MC and RH measurements (upper/second-floor attic)

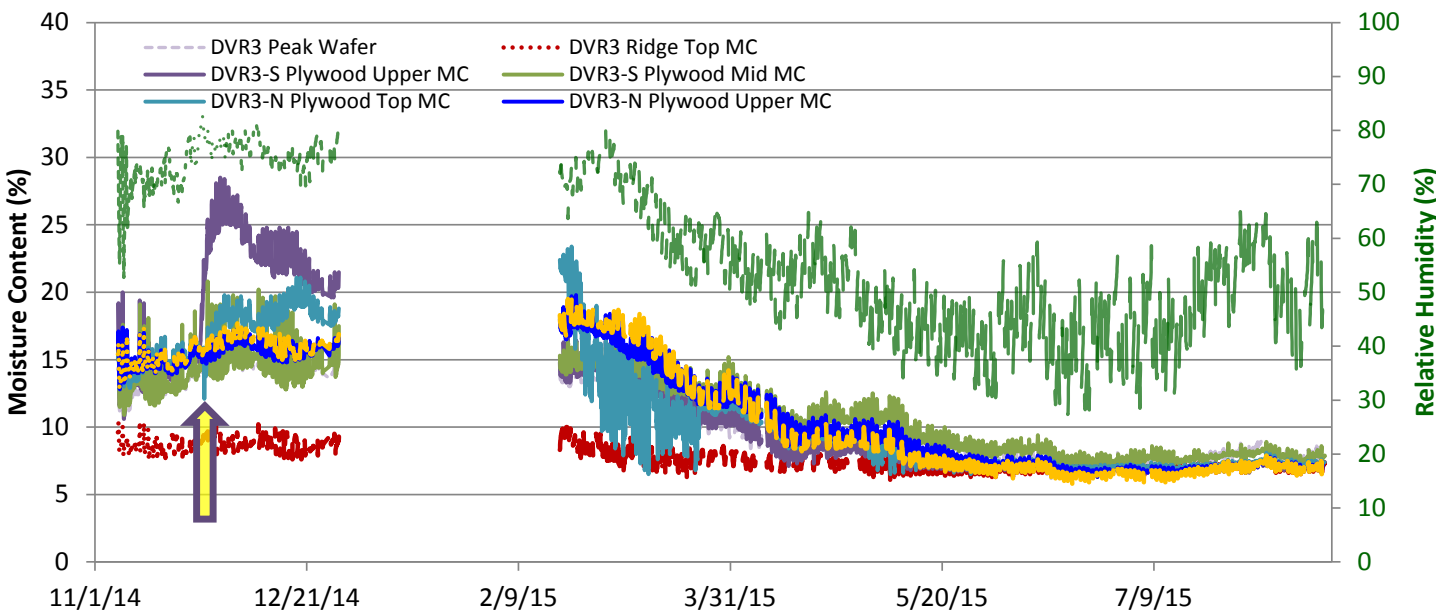

Figure 62. Diffusion vent ridge (DVR3) MC and RH measurements (lower/first-floor attic) 
The ridge top MCs (red dotted data) are among the driest in the diffusion vent roofs but one of the wettest in the unvented roof (Figure 59). This is consistent with interior-sourced moisture accumulation at the ridge (in UVR1) versus high localized drying directly under the permeable roof membrane (in DVR1/2/3).

Interior measurements show that the second-floor/upper attic has much higher dew points than the first-floor/lower west attic (Figure 53 and Figure 54). The MC and RH measurements were compared to determine if a discernable difference could be seen between DVR1 and DVR2 (upper attic) and DVR3 (lower attic). No clear pattern was seen; in fact, MCs and RHs are arguably higher in DVR3. DVR3's performance relative to DVR1 and DVR2 is discussed further in Sections 4.8.2 and 4.8.3.

One anomaly was seen at the south plywood upper MC of DVR3 (yellow/purple arrow in Figure 62): MC jumped suddenly in late November 2014; the moisture then dried to safe levels in the spring. This is suspected to be rain leakage; a thunderstorm in the weather data coincided with the jump. However, MC jumps (i.e., further water leakage) did not recur.

\subsection{Diffusion Vent Hip Measurements}

MC and RH measurements for the diffusion vent hips are plotted in Figure 63 (DVH1, lower measurements) and Figure 64 (DVH2, upper measurements). Both of these packages are in the lower/first-floor attic.

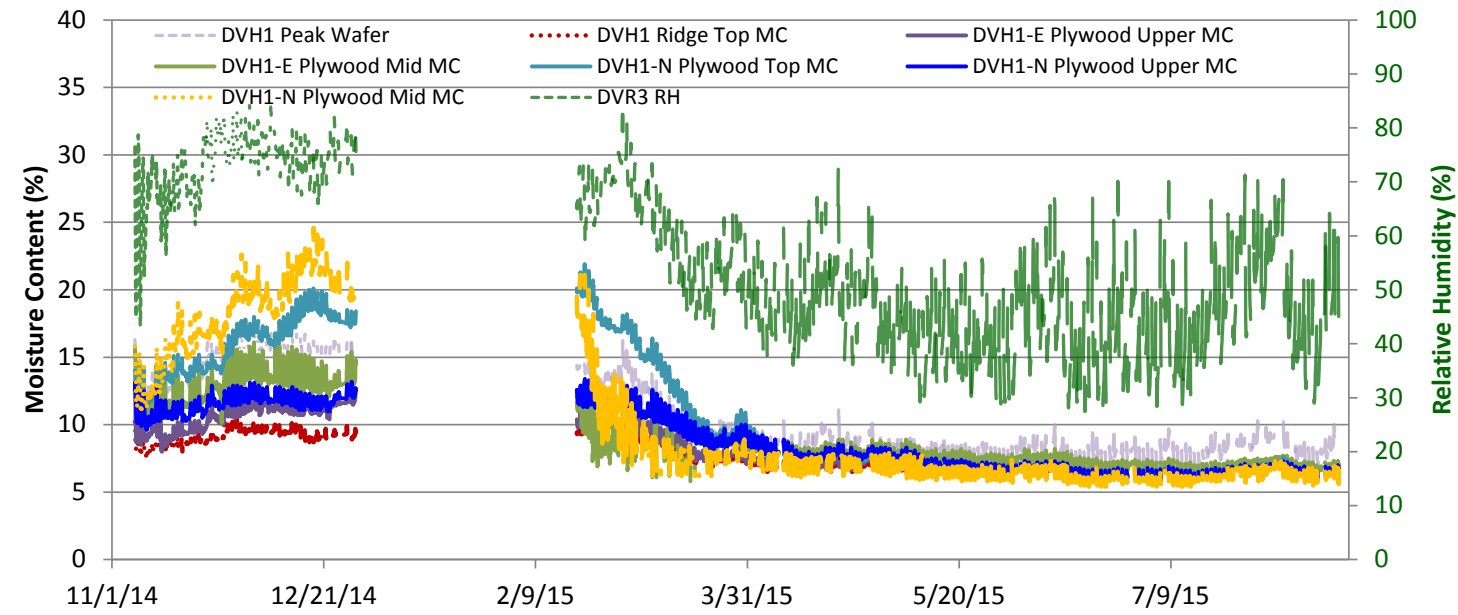

Figure 63. Diffusion vent roof hip (DVH1; lower) MC and RH measurements 


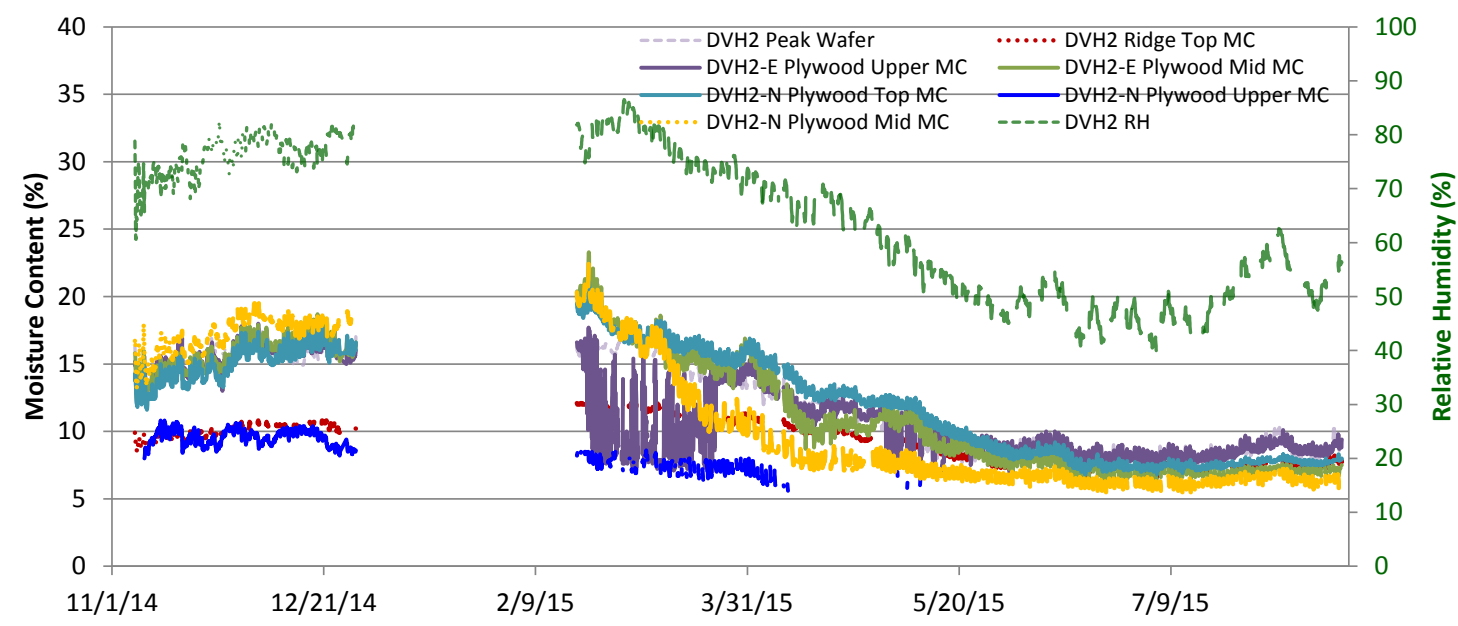

Figure 64. Diffusion vent roof hip (DVH2; upper) MC and RH measurements

A similar pattern to the diffusion vent ridges was seen with high MCs after the data gap, but they were not as wet as the unvented roof. Peak MCs were in the $18 \%-23 \%$ range; MCs then dried as outdoor temperatures increased. RH measurements followed a similar pattern; peak RHs were about $85 \%$.

One anomaly was that the "midheight" sheathing MCs (dotted yellow) were among the wettest before and after the data gap (contrary to the pattern in other roofs). However, as the roofs dried into the spring, the order of MCs returned to the familiar top-down pattern.

Ridge top MCs (red dotted line) were among the driest, showing localized drying directly under the vapor-permeable ridge membrane.

\subsection{Roof-Wall Interface Measurements}

$\mathrm{MC}$ and $\mathrm{RH}$ measurements for the roof-wall interfaces are plotted in Figure 65 (RW1, significant downhill roof area below) and Figure 66 (RW2, minimal downhill roof area below). Both are located in the lower attic. The roof-wall conditions are measured because this location has no diffusion vents, but it is the top termination of rafter bays (and therefore has the potential for moisture accumulation). The difference in downhill area was that moisture adsorption and desorption from the sheathing may affect the degree of moisture accumulation at the ridge.

Similar patterns were seen of higher wood MCs after the data gap, which then dried in the spring. However, absolute values of MCs were higher more than $20 \%$ higher than the previous diffusion vent measurements. This might be ascribed to either the geometry (no diffusion vent) or possibly shading issues (discussed in Section 4.8.3). Similarly, RH levels were slightly higher than previous diffusion vent measurements.

No clear differentiation was seen between the two measurements, which would indicate the effect of downhill contributory roof area. RW1 shows a clear pattern of vertical moisture stratification in the springtime MC measurements. 


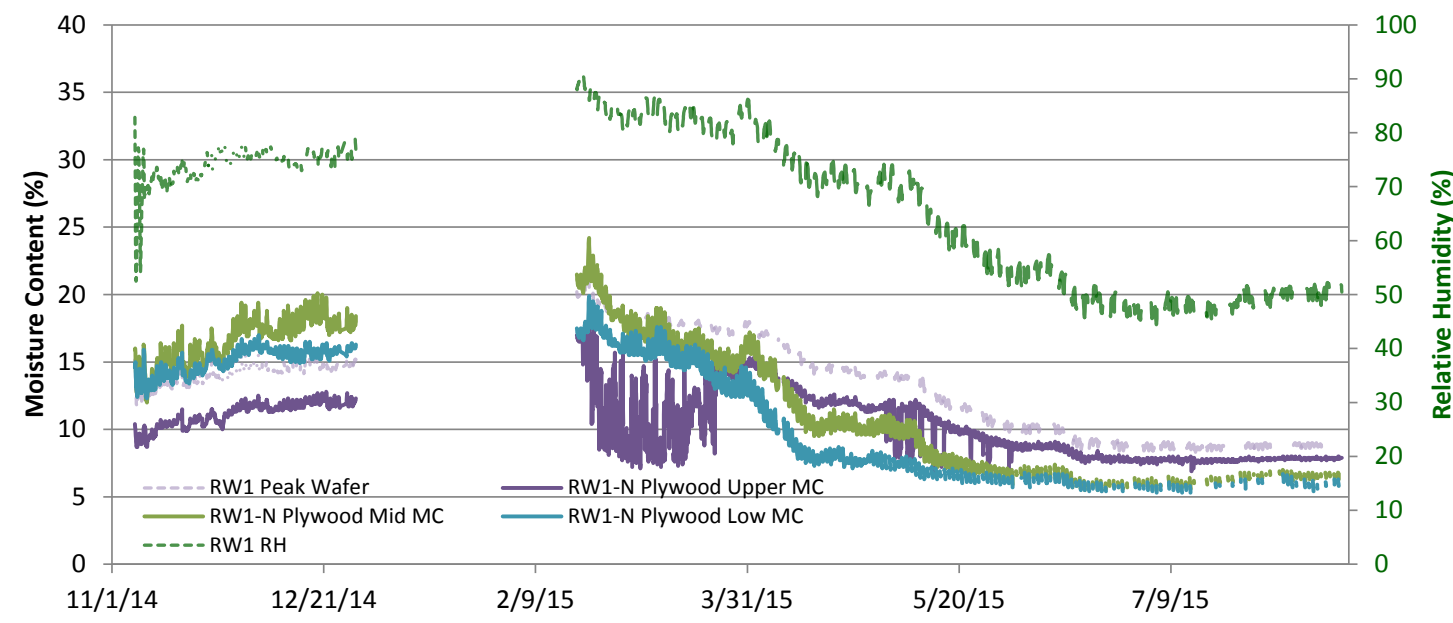

Figure 65. Roof-wall (RW1) MC and RH measurements (downhill area)

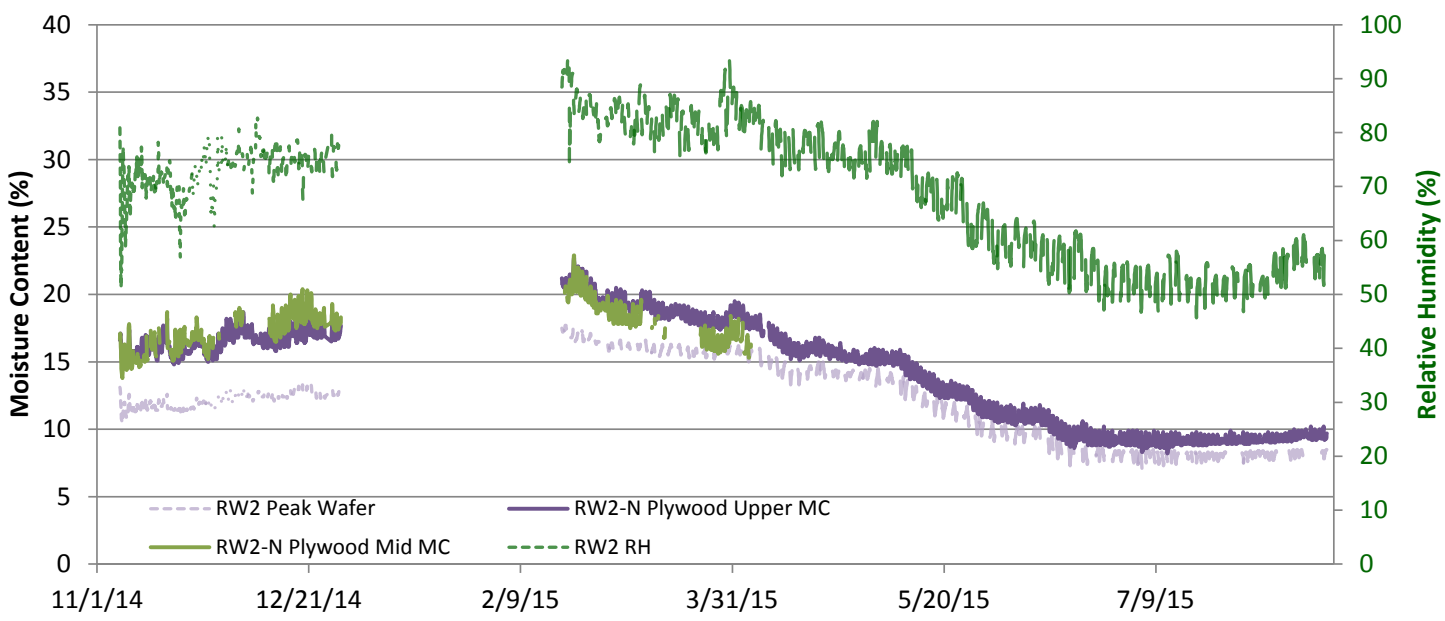

Figure 66. Roof-wall (RW2) MC and RH measurements (no downhill area)

\subsection{Roof Measurement Summary and Analysis}

\subsubsection{Diffusion Vent versus Unvented Roof Comparison}

To understand the relative behaviors of the diffusion vent roof and a conventional unvented roof, key results from DVR1 and UVR1 were plotted side by side in Figure 67. These two roofs are directly adjacent on the same ridge. The plot includes the MC of the ridge wafer sensor (left hand axis), and RH at the ridge (right-hand axis).

Before the data gap (early winter 2014), the two roofs were comparable; the unvented roof had slightly higher moisture levels. After the data gap (winter-spring 2015), after interior moisture loading and cold outdoor temperatures, the two roofs showed a marked difference. The wafer sensor indicated possible condensation risks in the unvented roof with long periods of high $\mathrm{RH}$ $(95 \%-100 \%)$. The diffusion vent roof stayed drier; only a few winter hours exceeded $80 \% \mathrm{RH}$, and wafer measurements were well in the safe range (lower than $15 \% \mathrm{MC}$ ). 
As outdoor temperatures increased, the unvented roof dried rapidly. This is consistent with a vapor-impermeable exterior layer (self-adhered membrane) and a strong temperature gradient, which drove moisture downward and thus dried the roof. The diffusion vent roof also showed a drying pattern during the spring, but RHs remained slightly higher in the spring and summer. This is because the diffusion vent allowed vapor communication with the exterior, which was at a higher dew point than the interior.

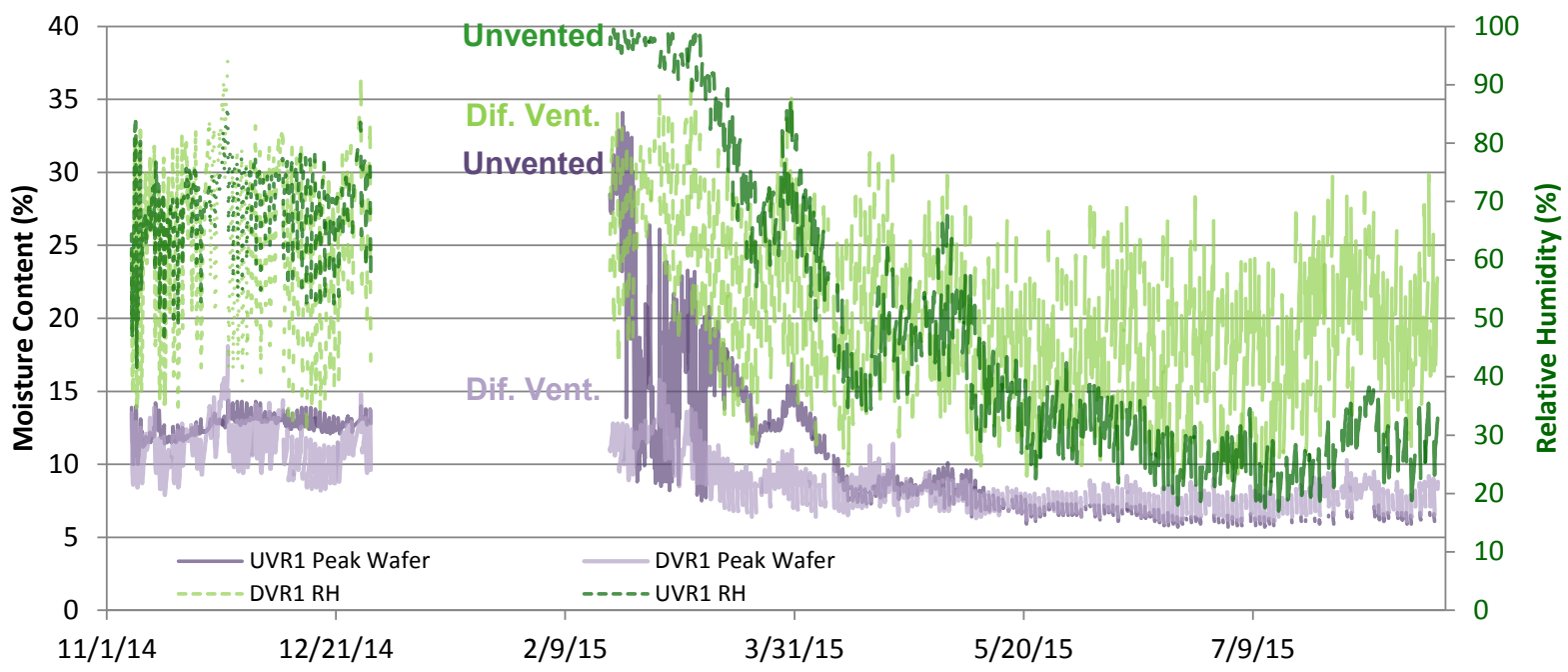

Figure 67. Comparison of unvented (UVR1) and diffusion vent (DVR1) ridge wafer MC and RH

\subsubsection{Peak Relative Humidity, Wafer Moisture Content, and Wood Ridge Moisture Content Data Distributions}

The field monitoring work covered eight roof assemblies, so presenting results across all roofs is difficult. To distill the data into a more understandable form, results are presented as whisker and box plots that show the overall range and distribution of measured MCs. The whisker and box plots show median (center of box), lower and upper quartile of data (extent of box), and maximum/minimum (lines extending from box).

Figure 68 shows the distribution of ridge RH measurements; the unvented roof(UVR1) is the only one that reaches $100 \% \mathrm{RH}$. The diffusion vent roofs are demonstrably drier than the unvented roof. Most of the roofs have hours that exceed $80 \% \mathrm{RH}$; however, given the discontinuity (gap) in the data, an ASHRAE 160 analysis (ASHRAE 2009, 2011) does not provide useful information based on a 30-day rolling average.

Therefore, the number of hours exceeding $80 \% \mathrm{RH}$ is shown in Table 8: it includes the number of hours and the percentage of the total recording period higher than $80 \% \mathrm{RH}$. It shows that most diffusion vent ridges had minimal $(0 \%-3 \%)$ time higher than $80 \% \mathrm{RH}$, while the unvented roof had significant (13\%) time higher than that level. However, several roofs (DVH2, RW1, and RW2) had extended periods higher than $80 \% \mathrm{RH}$; they also had distributions on the high end of the scale (Figure 68). The reason for this behavior is covered in more detail below. 
Table 8. Summary of Ridge/Peak RH Conditions Higher Than $\mathbf{8 0} \% \mathbf{R H}$

\begin{tabular}{c|c|c|c|c|c|c|c|c}
\hline Roof & UVR1 & DVR1 & DVR2 & DVR3 & DVH1 & DVH2 & RW1 & RW2 \\
\hline \# Hours $>\mathbf{8 0} \%$ RH & 722 & 147 & 3 & 47 & 84 & 584 & 1024 & 1117 \\
\hline \% of Hours $>\mathbf{8 0} \%$ RH & $13 \%$ & $3 \%$ & $0 \%$ & $1 \%$ & $2 \%$ & $11 \%$ & $19 \%$ & $20 \%$ \\
\hline
\end{tabular}

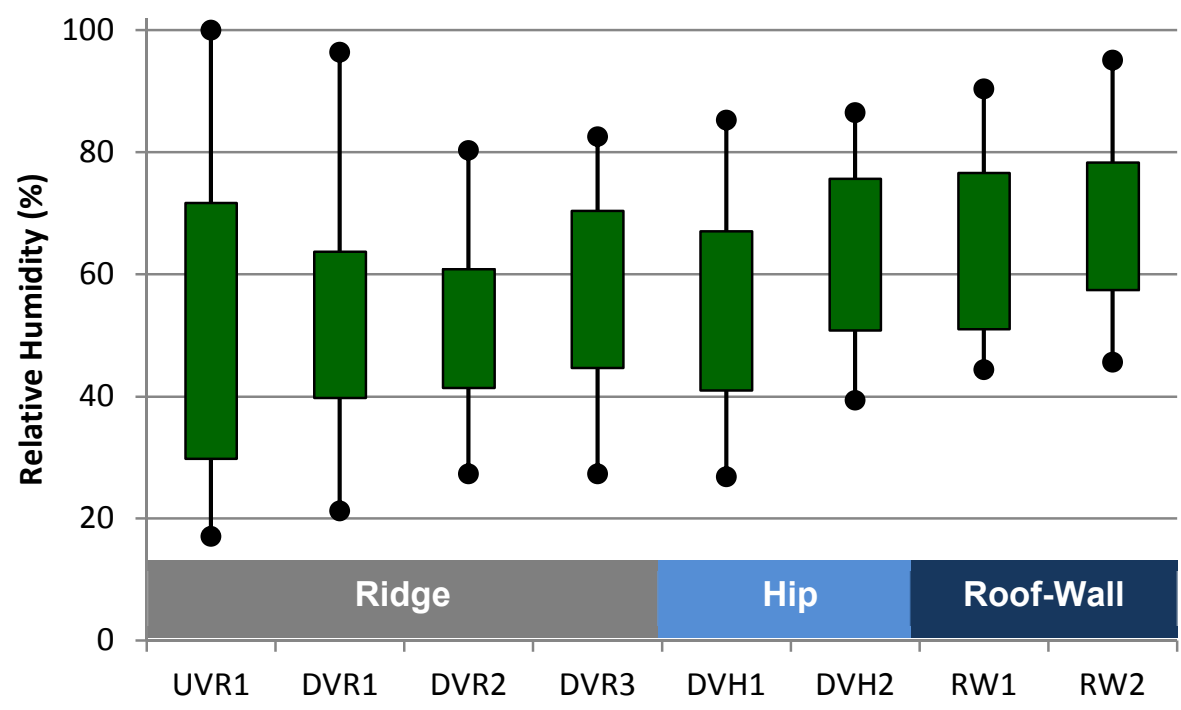

Figure 68. Box/whisker plot of roof peak RH measurements

As another comparison, the peak wafer MCs are plotted for the roofs in Figure 69; they show a pattern that is analogous to the previous RH measurements.

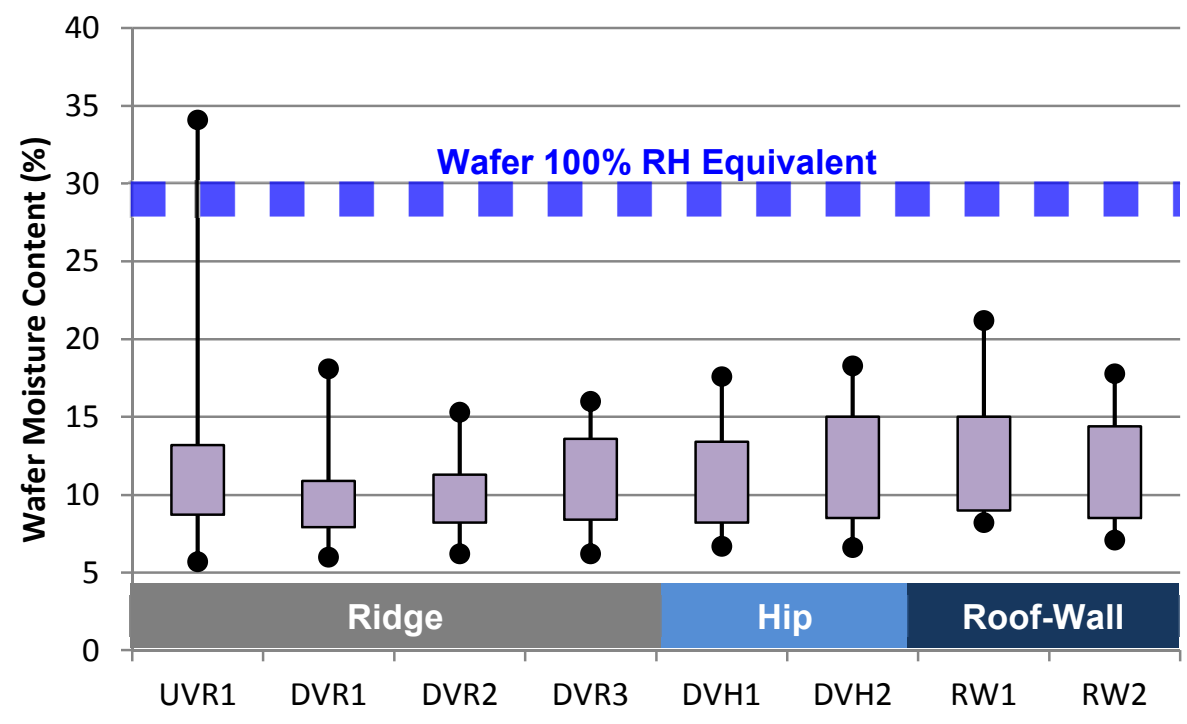

Figure 69. Box/whisker plot of roof peak wafer MC measurements

However, the unvented roof is clearly differentiated; periods of wafer measurements exceed the $100 \% \mathrm{RH}$-equivalent (28\%-30\% MC) level. All other roofs have MCs well in the safe range 
(almost all lower than 20\%). But again, roofs DVH2, RW1, and RW2 are noticeable outliers with higher moisture levels.

Earlier plots demonstrated that the wood ridge at the ridge and hips was the driest location of the diffusion vent roofs, but the dampest in the unvented roof. This is shown in the box and whisker plot in Figure 70. It demonstrates the localized drying available at the ridge of the diffusion vent roof compared to the moisture accumulation (lack of drying) at the unvented roof. The unvented roof had peak MCs higher than $25 \%$.

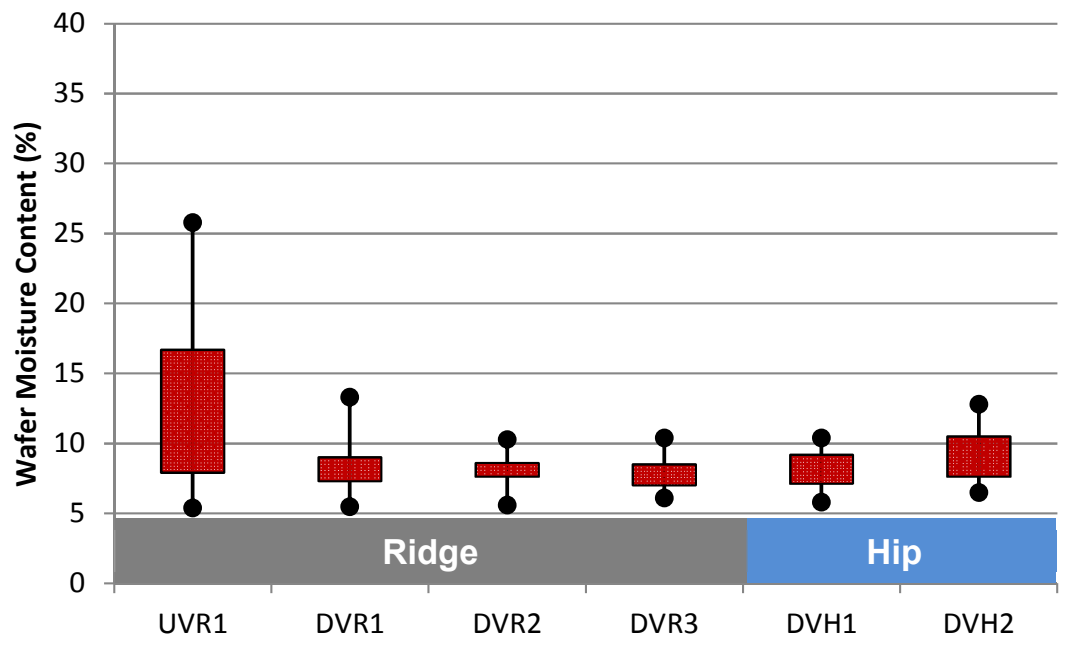

Figure 70. Box/whisker plot of ridge top wood MC measurements

\subsubsection{Building Shading Patterns}

One possible explanation for moisture conditions at DVH2, RW1, and RW2 is the shading patterns created by the building (Figure 71).

The lower diffusion vent hip measurement (DVH1) is fully exposed to the sun, while the upper measurement (DVH2) is shaded by the adjacent second story and roof. The roof-wall interfaces (RW1 and RW2) lie directly north of the wall in shadow. DVR3 (diffusion vent at the front of the house) is shaded for part of the day (morning), depending on the season and sun position. All these observations are consistent with higher RHs and MCs seen at RW1, RW2, and DVH2. 


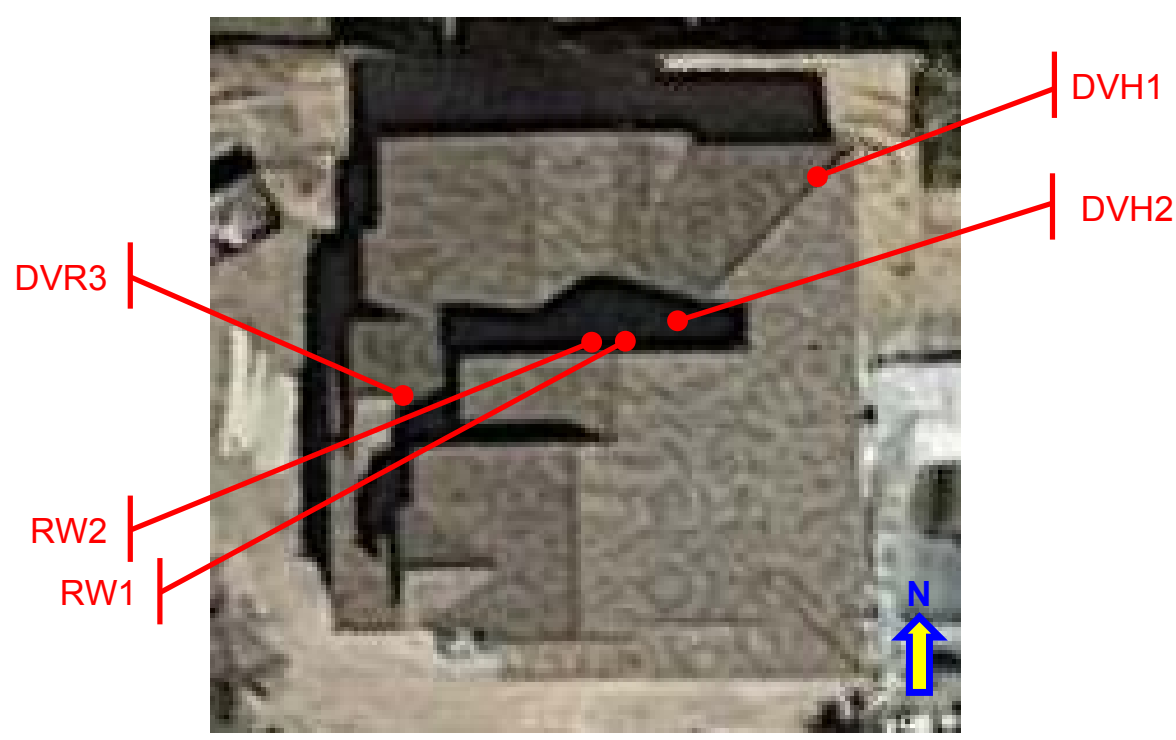

Figure 71. Overhead view of roof shading with key sensor locations

To confirm this theory, the temperature at the ridge is plotted for DVH1 and DVH2 in Figure 72 (March-April). It shows that the upper diffusion vent hip measurement had much cooler peak temperatures than the lower measurement (e.g., $95^{\circ} \mathrm{F}$ versus $115^{\circ} \mathrm{F}$ peak ranges), because the upper measurement was shaded.

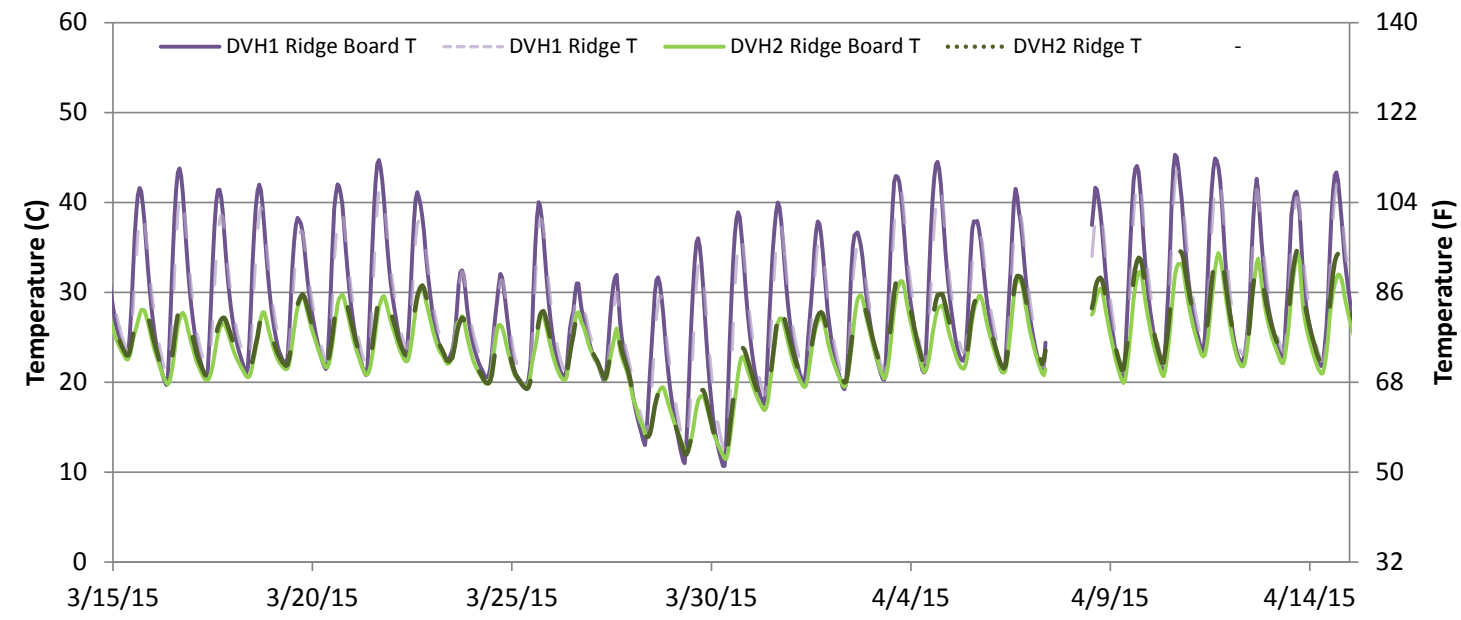

Figure 72. DVH1 versus DVH2 ridge and ridge board temperatures, March-April 2015

However, the temperature difference becomes much smaller during the summer, as shown by July-August data (Figure 73); this is due to the higher summertime sun angle, which reduces the shading provided by the second floor. 


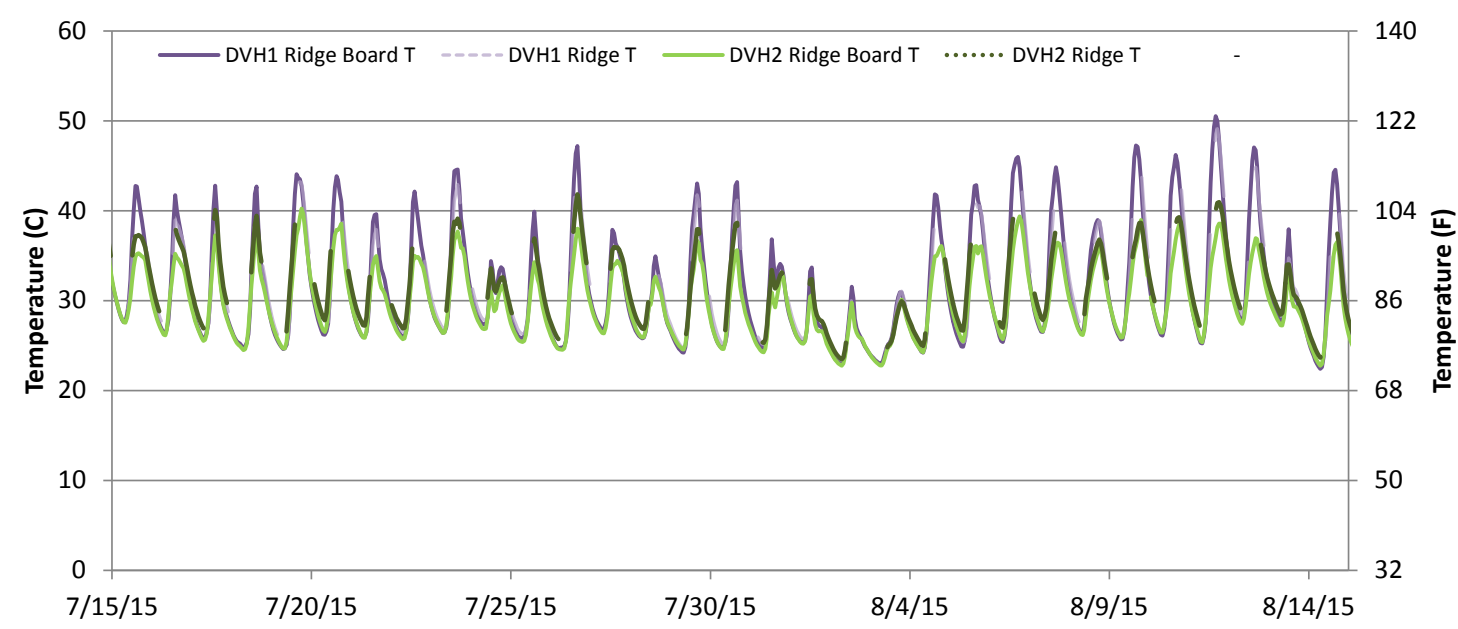

Figure 73. DVH1 versus DVH2 ridge and ridge board temperatures, July-August 2015

The roof-wall peak (RW1 and RW2) had temperatures that were consistent with the shaded upper diffusion vent hip ridge (DVH2).

\subsubsection{Roof Sheathing Hours Higher Than 20\% Moisture Content}

As another comparison of moisture performance, all roof sheathing MCs were examined for all eight roofs. Numbers of hours higher than 20\% MC were tabulated and compared; given that 41 measurements were taken, a full table is not presented here. The majority of the measurements had less than $5 \%$ of the monitoring period higher than $20 \% \mathrm{MC}$, but the three exceptions were:

- Unvented roof (UVR1) ridge top: 5\%/300 hours higher than 20\% MC. This was indicative of moisture accumulation in the unvented roof.

- Diffusion vent ridge (DVR3) south upper plywood sheathing: 13\%/712 hours higher than $20 \%$ MC. This was the suspected rain leak, which occurred in November, but did not recur.

- Diffusion vent hip (DVH1, lower measurement) north mid plywood sheathing: $6 \% / 358$ hours higher than $20 \%$ MC. This is an unexplained anomaly: all the $20 \% \mathrm{MC}$ measurements occur before the data gap under low interior moisture conditions. 


\section{Conclusions and Further Work}

\subsection{Conclusions and Further Work}

The data collected to date (for 9 months, capturing winter through summer) indicate that the diffusion vent roof shows greater moisture safety than the conventional unvented roof design. The unvented roof had extended periods (during cold winter periods) of $95 \%-100 \% \mathrm{RH}$, and wafer (wood surrogate RH sensor) measurements indicated possible condensation. The high moisture levels were concentrated at the roof ridge, which is consistent with previous field experience in Texas, Florida, and California. In contrast, the diffusion vent roofs had drier conditions; most peak MCs (sheathing) were lower than $20 \%$. In the spring, as outdoor temperatures increased, all roofs dried well into the safe range.

The unvented roof shows moisture levels higher than those typically recommended for durability; wintertime peaks were much higher than 20\% MC. For reference, decay fungi were inhibited when MC was lower than 20\% (FPL 2010); optimum growth occurred in the $25 \%-30 \%$ $\mathrm{MC}$ range. However, the roof dried in the spring. It would be difficult to say that the roof has truly failed based on the current monitoring results. In addition, some other roof areas showed brief periods higher than 20\% MC. Partial disassembly of the roof from the interior might provide greater insight at the conclusion of the experiment.

The results are somewhat limited, given the interior conditions to date. These conditions have included unoccupied/unconditioned periods (during construction) followed by unoccupied/semiconditioned periods (also during construction) and now occupied/conditioned periods (May 2015 onward). Future data under occupied conditions will be of strong interest.

Monitoring will continue at least through spring 2016 (capturing a second winter and following spring, which would be in the range of 18 months of data). The interior moisture levels in winter 2015-2016 may clarify the risks of unvented roofs versus the diffusion vent detail. Winter 20142015 had high interior moisture levels due to drying of construction moisture. With occupied conditions there has been interior moisture generation, but cooling system operation resulted in dehumidification (and less stored moisture in finishes and furnishings). The net effect of this change could be higher or lower interior moisture levels depending on occupant behavior, air leakage rates, and ventilation rates.

\subsection{Research Questions}

Answers to the research questions are provided below; answers are shown in italics.

- Does implementing an unvented cathedralized attic with air-permeable insulation (such as blown fiberglass) present issues in a hot-humid climate? One potential issue is air barrier continuity at roof penetrations and at the perimeter roof-to-wall interface. What is the air barrier performance of the assembly as installed?

Overall, implementation of the unvented roof assembly went smoothly; the prototype insulation system (box netting) provided a full-depth insulation installation and adapted to site conditions without issues. 
Overall house air leakage was higher (7.6 ACH50) than 2012 International Energy Conservation Code (ICC 2012) targets (5 ACH50). The air leakage of the unvented attics was also measured; air leakage was high in the lower attic (over the first floor). Measurements indicated significant leakage from the lower attic to the exterior (196 in. ${ }^{2}$ EqLA). Differential pressure measurements showed that the attic was equally leaky to the interior and the exterior. In comparison, the upper attic had 35 in. ${ }^{2}$ EqLA to exterior, and the conditioned space (first and second floors) had $311 \mathrm{in}^{2}$ EqLA (without door gaskets or interior finishes).

These air leakage results indicate that complicated details and roof-wall intersections can result in air leakage. The self-adhered roof membrane had less than ideal adhesion on the roof-to-vertical OSB wall surfaces. This is not an issue for rain control but resulted in air barrier failures at the roof-wall connection. However, the field of the roof and the diffusion vent ridge detail were not significant sources of air leakage.

- Does installing the diffusion vent present any issues with rain control or durability? For instance, are fastener penetrations a greater issue with this material? Did the roofing crew report any installation issues?

The roofing crew was monitored during the diffusion vent detail installation; although the crew members experienced a learning curve, no notable issues were reported, and the resulting assemblies appear to be performing well. One possible issue is adhesion between the air seal tape detail at the diffusion vent perimeter and the fibrous facing of the roof self-adhered membrane.

One possible roof leak was seen at the south plywood upper MC of DVR3 in November 2014; a sudden jump in MC occurred that later dried. This jump coincided with thunderstorm activity. However, no further wetting was seen in the data. Results from this sensor will be tracked over time.

- Do wood roof sheathing and framing MCs remain within acceptable ranges throughout the winter in this roof design in a Florida climate? Are MCs at the ridge higher than at lower sections of the roof as experienced in previous work?

The majority of the MC measurements remained lower than 20\%, which is the typical threshold for mold growth. Exceptions included the unvented roof design, a suspected roof leak, and an anomaly during the construction period.

The majority of the roofs showed moisture stratification; higher (wetter) MCs occurred at the ridge and upper sections of the roof and lower (drier) MCs occurred at the mid and lower measurements.

- Does the conventional unvented roof assembly experience higher MCs than the diffusion vent roof, and do these moisture levels constitute failure?

The unvented roof had consistently higher wintertime moisture levels than the diffusion vent roofs. Wintertime RH levels cycled between 95\%-100\% for part of the winter, and 
the wafer (surrogate RH) sensor showed roof ridge measurements consistent with condensation. These unvented roof levels were markedly wetter than the other roofs.

However, in the spring all MCs dropped to the safe range (lower than 10\%) in the unvented roof, so it would be difficult to consider this behavior a true failure. Field examination and possible disassembly of the roof would provide further information.

- Do the reservoir cladding nature of concrete roof tile and the vapor-permeable water diffusion vent present any risks of inward vapor drive? Or is the inward vapor drive risk a nonissue because of the vapor-open nature of the interior insulation assembly?

This question was partially answered by the European literature; Künzel and Sedlbauer (2001) monitored compact roof assemblies with clay and concrete barrel tile in Holzkirchen, Germany (near Munich; roughly CZ5). Both assemblies were cathedral ceilings insulated with blown-in cellulose insulation. Rafter MCs were monitored over the course of a year. The south orientation experienced a strong inward vapor drive effect in summertime in the clay tile roof (30\%+MC at the rafters); however, no such effect was seen in the concrete tile. This effect was ascribed to the difference in water uptake (A-value) or water absorption coefficient; concrete tile is much less absorptive than clay tile. On the north orientation, no inward drive effects were noted.

Concrete roof tiles were used in this work (and are typical for production builders). No evidence of inward vapor drive issues was seen in the field data (consistent with the European literature). Although springtime ridge RH levels in the diffusion vent roofs are slightly higher than in the unvented roof, levels are well within the safe range. Moisture accumulation within the assembly due to inward drive is unlikely, given the vapor-open assembly (loose-blown fiberglass and air-permeable insulation mesh). 


\section{References}

ASHRAE. 2009. ASHRAE Standard 160-2009 -- Criteria for Moisture-Control Design Analysis in Buildings (ANSI/ASHRAE Approved). Atlanta, GA: American Society of Heating, Refrigerating and Air-Conditioning Engineers, Inc.

ASHRAE. 2011. ANSI/ASHRAE Standard 160-2009: Criteria for Moisture-Control Design Analysis in Buildings: Addendum a. Atlanta, GA: American Society of Heating, Refrigerating and Air-Conditioning Engineers, Inc.

Bohac, D. 2002. "Zone Pressure Diagnostics: A New Protocol Shows How To Make a Valuable Diagnostic Test Even More Useful.” Home Energy Magazine, May/June 2002.

Boudreaux, P., Pallin, S., and Jackson, R. 2013. Moisture Performance of Sealed Attics in the Mixed-Humid Climate (Technical Report). Oak Ridge, TN: Oak Ridge National Laboratory, Energy and Transportation Science Division, ORNL/TM-2013/525.

Derome, D. 2005. "Moisture Accumulation in Cellulose Insulation Caused by Air Leakage in Flat Wood Frame Roofs.” Journal of Building Physics, vol. 28(3):269-87.

Fitzgerald, J. 2010. Personal communication.

FPL. 1987. The Encyclopedia of Wood. New York: Sterling Publishing Company, Inc.

FPL. 2010. Wood Handbook—Wood As an Engineering Material (Technical Report). Madison, WI: U.S. Department of Agriculture, Forest Service, Forest Products Laboratory, FPL-GTR-190.

Gibson, S. 2013. "Lawsuits Name Makers of Spray Foam Insulation." Green Building Advisor, April 26 2013. Newtown, CT: Taunton Press.

ICC. 2009. 2009 International Residential Code for One- and Two-family Dwellings. Country Club Hills, IL: International Code Council.

ICC. 2012. 2012 International Energy Conservation Code. Country Club Hills, IL: International Code Council.

James, W.L. 1975; revised 1988. Electrical Moisture Meters for Wood (Technical Report). Madison, WI: Forest Products Laboratory, FPL-GTR-6.

Künzel, H., and Sedlbauer, K. 2001. "Steildächer-feuchte- und wärmetechnische Ausbildung." Bauphysik-Kalendar, Ernst \& Sohn, 13086 Berlin, S. 459-82.

Lstiburek, J. 2006. "Understanding Attic Ventilation.” ASHRAE Journal, 48(4):36-38, 40, 4245. Atlanta, GA: American Society of Heating, Refrigerating and Air-Conditioning Engineers, Inc. http://buildingscience.com/documents/digests/bsd-102-understanding-attic-ventilation. 
Lstiburek, J. 2010a. "Building Sciences: Mind the Gap, Eh?” ASHRAE Journal, January 2010, 57-63. Atlanta, GA: American Society of Heating, Refrigerating and Air-Conditioning Engineers, Inc. Accessed June 26, 2015: http:/www.buildingscience.com/documents/insights/bsi-038-mind-the-gap-eh/.

Lstiburek, J. 2010b. "Building Sciences: Don't Be Dense with Insulation.” ASHRAE Journal, August, pp. 54-57. Atlanta, GA: American Society of Heating, Refrigerating and AirConditioning Engineers, Inc. www.buildingscience.com/documents/insights/bsi-043-dont-bedense/.

Lstiburek, J. 2011. “A Crash Course in Roof Venting.” Fine Homebuilding Magazine, August/September, pp. 68-72. Newtown, CT: Taunton Press. www.buildingscience. com/documents/published-articles/pa-crash-course-in-roof-venting/view.

Lstiburek, J. 2014. "Building Sciences: Cool Hand Luke Meets Attics." ASHRAE Journal, April, pp. 52-57, Atlanta, GA: American Society of Heating, Refrigerating and Air-Conditioning Engineers, Inc. www.buildingscience.com/documents/insights/bsi-077-cool-hand-luke-meetsattics.

Miller, W.A., Wilson, P., and Karagiozis, A. 2006. "The Impact of Above-Sheathing Ventilation on the Thermal and Moisture Performance of Steep-Slope Residential Roofs and Attics." Presented at the 15th Symposium on Hot and Humid Climates, Orlando, FL.

Morin, P. 2011. “Zone Pressure Diagnostics (ZPD) for Optimal Air Sealing and Insulation.” The Energy Conservatory, accessed March 2014: www.energyconservatory.com/sites/default/files/documents/ZPD_Basics.pdf.

NREL. 2013. FY 2014 Residential Energy System Research Needs. Golden, CO: National Renewable Energy Laboratory.

Pallin, S., Boudreaux, P., and Jackson, R. 2014. Indoor Climate and Moisture Durability Performances of Houses with Unvented Attic Roof Constructions in a Mixed-Humid Climate (Technical Report). Oak Ridge, TN: Oak Ridge National Laboratory, Energy and Transportation Science Division, ORNL/TM-2014/549.

Rudd, A.F., and Lstiburek, J.W. 1998. "Vented and Sealed Attics in Hot Climates" ASHRAE Transactions, TO-98-20-3.

Salonvaara, M., Karagiozis, A., and Desjarlais, A. 2013. "Moisture Performance of Sealed Attics in Climate Zones 1 to 4." Proceedings: Thermal Performance of the Exterior Envelopes of Buildings XII. Atlanta, GA: American Society of Heating, Refrigerating and Air-Conditioning Engineers, Inc.

Schumacher, C.J., and LePage, R. 2012. BA-1308: Moisture Control for Dense-Packed Roof Assemblies in Cold Climates: Final Measure Guideline. www.buildingscience.com/documents/bareports/ba-1308-moisture-control-dense-packed-roofassemblies-cold-climates/view 
Schumacher, C.J. 2011. BA-1109: Building America High Impact Task: Support of Standards Development-Dense-pack Airflow Resistance Final Research Report.

www.buildingscience.com/documents/bareports/ba-1109-high-impact-project-densepackairflow-resistance/.

Smegal, J., and Straube, J. 2014. Ventilation and Vapour Control for SPF-insulated Cathedral Ceilings. Report for the Canadian Urethane Foam Contractors Association Inc. Waterloo, ON: Building Science Consulting Inc.

Straube, J., Onysko, D., and Schumacher, C. 2002. "Methodology and Design of Field Experiments for Monitoring the Hygrothermal Performance of Wood Frame Enclosures." Journal of Thermal Envelope and Building Science, 26(2).

Straube, J., and Burnett, E. 2005. Building Science for Building Enclosures, Building Science Press, Westford, MA.

TEC 2015. "How Do I Calculate the Leakage Area?" The Energy Conservatory, accessed May 2015: http://support.energyconservatory.com/hc/en-us/articles/203529734-How-do-I-calculatethe-leakage-area-.

Ueno, K., and Straube, J. 2008. "Laboratory Calibration and Field Results of Wood Resistance Humidity Sensors", Proceedings of BEST 1 Conference, Minneapolis, June 10-12, 2008. 


\section{Appendix A: Testing and Monitoring Equipment}

The testing and monitoring equipment used at the tile unvented test roof is described in Table 9.

Table 9. Testing and Monitoring Equipment Specifications

\begin{tabular}{|c|c|}
\hline Measurement & Equipment and Specifications \\
\hline Temperature & Negative temperature coefficient thermistor, $0.1^{\circ} \mathrm{C}\left( \pm 0.2^{\circ} \mathrm{F}\right)$ \\
\hline RH & $\begin{array}{c}\text { Thermoset polymer capacitive RH sensor, } \\
\qquad \pm 3.5 \% \mathrm{RH}\end{array}$ \\
\hline Wood MC & $\begin{array}{l}\text { Electric resistance-based moisture content pin sensors } \\
\text { (see Appendix B) }\end{array}$ \\
\hline $\begin{array}{l}\text { Data Acquisition and } \\
\text { Collection }\end{array}$ & $\begin{array}{c}\text { Campbell Scientific CR1000 measurement and control system with } \\
\text { Campbell Scientific AM16/32B Multiplexers }\end{array}$ \\
\hline $\begin{array}{c}\text { Outdoor } \\
\text { Temperature/RH }\end{array}$ & $\begin{array}{c}\text { Campbell Scientific } \mathrm{HMP} 60 \text { - } \mathrm{L}-40^{\circ} \mathrm{C} \text { to }+60^{\circ} \mathrm{C}\left(-40^{\circ} \mathrm{F} \text { to } 140^{\circ} \mathrm{F}\right) \\
\text { range; } 0.6^{\circ} \mathrm{C}\left( \pm 1.1^{\circ} \mathrm{F}\right) \text { accuracy; } \\
\text { RH accuracy at } 0^{\circ} \text { to }+40^{\circ} \mathrm{C}\left(32^{\circ} \text { to } 104^{\circ} \mathrm{F}\right) \text { : } \\
\pm 3 \% \mathrm{RH}(0 \%-90 \% \mathrm{RH}) ; \pm 5 \% \mathrm{RH}(90 \%-100 \% \mathrm{RH}) \\
\mathrm{RH} \text { Accuracy at }-40^{\circ} \text { to } 32^{\circ} \mathrm{F}\left(-40^{\circ} \text { to } 0^{\circ} \mathrm{C}\right) \text { and }+40^{\circ} \text { to }+60^{\circ} \mathrm{C} \\
\left(104^{\circ} \text { to } 140^{\circ} \mathrm{F}\right): \\
\pm 5 \% \mathrm{RH}(0 \%-90 \% \mathrm{RH}) ; \pm 7 \% \mathrm{RH}(90 \%-100 \% \mathrm{RH})\end{array}$ \\
\hline Infrared Observation & $\begin{array}{c}\text { FLIR b40 Infrared Camera } \\
\left(-20^{\circ} \mathrm{C} \text { to } 120^{\circ} \mathrm{C}\left[-4^{\circ} \mathrm{F} \text { to } 248^{\circ} \mathrm{F}\right] \text { temperature range; }\right. \\
\left. \pm 2^{\circ} \mathrm{C} \text { or } \pm 2 \% \text { of reading temperature accuracy }\right)\end{array}$ \\
\hline $\begin{array}{l}\text { Air Leakage } \\
\text { (higher flow fans) }\end{array}$ & $\begin{array}{l}\text { The Energy Conservatory Minneapolis Blower Door Model } 3 \text { Fan } \\
300 \text { to 6,300 CFM (Ring B/Open) } \\
\text { Flow Accuracy: } \pm 3 \% \text { with DG- } 700\end{array}$ \\
\hline $\begin{array}{l}\text { Air Leakage } \\
\text { (lower flow fans) }\end{array}$ & $\begin{array}{l}\text { The Energy Conservatory Minneapolis Duct Blaster Series B Fan } \\
10 \text { to } 1500 \text { CFM (Ring 3/Open) Flow Accuracy: } \\
\pm 3 \% \text { of reading or } \pm 1 \text { CFM, whichever is greater, with DG-700 }\end{array}$ \\
\hline$\Delta \mathrm{P}$ Measurement & $\begin{array}{l}\text { The Energy Conservatory DG-700 Pressure and Flow Gauge } \\
-1,250 \text { to }+1,250 \mathrm{~Pa} \text {. Accuracy: } 1 \% \text { of pressure reading or } 0.15 \mathrm{~Pa} \text {, } \\
\text { whichever is greater }\end{array}$ \\
\hline
\end{tabular}




\section{Appendix B: Wood Moisture Content Error Analysis}

\section{Electrical Resistance Circuit and Calculation of $\mathbf{R}_{\mathbf{w}}$}

The data acquisition system was a Campbell Scientific CR1000 measurement and control system with Campbell Scientific AM16/32B Multiplexers. Wood MC was measured via the electrical resistance of wood using the circuit shown in Figure 74 and methods described by Straube et al. (2002). A nominal 12-V excitation voltage is supplied by the data logger; the current runs through the wood and then the sense resistor $\left(R_{S}\right)$ in series. Voltage drop across the sense resistor is used to calculate the electrical resistance of the wood $\left(\mathrm{R}_{\mathrm{w}}\right)$.

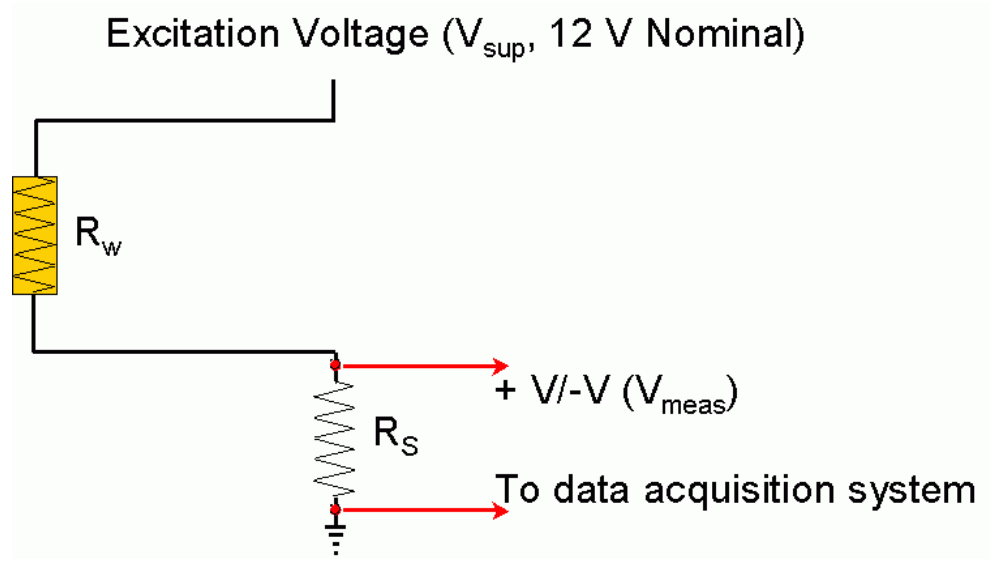

Figure 74. Schematic of resistance measurement circuit

The resistance of the wood is calculated using Equation 1 (based on the circuit in Figure 74).

Equation 1: Calculation of wood electrical resistance $\left(\mathbf{R}_{\mathrm{w}}\right)$

$$
R_{W}=\frac{R_{S}\left(V_{\text {sup }}-V_{\text {meas }}\right)}{V_{\text {meas }}}
$$

Where: $\quad \mathrm{R}_{\mathrm{W}}=$ resistance of wood

$\mathrm{R}_{\mathrm{S}}=$ sense resistor

$\mathrm{V}_{\text {sup }}=$ circuit supply voltage $(12 \mathrm{~V}$ nominal)

$\mathrm{V}_{\text {meas }}=$ measured voltage

\section{Error Analysis of Electrical Resistance Measurements}

The error of the wood electrical resistance measurement $\left(\mathrm{R}_{\mathrm{w}}\right)$ can be found as a function of the measurands and uncertainties $\left(\Delta \mathrm{R}_{\mathrm{S}}, \Delta \mathrm{V}_{\text {sup }}, \Delta \mathrm{V}_{\text {meas }}\right)$ per Equation 2 and Equation 3:

Equation 2: Calculation of electrical resistance error (step 1)

$$
\operatorname{Error}\left(R_{W}\right)=\sqrt{\left(\frac{\partial R_{W}}{\partial R_{S}} \Delta R_{S}\right)^{2}+\left(\frac{\partial R_{W}}{\partial V_{\text {Sup }}} \Delta V_{\text {Sup }}\right)^{2}+\left(\frac{\partial R_{w}}{\partial V_{\text {meas }}} \Delta V_{\text {meas }}\right)^{2}}
$$


Equation 3: Calculation of electrical resistance error (step 2)

$$
\operatorname{Error}\left(R_{W}\right)=\sqrt{\left(\frac{V_{\text {sup }}-V_{\text {meas }}}{V_{\text {meas }}} \Delta R_{S}\right)^{2}+\left(\frac{R_{S}}{V_{\text {meas }}} \Delta V_{\text {Sup }}\right)^{2}+\left(\frac{R_{S} V_{\text {sup }}}{\left(V_{\text {meas }}\right)^{2}} \Delta V_{\text {meas }}\right)^{2}}
$$

The inputs for these calculations follows:

- $\mathrm{V}_{\text {sup }}=$ circuit supply voltage: $12 \mathrm{~V}$ (nominal)

- $\mathrm{V}_{\text {meas }}=$ measured voltage: varies with wood $\mathrm{MC}$ (see Table 10)

- $\quad \mathrm{R}_{\mathrm{S}}=$ sense resistor: $10 \mathrm{k} \Omega(10,000 \Omega)$

- $\Delta \mathrm{V}_{\text {sup }}=$ circuit supply voltage error: measured by the data acquisition equipment with an accuracy of $0.01 \mathrm{~V}$.

- $\Delta \mathrm{V}_{\text {meas }}=$ measured voltage error: varies with wood $\mathrm{MC}($ see Table 10$)$

- $\Delta \mathrm{R}_{\mathrm{S}}=$ sense resistor error: $\pm 1 \%$ precision resistors used (error $100 \Omega$ ).

The voltage measurement accuracy of the Campbell equipment varies with the voltage measurement range. At a temperature range of $0^{\circ}-40^{\circ} \mathrm{C}\left(32^{\circ}-104^{\circ} \mathrm{F}\right)$ (the logging equipment was kept at room temperature conditions throughout this research), the error is $\pm 0.06 \%$ of reading + offset, where the offset is a function of the voltage range and measurement type (single-ended versus differential).

The error was calculated for MC ranges (and resistances) that are typical for this research in Table 10; the error is presented in terms of absolute value $(\Omega)$, and percentage of measurement.

Table 10. Calculation of Wood Resistance Error $\left(\Delta r_{w}\right)$ at Various Wood MC Levels

\begin{tabular}{cccccc}
\hline $\begin{array}{c}\text { Wood } \\
\mathbf{M C}\end{array}$ & $\begin{array}{c}\text { Resistance } \\
\mathbf{R}_{\mathbf{w}}(\boldsymbol{\Omega})\end{array}$ & $\begin{array}{c}\text { Voltage } \\
\text { Measurement } \\
\mathbf{V}_{\text {meas }}(\mathbf{V})\end{array}$ & $\begin{array}{c}\text { Voltage } \\
\text { Measurement } \\
\text { Error } \Delta \mathbf{V}_{\text {meas }}\end{array}$ & $\begin{array}{c}\text { Wood } \\
\text { Resistance } \\
\text { Error }\left(\boldsymbol{\Delta} \mathbf{R}_{\mathbf{w}}\right) \\
(\boldsymbol{\Omega})\end{array}$ & $\begin{array}{c}\text { Error \% } \\
\text { Measurement }\end{array}$ \\
\hline $\mathbf{8 \%}$ & $5,240,169,344$ & 0.00002 & $3.01575 \mathrm{E}-06$ & $692,091,507$ & $13.2 \%$ \\
$\mathbf{1 2 \%}$ & $105,337,360$ & 0.0011 & $3.68945 \mathrm{E}-06$ & $1,110,734$ & $1.1 \%$ \\
$\mathbf{1 6 \%}$ & $10,032,756$ & 0.0119 & $1.01894 \mathrm{E}-05$ & 101,040 & $1 \%$ \\
$\mathbf{2 4 \%}$ & 601,088 & 0.196 & 0.000121023 & 6,044 & $1 \%$ \\
$\mathbf{3 2 \%}$ & 110,502 & 0.996 & 0.000602501 & 1,112 & $1 \%$ \\
$\mathbf{4 0 \%}$ & 34,508 & 2.696 & 0.001624671 & 348 & $1 \%$ \\
\hline
\end{tabular}

The results in Table 10 indicate that error is typically about $1 \%$ for most MCs. However, at low $\mathrm{MCs}(8 \%)$, resistances become very high ( $\mathrm{G} \Omega$ range); accordingly, voltages are very low (20 $\mu \mathrm{V})$. But as discussed in the next section, the resistance measurement has a much smaller effect on calculated wood MC measurements under dry conditions. In addition, low (or dry) MCs are of lower importance in building enclosure research: the key measurements occur during higher $\mathrm{MCs}$, which are indicative of failures or problems. 


\section{Error Analysis of Moisture Content Measurements}

The end result of interest is the $\mathrm{MC}$ of the wood, as calculated from resistance measurements. The relationship used to obtain $\mathrm{MC}_{\text {uncorrected }}$ (not corrected for temperature or species) is taken from Straube et al. (2002), who used the equation developed by U.S. Department of Agriculture Forest Products Laboratory, as shown in Equation 4.

\section{Equation 4: Calculation of wood MC from electrical resistance}

$$
M C_{\text {uncorrected }}=10 \exp \left(2.99-2.113\left(\log _{10}\left(\log _{10}\left(R_{w}\right)\right)\right)\right)
$$

The uncertainty figures from Table 10 were used to perform a perturbation analysis of the MC measurements, calculating the resulting wood MC when the wood resistance error $\left(\Delta R_{w}\right)$ is added to the base measurement $\left(\mathrm{R}_{\mathrm{w}}\right)$. The results are shown in Table 11 .

Table 11. Calculation of Wood MC Error $\left(\Delta \mathbf{m c}_{\text {uncorrected }}\right)$ at Various Wood MC Levels

\begin{tabular}{cccccc}
\hline $\begin{array}{c}\text { Wood } \\
\text { MC }\end{array}$ & $\begin{array}{c}\text { Wood } \\
\text { Resistance } \\
\mathbf{R}_{\mathbf{W}}(\boldsymbol{\Omega})\end{array}$ & $\begin{array}{c}\text { Wood } \\
\text { Resistance } \\
\text { Error } \\
\mathbf{R}_{\mathbf{W}}+\boldsymbol{\Delta} \mathbf{R}_{\mathbf{W}}(\boldsymbol{\Omega})\end{array}$ & $\begin{array}{c}\text { Wood MC with } \\
\text { Error }\end{array}$ & $\begin{array}{c}\Delta \text { MC } \\
(\text { Error) }\end{array}$ & $\begin{array}{c}\Delta \mathbf{M C} \\
(\text { Error) } \%\end{array}$ \\
\hline $\mathbf{8 \%}$ & $5,240,169,344$ & $5,932,260,851$ & $7.9 \%$ & -0.09 & $1.2 \%$ \\
$\mathbf{1 2 \%}$ & $105,337,360$ & $106,448,095$ & $12.0 \%$ & -0.01 & $0.1 \%$ \\
$\mathbf{1 6 \%}$ & $10,032,756$ & $10,133,796$ & $16.0 \%$ & -0.02 & $0.1 \%$ \\
$\mathbf{2 4 \%}$ & 601,088 & 607,132 & $24.0 \%$ & -0.04 & $0.2 \%$ \\
$\mathbf{3 2 \%}$ & 110,502 & 111,614 & $31.9 \%$ & -0.06 & $0.2 \%$ \\
$\mathbf{4 0} \%$ & 34,508 & 34,857 & $39.9 \%$ & -0.08 & $0.2 \%$ \\
\hline
\end{tabular}

The wood MC error is $1.2 \%$ of the measurement at $8 \%$ wood MC (compared to the $13.2 \%$ electrical resistance measurement error); this is a function of the $\log _{10}\left(\log _{10}\right)$ calculation of wood $\mathrm{MC}$ (Equation 4). At higher MCs, the error becomes much smaller $(0.1 \%-0.2 \%$ of measurement).

\section{Synthesis and Other Sources of Error}

Clearly, the uncertainty of MC caused by electrical resistance measurement error is insignificant in terms of the uncertainties typically accepted in field measurements (e.g., $\pm 3 \%$ for many $\mathrm{RH}$ sensors). Overall, the uncertainty is not founded in the measurements or computations: more of the uncertainty is caused by the variability of samples, because wood is a nonhomogenous, natural material.

As another example, Ueno and Lstiburek (2015) measured sheathing MCs in six double-stud walls; three sheathing MCs were measured in each wall (low, middle, and high). These walls were identical in the one-dimensional section and measured the same material. However, peak differences of $\sim 5 \% \mathrm{MC}$ were seen in nominally identical (same wall/same orientation) measurements. Part of the difference was ascribed to the nature of OSB sheathing: it is composed of wood wafers from multiple trees; measurement across various wafer flake boundaries could also influence MC measurements. 
Another potential source of error is electrical noise; at high MCs, the voltages are very low (about $20 \mu \mathrm{V}$ ). The $60 \mathrm{~Hz}$ filtering feature was used in the data logger voltage measurements to reduce these effects. Similarly, wiring damage can influence measurements, especially at high MCs. Wiring damage has occurred in the past at monitoring projects at active jobsites; some unexplained $\mathrm{MC}$ data anomalies occurred later.

The formula for $\mathrm{MC}_{\mathrm{uncorrected}}$ reflects the wide range of resistance measurements found in the MCs of interest ( $8 \%-25 \% \mathrm{MC} ; \mathrm{k} \Omega$ to $\mathrm{G} \Omega$ range); this is also shown in Figure 75 , taken from Forest Products Laboratory (FPL 1987), which plots the logarithm of resistance against MC:

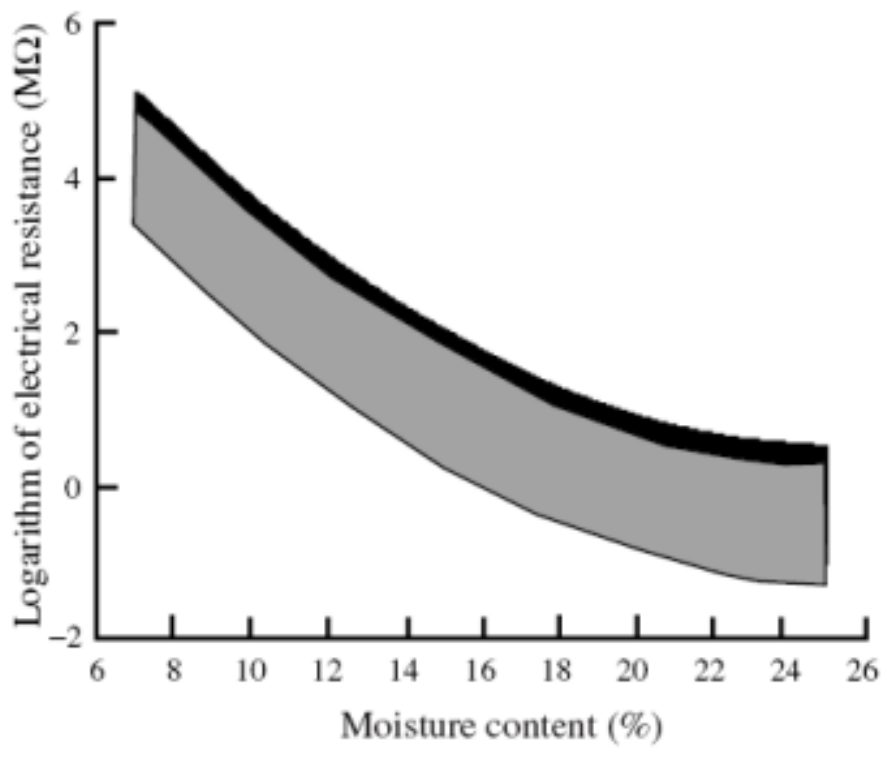

Figure 75. Log of $R_{W}$ versus \% MC

Source: FPL (1987)

The gray region shows the degree of variability seen due to species corrections: this can be a significant source of error. This becomes significant, as mentioned earlier, when a grouping of species (such as Southern yellow pine or spruce-pine-fir) is used: if a single species correlation is used for several species in a commercial group, this will result in less precision than if the species were considered separately (James 1988). The problem then becomes identifying the species of the sample. 


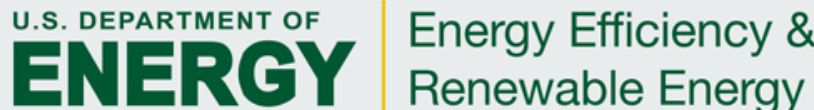

